\title{
A REVIEW ON HEAT TRANSFER ENHANCEMENT WITH NANOFLUIDS
}

\section{Zhixiong Guo}

\author{
Department of Mechanical and Aerospace Engineering, Rutgers, The State \\ University of New Jersey, Piscataway, New Jersey 08854, USA; \\ Tel.: +1 848445 2024; Fax: +1 732445 3024, E-mail: guo@jove.rutgers.edu
}

Original Manuscript Submitted: 7/17/2019; Final Draft Received: 8/30/2019

Advances in technology miniaturization with increasing power density call for new technologies for enhancing heat transfer. Enhancement of heat transfer with the use of nanofluids has been a hectic topic of research and development since the term "nanofluid" was first used in 1995, mainly because the thermophysical properties of nanofluids in most reports in the literature showed supremacy or improvement over their base fluids, which may not allow fulfillment of the present cutting-edge technology needs. Significant progress in this field has been made in the past two decades. This review summarizes a variety of the experimentally measured thermal properties of common nanofluids, the enhancement mechanisms discovered or hypothesised, the models used for properties and heat transfer characteristics, and the applications of nanofluids for enhancing heat transfer. The model of an artificial neutral network is particularly emphasized. Applications to cooling technology, renewable energy and energy systems, and building technology are detailed. Challenges and areas for future research are identified.

KEY WORDS: heat transfer enhancement, nanofluid, thermal properties, artificial neutral network, rapid cooling, thermal management, solar energy, renewable energy, energy storage, building technology

\section{INTRODUCTION}

Heat transfer enhancement or augmentation or intensification refers to the improvement of thermal performance of any heat transport process, heat exchanging medium, component, device, or equipment. It could mean that the heat transfer rate of a given surface is increased; the peak temperature of a chip hot spot is reduced; the critical heat flux for pool boiling heat transfer is soared; the thermal conductivity, specific heat capacity, or latent heat of an energy storage medium is raised; etc. A variety of techniques or methodologies can be applied to such effects.

In the literature (Bergles et al., 1983, 1991; Bergles, 1998; Webb and Kim, 2005), the methodologies for augmenting convective heat transfer were generally classified into three categories: passive techniques, active techniques, and compound techniques. The passive ones do not require external power through techniques such as extended surfaces (fins), rough surfaces, treated surfaces, dimples and protrusions, inserts, coiled tubes, swirl-flow devices, displaced enhancement devices, or fluid or particle additives; whereas, the active techniques require external power to bring about the effect, including mechanical aids, surface vibration, fluid vibration, electric or magnetic field, injection, suction, jet impingement, etc. Compound enhancement combines two or more of the above techniques to produce an effect that is larger than any of 


\begin{tabular}{|c|c|c|}
\hline \multicolumn{3}{|c|}{ NOMENCLATURE } \\
\hline$C_{p}$ & heat capacity, $\mathrm{kJ} / \mathrm{kg} \cdot \mathrm{K}$ & Greek Symbols \\
\hline$d$ & diameter, $\mathrm{m}$ & $\alpha \quad$ thermal diffusivity \\
\hline$D_{h}$ & hydrodynamic diameter, $\mathrm{m}$ & $\left(\mathrm{m}^{2} / \mathrm{s}\right)$ \\
\hline$f$ & friction factor & viscosity, $\mathrm{kg} /(\mathrm{m} \cdot \mathrm{s})$ \\
\hline$k$ & thermal conductivity, $\mathrm{W} /(\mathrm{m} \cdot \mathrm{K})$ & density, $\mathrm{kg} / \mathrm{m}^{3}$ \\
\hline$K_{\mathrm{B}}$ & Boltzmann constant & $\phi \quad$ volume fraction \\
\hline$m$ & mass, $\mathrm{kg}$ & \\
\hline $\mathrm{Nu}$ & Nusselt number & Subscripts \\
\hline $\mathrm{Pe}$ & Peclet number & base fluid \\
\hline $\operatorname{Pr}$ & Prandtl number & cluster \\
\hline $\operatorname{Re}$ & Reynolds number & eff effective \\
\hline$r$ & radius, $\mathrm{m}$ & nf nanofluid \\
\hline$T$ & temperature, $\mathrm{K}$ & particle \\
\hline
\end{tabular}

the enhancement techniques operating separately (Bergles, 2011). Bergles (2002) considered the compound techniques as the fourth-generation heat transfer technology or third-generation enhancement. The current state-of-the-art heat transfer enhancement techniques are achievable via nanotechnology, e.g., surface phonon polaritons (Shen et al., 2009), near-field enhancement (Song et al., 2015), and molecular or atomic level engineering (Xu et al., 2018). Heat transfer manipulation via use of thermal metamaterials (Han et al., 2014) that will enhance heat transfer in certain directions also fits into the category of heat transfer enhancement.

As devices in modern technology continue to require increased power capabilities with reduced spatial profiles, it is critical to explore a multitude of methods for enhancing heat transfer (Kuzma-Kichta and Leontiev, 2018). For example, rapid cooling of such devices is a key issue in high-tech industries such as microelectronics and high-end military weapons. Conventional approaches by using fins and microchannel sinks have already stretched to their limits. Therefore, there is an urgent need for new methods and innovative concepts to achieve ultrahigh heat flux removal or supply. Heat transfer enhancement is now a major area of research and development in thermal management (Nasir et al., 2018; Terekhov et al., 2018), electronic components (Yilmazoglu et al., 2019), electronics packaging (Abbood et al., 2018; Zhang et al., 2019a), energy and power industry (Alva et al., 2018; Wang et al., 2019; Zhang et al., 2019b), new building technology (Iasiello et al., 2018; Huang and Deng, 2018), engines (Dong et al., 2019; Kim, 2019), aerospace technologies (Matysiak and Platek, 2019; Ligrani et al., 2019), etc. It was estimated that at least $10 \%$ of the archival heat transfer literature was directed toward enhancement (Bergles and Manglik, 2013). Because heat transfer research in the micro-/nanoscales and the molecular and atomic levels also contributes to this effect and has been swiftly increasing in the past decade, the research in augmentation of heat transfer expands substantially.

The late Ralph L. Webb with the late Arthur E. Bergles founded the Journal of Enhanced Heat Transfer in 1993. The journal was first published in 1994 and has a wealth of archival papers on many aspects of enhanced or high-performance heat and mass transfer. Some excellent 
review articles published recently in this journal included heat transfer enhancement for turbine blade internal cooling (Wright and Han, 2014), heat exchangers (Zimparov et al., 2016; Thome, 2017a; Samokhvalov et al., 2018), heat pipes (Cao and Faghri, 2017), horizontal tube falling film and flooded evaporators (Balaji et al., 2018), solar air heaters (Sahu and Prasad, 2016), boiling and evaporation (Tong et al., 2017; Shatto and Peterson, 2017; Thome, 2017b), extended surfaces and rough surfaces (Shome and Jensen, 2017; Taylor and Hodge, 2017; Chamra and Webb, 2017), and a brief review of 2018 literature on enhanced heat transfer (Guo, 2019), to name a few.

Many other journals in thermal sciences, energy, and fluid flow have also documented a large number of papers contributing to heat transfer enhancement research and development. For example, excellent reviews worthy of mention include heat transfer enhancement with nanofluids (Kakac and Pramuanjaroenkij, 2009, 2016; Hussein et al., 2014), enhanced thermal energy storage with phase-change materials (Ibrahim et al., 2017; Lin et al., 2018), swirl flow devices (Sheikholeslami et al., 2015), enhancing the performance of solar collectors (Akbarzadeh and Valipour, 2018; Bellos et al., 2018), nanofluids in porous media (Kasaeian et al., 2017), compound enhancement techniques (Rashidi et al., 2019), etc.

Given the overwhelming amount of technical information and the explosive growth in this field, it would be a formidable task to look at everything. The present author initially intended to write a comprehensive review on "recent trends in heat transfer enhancement research and development." Instead, he found that the contents for the single topic on nanofluids for enhancing heat transfer are sufficient to form a lengthy review paper.

A topic search in the Web of Science conducted on July 24, 2019 with keywords "nanofluid" or "nanofluids" resulted in 2,388, 3,109, and 3,201 papers for each year in 2016, 2017, and 2018, respectively. Figure 1 presents the publication number data acquired from such topic searches

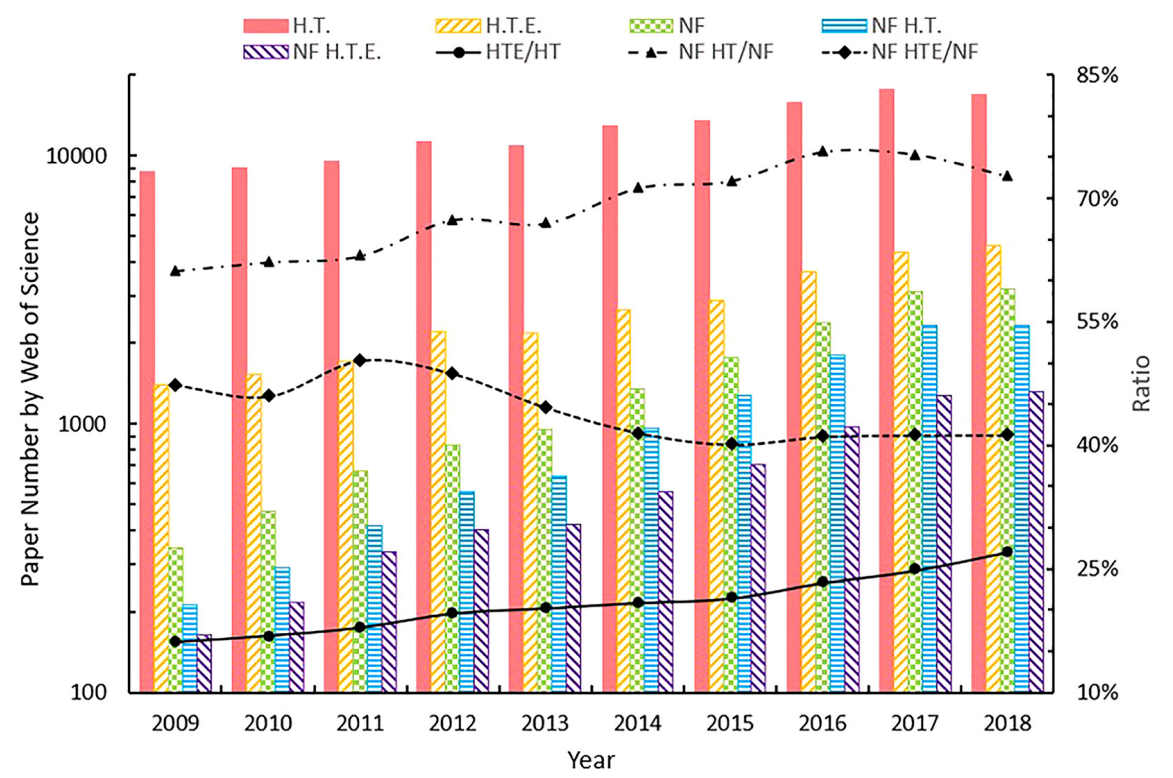

FIG. 1: Numbers of published papers indexed in the Web of Science through a topics search in the research areas of heat transfer (H.T.), heat transfer enhancement (H.T.E.), nanofluids (NF), heat transfer with nanofluids (NF H.T.), and heat transfer enhancement with nanofluids (NF H.T.E.)

Volume 27, Issue 1, 2020 
for the period from 2009 to 2018 . The research papers on heat transfer (search \#1 with key word "heat transfer") have seen a steady increase from 8,723 in 2009 to 17,010 in 2018, a 95\% increase in 10 years. The ratio of heat transfer enhancement papers (search \#2 with key words "heat transfer enhancement" or "heat transfer augmentation" or "heat transfer intensification" or "enhanced heat transfer" or "augmented heat transfer" or "intensified heat transfer") over the heat transfer (search \#1) research steadily increased from 16\% in 2009 to $27 \%$ in 2018. This indicates that the research on heat transfer enhancement has become more and more important. In the same period, the research papers on nanofluids (search \#3 with key words "nanofluid" or "nanofluids") have been hiked from 345 in 2009 to 3,201 in 2018, an increase of 827.8\%; whereas, the ratio of heat transfer enhancement with nanofluids (search \#4 with combination of search \#2 and search \#3) over the nanofluid research varies in a narrow range of $40 \%$ (in 2015) and 50.2\% (in 2011). Figure 1 also plots the percentage ratio of heat transfer research in nanofluids (search \#5 with combination of search \#1 and search \#3). Clearly, the research on nanofluids has been dominantly focused on heat transfer.

In recent years, numerical and experimental studies combining nanofluids, ribs, and/or inserts for enhancing heat transfer have been conducted (Pal and Bhattacharyya, 2018; Arulprakasajothi et al., 2018; Kumar et al., 2019; Mageshbabu et al., 2019). Effective thermal conductivity, viscosity, and specific heat capacity of nanofluids were measured (Chitra et al., 2015; Sertkaya, 2018). Numerical modeling of nanofluids flow and heat transfer in microchannels for enhanced cooling technology has been performed (Nandakrishnan et al., 2018; Bianco et al., 2018; Ragani and Bahrami, 2019; Toghraie et al., 2019). Enhanced heat conduction and pool boiling were investigated with nanoscale graphene coated on various substrates (Diaz and Guo, 2019). Effects of Lorentz forces (Li et al., 2019) and magnetic field (Dehghani et al., 2019) on nanofluid flow have been considered. Entropy generation with use of nanofluids was analyzed (Ismael et al., 2018; Kaya et al., 2019). Nanofluids have also been applied to enhance heat transfer in heat exchangers (Khanlari et al., 2019) and heat pipes (Sözen et al., 2018). Performance of hybrid nanofluids with two or more types of nanoparticles (NPs) has been explored (Hassan et al., 2018; Parsian and Akbari, 2018).

With a primary focus on assessing the recent trends and challenges and potentials for continuous growth in heat transfer enhancement with nanofluids, the rest of this paper is organized into several sections in conjunction with the property characterization, modeling, and applications of nanofluids for heat transfer. In Section 2, the thermophysical properties of common nanofluids and heat transfer characteristics are summarized. In Section 3, the enhancement mechanisms are briefed. In Section 4, thermal models are recapped and compared to experiments. The artificial neutral network (ANN) approach is particularly emphasized. In Section 5, applications to heat transfer enhancement are provided, in which cooling technology, solar energy and energy storage, and building technology are also involved. Finally, some challenges and areas for future research are envisioned. This review does not provide information on the synthesis of NPs and the preparation of nanofluids. Interested readers could find many review articles involving these areas, such as in Wang and Mujumer (2007), Yu and Xie (2012), and Sezer et al. (2019).

\section{THERMAL PROPERTIES AND CHARACTERISTICS}

\subsection{Stability}

Low thermal conductivity is a primary limitation in conventional heat transfer fluids such as ethanol, heating oil, and water. High-conductivity millimeter- or micrometer-scale particles have 
been added to fluids to enhance heat transfer; however, rapid settling of these particles in fluids as well as clogging or corrosion in the flow channels has been a major hurdle to develop useful suspensions for practical applications. Choi and Eastman (1995) at Argonne National Laboratory proposed the term "nanofluid," which is a fluid containing a small quantity of nanometer-sized particles $(1 \sim 100 \mathrm{~nm})$ that are uniformly and stably suspended in a base fluid. Electrostatic repulsive forces between NPs and steric stabilization enabled the long-term stability of the colloids (Yu et al., 2017). The NPs used in nanofluids for heat transfer purpose are typically made of high thermal conductivity metals (e.g., $\mathrm{Au}, \mathrm{Ag}, \mathrm{Cu}$ ), metal oxides (e.g., $\mathrm{Al}_{2} \mathrm{O}_{3}, \mathrm{CuO}$ ), carbides (e.g., $\mathrm{SiC}$ ), and carbon in various forms [e.g., carbon nanotubes (CNTs), fullerene, diamond, graphite, graphene].

Common base fluids include water, organic liquids, oils, lubricants, biofluids, polymeric solutions, and other common liquids. One important factor when choosing a heat transfer fluid is its compatibility with the thermal system in the real world. Other considerations include high thermal conductivity and specific heat, low viscosity and freezing point, high flash point, low toxicity, and thermal stability ( $\mathrm{Li}$ and Peterson, 2006), etc. On the basis of these criteria, water, ethylene glycol (EG), and oil are the most commonly used base fluids. Apart from liquid metals, water has the highest thermal conductivity of any liquid. At $30^{\circ} \mathrm{C}$ and $1 \mathrm{~atm}$, the thermal conductivity of water is $0.6259 \mathrm{~W} /(\mathrm{m} \cdot \mathrm{K})$ and that of ethylene glycol is $0.2463 \mathrm{~W} /(\mathrm{m} \cdot \mathrm{K})$ (Pastoriza-Gallego et al., 2011). Though EG has a low thermal conductivity, it could provide freeze protection that is beneficial in many applications. Use of oils has advantages for energy storage because of their large heat capacity.

The agglomeration of NPs results in not only the settlement and clogging of heat transfer microchannels but also the decreasing of thermal conductivity of nanofluids. The stability of nanofluids has a vital role in extending its shelf life and preserving the thermophysical properties. Yu and Xie (2012), Setia et al. (2013), and Yu et al. (2017) provided excellent reviews on the evaluation methods for the stability of nanofluids, the ways to enhance the stability, and the stability mechanisms. The simplest method for evaluating the stability of a nanofluid is the sedimentation method (Li et al., 2007; Ilyas et al., 2014). Other methods include the centrifugation method (Li and Kaner, 2005; Mehrali et al., 2015), the Zeta potential analysis (Fedele et al., 2011), and the spectral absorbency analysis (Hwang et al., 2007). Colloids with high zeta potential (negative or positive) are electrically stabilized; whereas, NPs with low zeta potentials tend to coagulate or flocculate. Kim et al. (2009) prepared Au nanofluids with an outstanding stability, although no dispersants were observed. The stability was attributed to the large negative zeta potential of Au NPs in water. Lee et al. (2014) proposed an innovative method to evaluate dispersion stability of nanofluids, in which the particle volume fraction change was identified by monitoring the suspension density using a hydrometer, and the particle size distribution change was analyzed using the dynamic light scattering method. Lemes et al. (2017) used multivariate image analysis to evaluate nanofluid stability. Evaluation of the thermal conductivity changes in nanofluids, caused by the sedimentation of NPs, was also proposed as a stability measuring approach known as the $3 \omega$-method (Martínez et al., 2018).

Adding dispersants is an effective method to enhance the stability of nanofluids (Tiara et al., 2017). Michael and Iniyan (2015) prepared the $\mathrm{CuO}$ /water nanofluid with the inclusion of surfactant sodium dodecyl benzene sulfonate (SDBS), as it provided the best CuO NP dispersion stability compared to pure water suspension and Triton X-100 surfactant suspensions. Of course, surfactants might cause some problems (Chen et al., 2008): they may contaminate the heat transfer media, and the surfactant molecules attaching on the surfaces of NPs may enlarge the thermal resistance between the NPs and the base fluid, which may limit the enhancement of the effective

Volume 27, Issue 1, 2020 
thermal conductivity (Zhou et al., 2012). Commonly used surfactants for nanofluids were available in Tiara et al. (2017). It should be pointed out that surfactants alone can alter heat transfer as well. Inoue et al. (2004) carried out experiments on nucleate pool boiling of water and water/ethanol mixtures with perfluoroalkyl compound on a wire and stated that the surfactant has little effect on critical heat flux (CHF). The presence of surfactant or polymer additives at low concentrations in water has been found to enhance the nucleate boiling heat transfer coefficient significantly (Wasekar and Manglik, 2017).

Use of surfactant-free functionalized nanoparticles is a promising approach to achieve longterm stability of nanofluid. Yang and Liu (2010) presented a work on the synthesis of functionalized silica $\left(\mathrm{SiO}_{2}\right)$ NPs by grafting silanes directly to the surface of the NPs in solutions. Zinc oxide NPs could be modified by polymethacrylic acid (PMAA) in aqueous system (Tang et al., 2006) without altering the crystalline structure of the ZnO NPs. Han et al. (2016) showed experimentally that the thermal management of a micro heater was substantially improved by introducing alternative heat-escaping channels into a graphene-based film bonded to functionalized graphene oxide through amino-silane molecules. Sonication can also be used to enhance the stability of nanofluid by rupturing the NPs attractional force within the sediments (Mahbubul et al., 2017). Manipulating the $\mathrm{pH}$ value of nanofluids changes the NPs surface and can strongly improve the stability of the dispersed NP suspensions (Azizian et al., 2016; Mohammadi et al., 2017; Witharana et al., 2013). Zhu et al. (2011) used a wet chemical method to prepare stable $\mathrm{CuO}$ nanofluids.

The DLVO theory (named after B. Derjaguin, E. Verway, L. Landau, and T. Overbeek) explains the aggregation of aqueous dispersions (Missana and Adell, 2000; Popa et al., 2010; Yu et al., 2017). It suggests that the stability of a particle in solution is determined by the sum of van der Waals attractive and electrical double layer repulsive forces that exist between particles as they approach each other due to the Brownian motion they are undergoing. If the attractive force is larger than the repulsive force, the two particles will collide and the suspension is not stable. If the particles have a sufficient high repulsion, the suspensions will exist in stable state. Silver NP suspensions are very stable due to the protective role of polyvinylpyrrolidone (PVP), as it retards the growth and agglomeration of NPs by steric effect (Singh and Raykar, 2008). PVP is also an efficient agent to improve the stability of graphite suspensions (Zhu et al., 2007) and silica aqueous suspensions (Perez Huertas et al., 2017).

\subsection{Thermal Properties}

Nanofluids have attracted increasing attention in recent years because of reports of greatly enhanced thermal properties. Thermophysical properties of a material affect the transfer and storage of heat and vary with the state variables, such as temperature, pressure, composition, and other relevant variables. These properties include thermal conductivity, specific heat capacity, thermal diffusivity, thermal expansion, latent of heat, thermal radiative properties, etc. The thermal conductivity of nanofluids depends on many factors except for the above-mentioned variables, such as concentration and agglomeration of NPs, particle-liquid interface, dispersion, interphase interactions, size and morphology of NPs, $\mathrm{pH}$ value, and Brownian motion.

The effective thermal conductivity was shown to be increased by up to $40 \%$ for a nanofluid consisting of EG containing $\sim 0.3$ vol \% Cu NPs of mean diameter $<10 \mathrm{~nm}$ (Eastman et al., 2001 ), over $250 \%$ for a CNT-oil nanofluid of approximately $\sim 1$ vol \% (Choi et al., 2001), and up to $86 \%$ by the dispersed graphene $(5.0 \mathrm{vol} \%)$ in ethylene glycol (Yu et al., 2011). The transient hot-wire method (Guo et al., 2018), the steady-state parallel plate technique (Wang et al., 1999), 
and the temperature oscillation technique (Das et al., 2003a) have been employed to measure the thermal conductivity of nanofluids. In general, nanofluids are electrically conductive; it is difficult to apply the ordinary transient hot-wire technique directly. A modified hot-wire cell and electrical system was proposed by Nagasaka and Nagashima (1981) by coating the hot wire with an epoxy adhesive that has excellent electrical insulation and heat conduction. However, Das et al. (2003a) pointed out that possible concentration of ions of the conducting fluids around the hot wire may affect the accuracy of such results. The oscillation method is purely thermal, and the electrical components of the apparatus are removed from the test sample; thus, ion movement should not affect the results.

It should be stressed that Putnam et al. (2006) did not observe significant enhancement in the thermal conductivity of nanofluids with small volume fractions of NPs such as C60-C70 and $\mathrm{Au}$. The observed largest increase in thermal conductivity for $4 \mathrm{~nm} \mathrm{Au}$ particles is $1.3 \% \pm 0.8 \%$, which was conflicted with the anomalous results of Patel et al. (2003). As Yang et al. (2013) noted, some nanofluid studies show inconsistency and controversy, reporting enhancement under some conditions and even deterioration under other conditions (Chien and Chuang, 2007; Lee and Mudawar, 2007). Excellent discussions on this issue may be found elsewhere (Wang and Mujumder, 2007; Cheng et al., 2008; Kakac and Pramuanjaroenkij, 2016; Hussein et al., 2014; Pryazhnikov et al., 2017; Raeisian et al., 2019).

Compared to the studies on thermal conductivity, there were limited rheological studies and heat capacity measurements reported in the literature. Pak and Cho (1998) measured the viscosity of alumina/water and titania/water nanofluids at 1-10 vol \% and found it to be much higher than that of pure water. The measured dynamic viscosity using a parallel plate rheometer for the $\mathrm{CuO}$ /water nanofluid is $7 \%$ lower than that measured by an Ostwald viscometer (Michael and Iniyan, 2015). The impacts of temperature, NPs mass fraction, and base fluid types were investigated on the dynamic viscosity of $\mathrm{CuO}$ nanofluids by Abdollahi et al. (2018). Their results indicated that by adding a tiny amount of $\mathrm{CuO}$ NPs to base fluids, relative viscosity of nanofluid increases. With the increase in temperature, the value of relative dynamic viscosity decreases significantly. In addition, their results declare that viscosity of nanofluid remains constant at various applied shear rates, indicating Newtonian behavior of nanofluid at various NPs load and temperature. While in the studies of hybrid nanofluids of multiwall carbon nanotubes

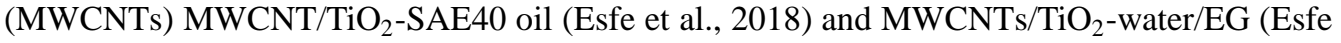
et al., 2019), the relation between viscosity and shear rate showed that behavior of the nanofluids is similar to behavior of non-Newtonian fluids. Bashirnezhad et al. (2016) reviewed recent experimental studies on viscosity of nanofluids. A comprehensive assessment on rheological characteristics of nanofluids for heat transfer applications is reported by Sohel Murshed and Estelle (2017). Azmi et al. (2016) reviewed the enhancement of effective thermal conductivity and effective dynamics viscosity of nanofluids. Measuring the viscosity of nanofluids is necessary for designing thermal systems and estimating the required pumping power as use of nanofluids may increase pumping power.

Nanofluids can be used for energy savings in energy storage and waste heat recovery systems (Shahrul et al., 2014). Specific heat capacity is necessary to analyze energy and exergy performances and thus, an important thermal property for nanofluids. Vajjha and Das (2009) measured the specific heat of three nanofluids containing $\mathrm{Al}_{2} \mathrm{O}_{3}, \mathrm{ZnO}$, and $\mathrm{SiO}_{2} \mathrm{NPs}$. Sekhar and Sharma (2015) investigated viscosity and specific heat of water-based $\mathrm{Al}_{2} \mathrm{O}_{3}$ nanofluids at low particle concentrations. Robertis et al. (2012) used the differential scanning calorimetry technique to measure specific heat in $\mathrm{Cu}-\mathrm{EG}$ nanofluids and found that the specific heat decreased for NPs suspension in the base fluid and increased with the increase of temperature. Elias et al. (2014)

Volume 27, Issue 1, 2020 
reported a similar trend for $\mathrm{Al}_{2} \mathrm{O}_{3}$ nanoparticles suspended in car radiator coolant. Akilu et al. (2018) also confirmed this tendency for $\mathrm{SiO}_{2}(80 \mathrm{wt} \%)-\mathrm{CuO} / \mathrm{C}(20 \mathrm{wt} \%)$-EG/glycerol hybrid nanofluids without surfactant.

However, the opposite trend as the specific heat nanofluids decreased with increase of temperature was observed by Saeedinia et al. (2012) for CuO-pure engine oil nanofluid. Michael and Iniyan (2015) found a decrease of specific heat with 0.05 vol \% addition of CuO NPs in water. On the other side, anomalous enhancement of specific heat capacity of silica nanofluids (Donghyun and Debjyoti, 2011) has been reported. Hentschke (2016) claimed that specific heat enhancement requires one or both of the following to be true: (i) every particle is surrounded by a nanolayer with a $C_{\mathrm{p}}$ exceeding the bulk fluid's $C_{\mathrm{p}, \mathrm{b}}$ by a large factor, and (ii) the effect of the particles on the base fluid has a long range (100 nm or more), which only requires a moderate change of specific heat in the attendant mesolayer. A relationship between the ionic exchange capacity of NPs and the specific heat enhancement of salt-based nanofluids was proposed by Mondragon et al. (2018). Moldoveanu and Minea (2019) measured specific heat of simple and hybrid oxide-water nanofluids.

It is a common practice to present the thermal conductivity enhancement $\left(k_{\text {eff }} / k_{\mathrm{b}}\right)$ of a nanofluid to its base fluid against NP volume or mass fraction and temperature in conjunction with other parameters, such as particle size. There is a lot of data on thermal properties available in the literature. Table 1 only selectively lists the thermal conductivity enhancement data and the relative viscosity $\left(\mu_{\mathrm{eff}} / \mu_{\mathrm{b}}\right)$, as well as the enhancement of specific heat capacity $\left(C_{\mathrm{p}, \mathrm{eff}} / C_{\mathrm{p}, \mathrm{b}}\right)$ for some common nanofluids experimentally measured in recent years. Some of the studies listed in Table 1 have measured all the three properties; whereas, many may have just measured one or two types of the properties.

As aforementioned, many other thermophysical properties are also important and have been investigated for nanofluids. For example, Wang et al. (2014) dispersed $\mathrm{TiO}_{2} \mathrm{NPs}$ into a paraffin wax (PW) matrix to prepare phase-change composite materials for enhanced energy storage and found that the latent heat of fusion (including the solid-solid and solid-liquid phase changes) increased from $167 \mathrm{~kJ} / \mathrm{kg}$ for the matrix to $193 \mathrm{~kJ} / \mathrm{kg}$ for the $\mathrm{TiO}_{2}-\mathrm{PW}$ composite at $0.7 \mathrm{wt} \%$ load of NPs. Bhuiyan et al. (2015) found that the latent heat of vaporization of $\mathrm{SiO}_{2}$ and $\mathrm{TiO}_{2}$ aqueous suspensions decreased with the increase in volume fraction $(0.05 \sim 0.25 \mathrm{vol} \%)$. Lee et al. (2015) showed that latent heat of vaporization can be substantially increased in graphite-water nanofluid, whereas substantially decreased in silver-water nanofluid. Nayak et al. (2010) found that the nanofluids have greater volumetric thermal expansion coefficients as compared to that of the base fluid. In their experiments, various NPs such as $\mathrm{Al}_{2} \mathrm{O}_{3}, \mathrm{CuO}, \mathrm{SiO}_{2}$, and $\mathrm{TiO}_{2}$ respectively were suspended in the water by ultrasonication. All nanofluids had the same concentration of $1 \mathrm{wt} \%$.

The density of a nanofluid can be measured as a ratio of the total mass of the NPs and base fluid to the total volume, which may result in the mixture law for ideal mixtures, as follows:

$$
\rho_{\mathrm{nf}}=(1-\varphi) \rho_{\mathrm{b}}+\varphi \rho_{\mathrm{p}}
$$

Recent experimental measurements discovered that use of Eq. (1) may lead to erroneous results (Sharifpur et al., 2016). The accuracy of the account for volume fraction $(\varphi)$ and particle density $\left(\rho_{p}\right)$ is the main cause. Under the ideal mixture assumption, Eq. (1) does hold, but the particle density should be replaced by the bulk material density which is heavier than particles density as porosity exists in particle powders. On the other side, the existence of nanolayer which is an interfacial layer between particles and base fluid will effectively reduce the volume fraction 


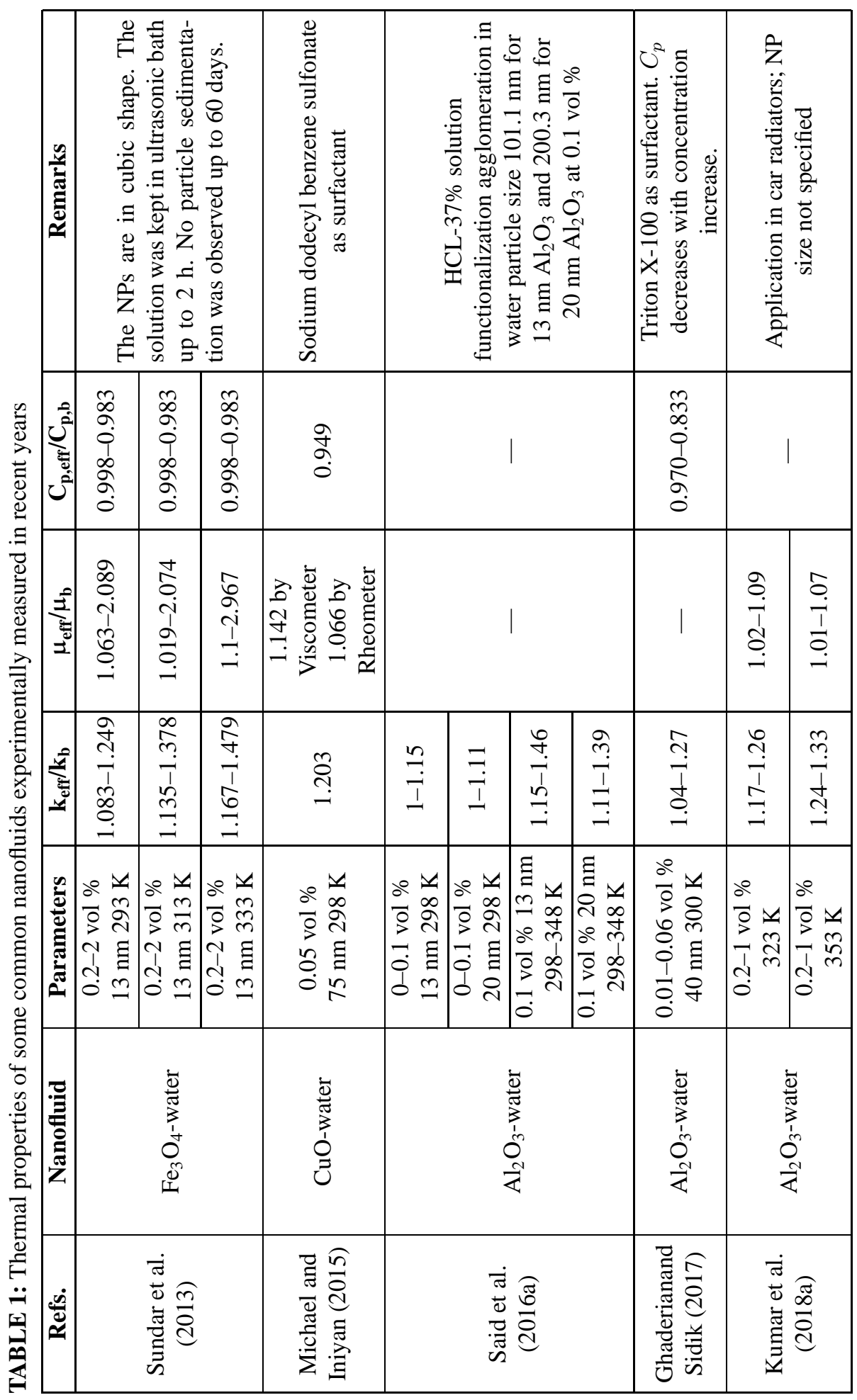




\begin{tabular}{|c|c|c|c|c|c|c|c|c|c|c|c|c|c|c|c|}
\hline & & & 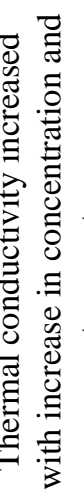 & & 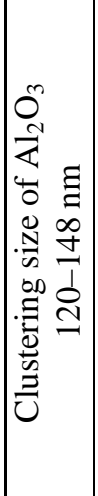 & 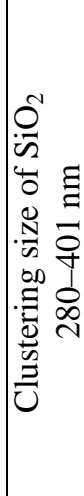 & & 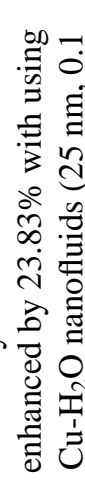 & 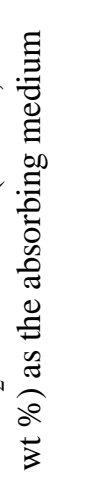 & \multicolumn{6}{|c|}{ 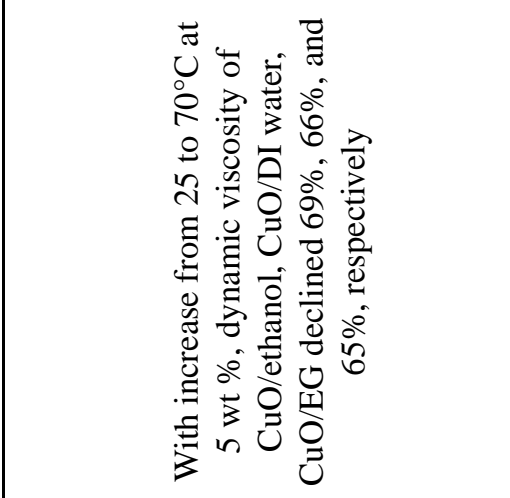 } \\
\hline & & \multicolumn{3}{|c|}{$\mid$} & 1 & $\mid$ & \multicolumn{3}{|c|}{$\mid$} & \multicolumn{2}{|c|}{ | } & \multicolumn{2}{|c|}{1} & \multicolumn{2}{|c|}{1} \\
\hline & & \multicolumn{3}{|c|}{ | } & | & $\mid$ & & $\mid$ & & 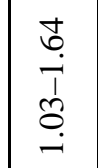 & 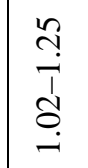 & $\begin{array}{l}\stackrel{1}{I} \\
\dot{I} \\
\stackrel{-}{-}\end{array}$ & 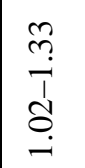 & $\begin{array}{l}\mathcal{I} \\
\mathfrak{i} \\
\mathfrak{1} \\
0 \\
0 \\
-\end{array}$ & 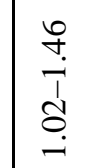 \\
\hline & & $\begin{array}{l}n \\
0 \\
0 \\
1 \\
-1 \\
0 \\
-1\end{array}$ & $\begin{array}{l}\exists \\
\\
1 \\
\infty \\
0 \\
0\end{array}$ & $\begin{array}{l}\stackrel{\infty}{\vdots} \\
\infty \\
\stackrel{\infty}{0} \\
\stackrel{0}{-1}\end{array}$ & 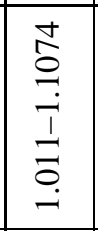 & 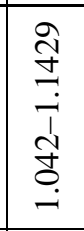 & 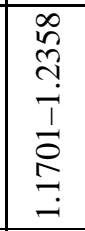 & 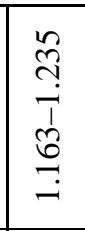 & 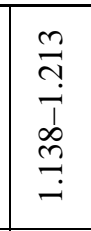 & \multicolumn{2}{|c|}{ | } & \multicolumn{2}{|c|}{ | } & \\
\hline & & $\begin{array}{ll}0 & v \\
0 & 0 \\
0 & 0 \\
\infty & m \\
0 & \vdots \\
1 & \vdots \\
0 & 0\end{array}$ & $\begin{array}{ll}0 & v \\
0 & 0 \\
0 & 0 \\
0 & 0 \\
0 & 0 \\
0 & \vdots \\
1 & 0 \\
0 & 0\end{array}$ & $\begin{array}{ll}0 & v \\
0 & 0 \\
0 & 0 \\
0 & 0 \\
0 & 0 \\
0 & \vdots \\
1 & \vdots \\
0 & 0 \\
0 & 0\end{array}$ & $\mid \begin{array}{ll}0 & \\
0 & \\
0 & \vdots \\
n & \vdots \\
0 & 0 \\
1 & n \\
n & 1 \\
8 & q \\
0 & \\
0 & \\
0\end{array}$ & 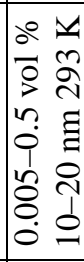 & 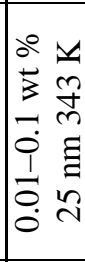 & 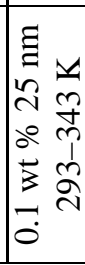 & 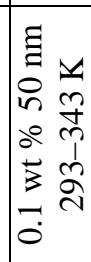 & 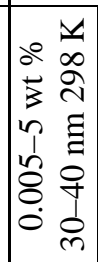 & 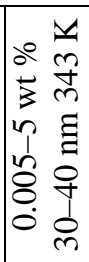 & \multicolumn{2}{|c|}{ 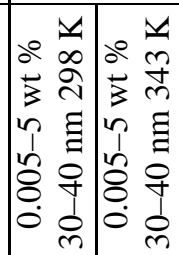 } & 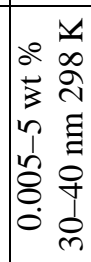 & 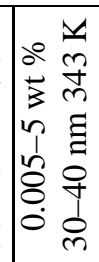 \\
\hline & & 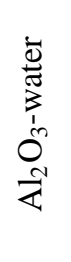 & 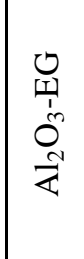 & 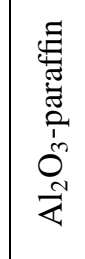 & 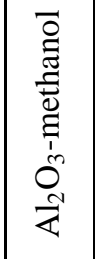 & 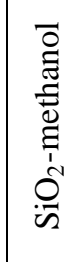 & \multicolumn{3}{|c|}{ 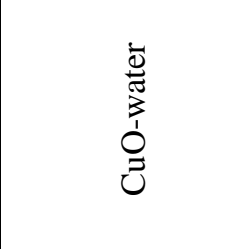 } & & 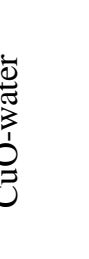 & \multicolumn{2}{|c|}{$\begin{array}{l}0 \\
\text { II } \\
0 \\
\Xi \\
0\end{array}$} & & 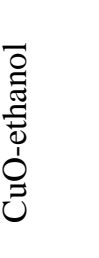 \\
\hline & \multicolumn{4}{|c|}{ 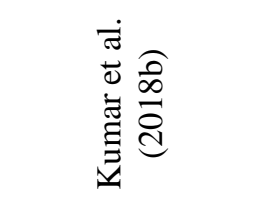 } & \multicolumn{2}{|c|}{ 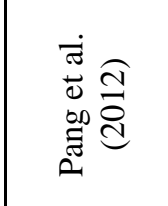 } & \multicolumn{3}{|c|}{ 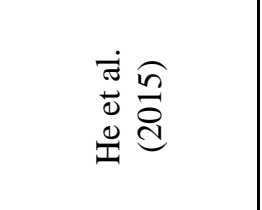 } & \multicolumn{6}{|c|}{ 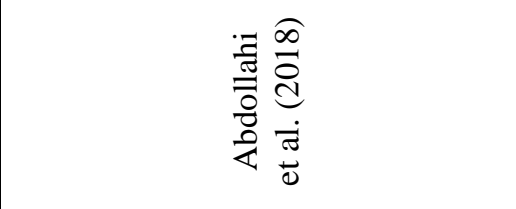 } \\
\hline
\end{tabular}




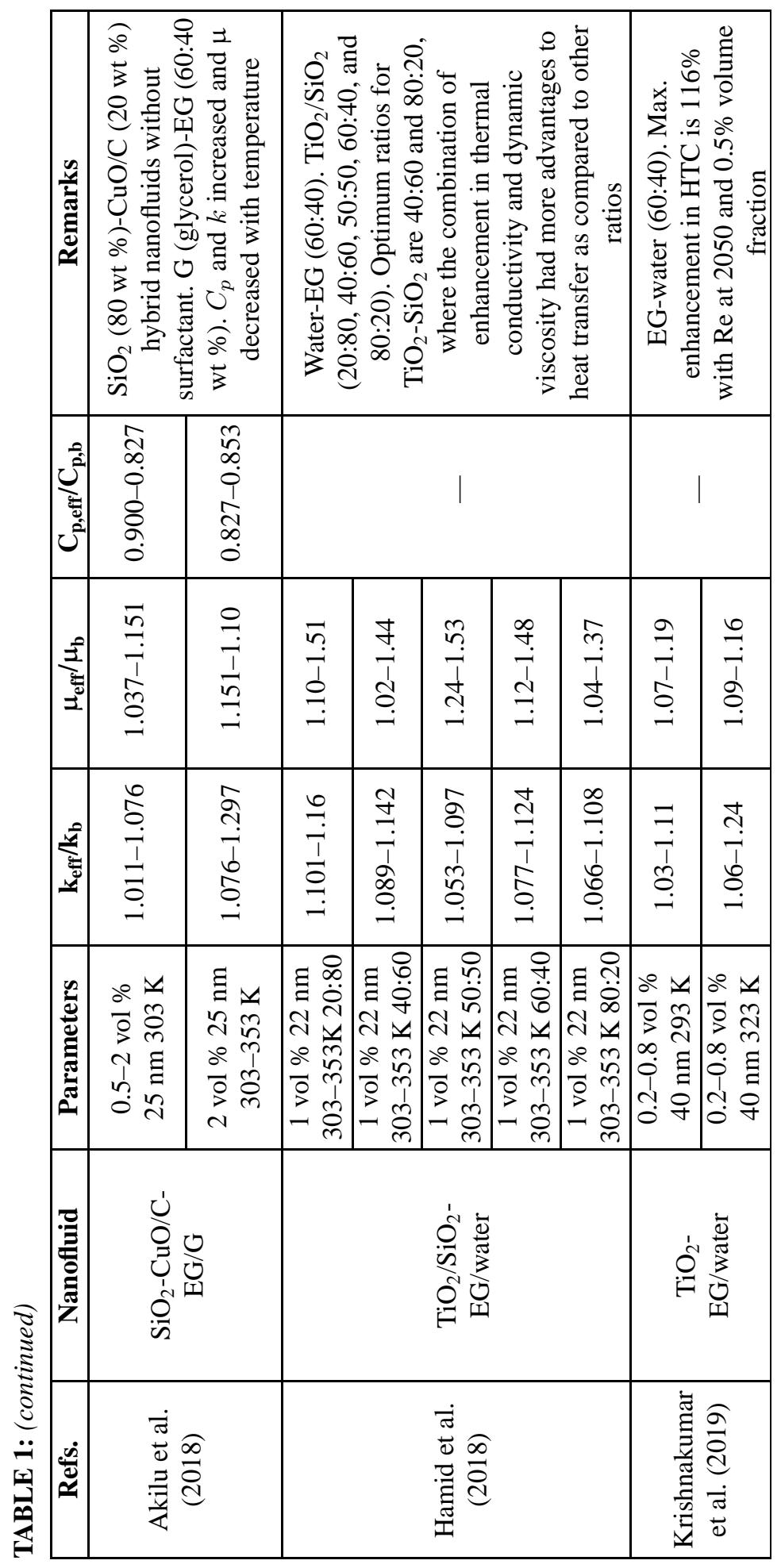




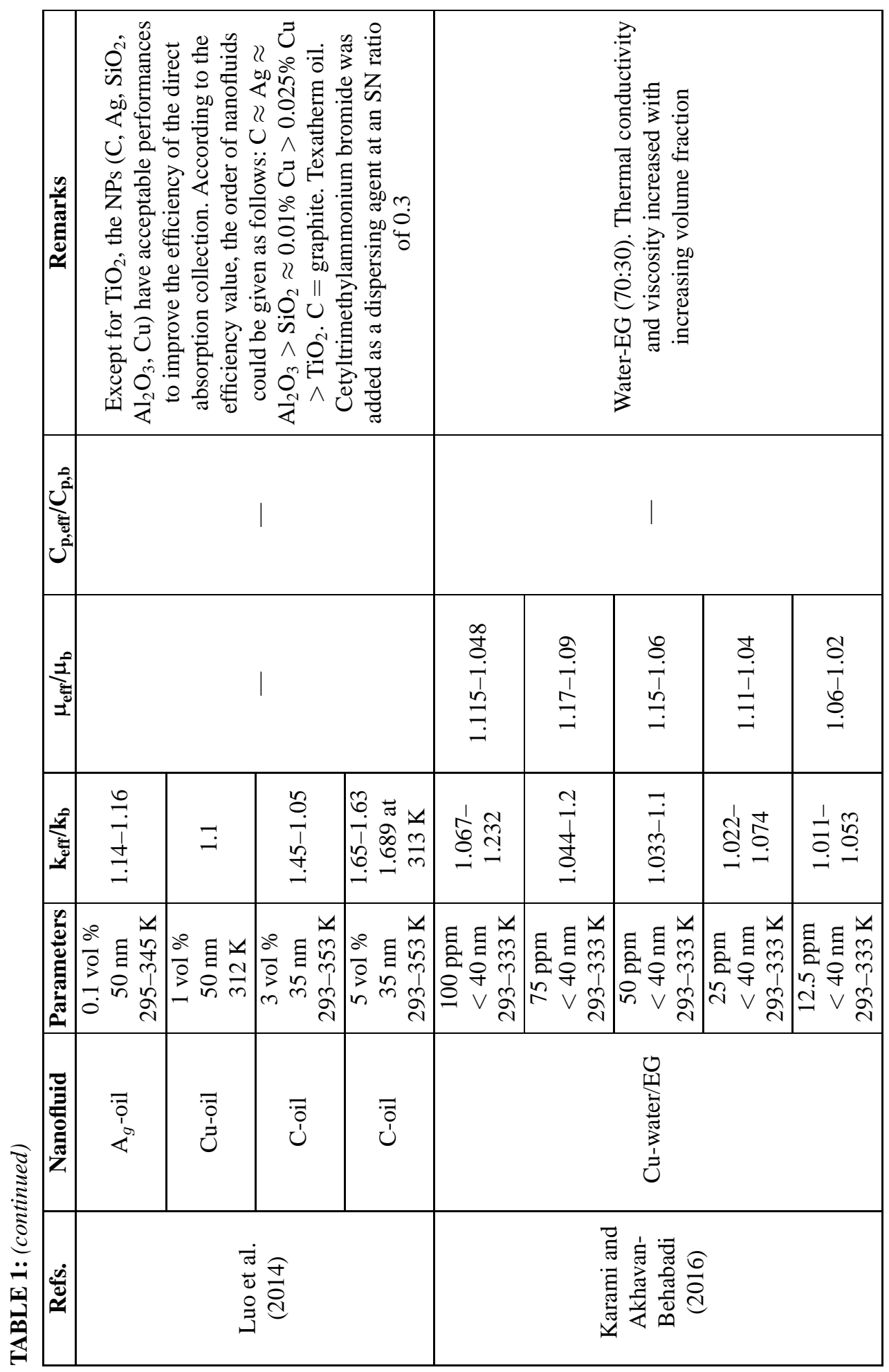




\begin{tabular}{|c|c|c|c|c|c|c|c|c|c|}
\hline 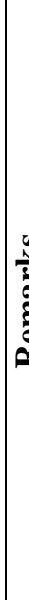 & & 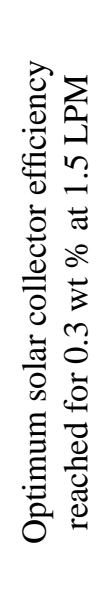 & & 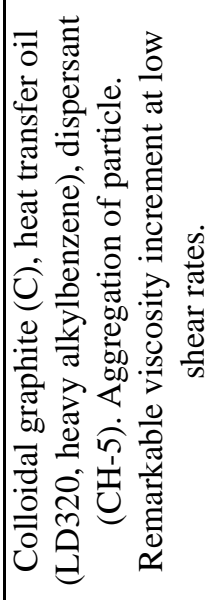 & 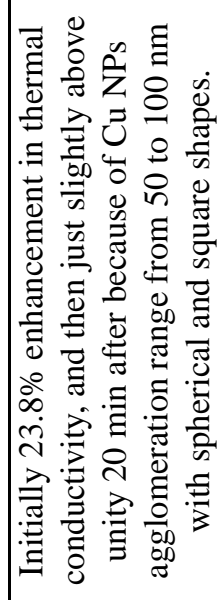 & 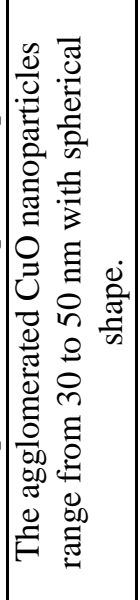 & & 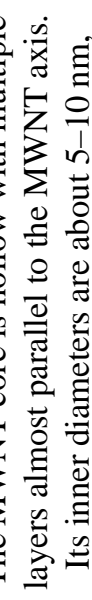 & 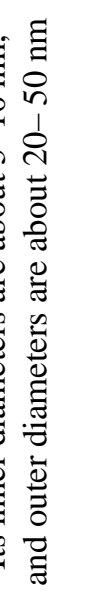 \\
\hline ك & & $\mid$ & & 1 & 1 & $\mid$ & 1 & 1 & 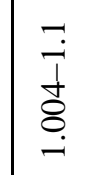 \\
\hline & & 1 & & $\mid$ & $\mid$ & $\mid$ & $\mid$ & $\mid$ & $\mid$ \\
\hline & 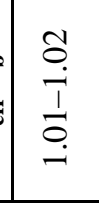 & $\begin{array}{l}\hat{\sigma} \\
\text { a. } \\
\underline{b} \\
0 \\
0 \\
\end{array}$ & 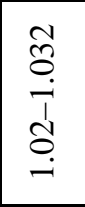 & 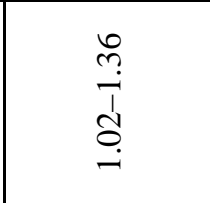 & 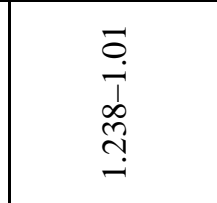 & 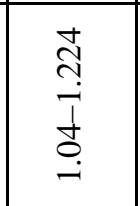 & 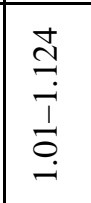 & 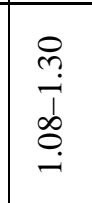 & $\mid$ \\
\hline 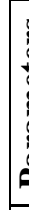 & $\mid \begin{array}{ll}0 & v \\
3 & \infty \\
3 & 0 \\
0 & 0 \\
0 & \vdots \\
1 & \vdots \\
0 & 0\end{array}$ & $\mid \begin{array}{ll}0 & 1 \\
0 & 0 \\
3 & 0 \\
0 & 0 \\
0 & 0 \\
1 & \vdots \\
0 & 0 \\
0 & 0\end{array}$ & \begin{tabular}{|cc} 
& 1 \\
3 & 1 \\
0 & 0 \\
0 & 0 \\
0 & 1 \\
1 & $\vdots$ \\
0 & 0 \\
0 & 0
\end{tabular} & 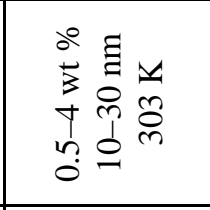 & 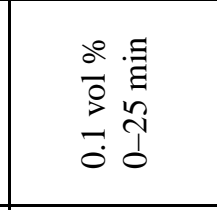 & 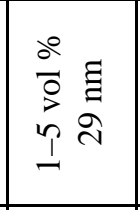 & 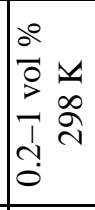 & $\begin{array}{ll}0 & \\
0 & 1 \\
0 & 1 \\
0 & \infty \\
1 & 2\end{array}$ & $\begin{array}{ll}0 & v \\
0 & n \\
0 & n \\
0 & 1 \\
0 & \frac{1}{0}\end{array}$ \\
\hline & & 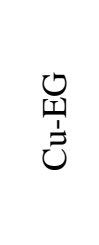 & & $\begin{array}{l}\overline{0} \\
\bar{U}\end{array}$ & 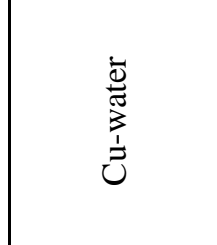 & 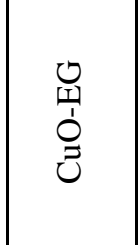 & $\begin{array}{l}0 \\
\text { II } \\
亡 \\
⿱ 亠 䒑 \\
\vdots \\
\sum\end{array}$ & 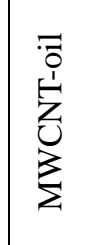 & 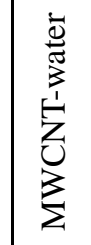 \\
\hline & & 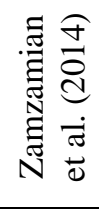 & & 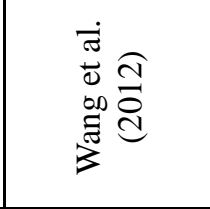 & \multicolumn{5}{|c|}{ 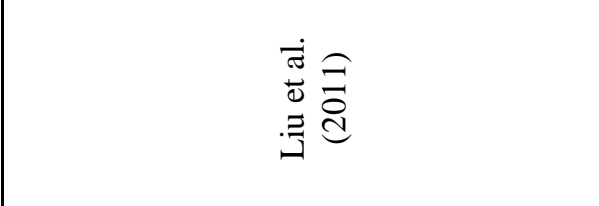 } \\
\hline
\end{tabular}

Volume 27, Issue 1, 2020 


\begin{tabular}{|c|c|c|c|c|c|}
\hline & 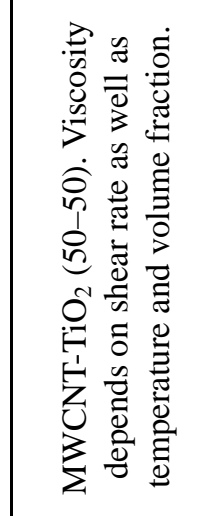 & \multicolumn{2}{|c|}{ 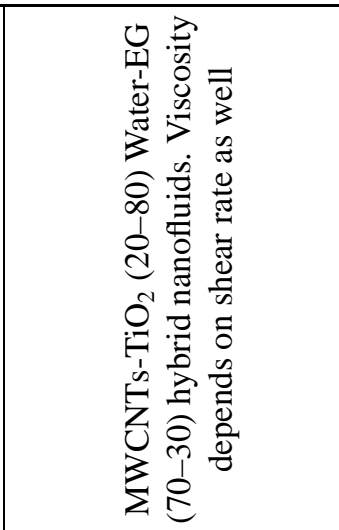 } & \multicolumn{2}{|c|}{ 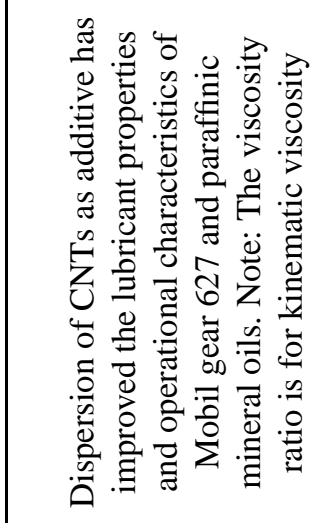 } \\
\hline & $\mid$ & | & & $\mid$ & 1 \\
\hline & 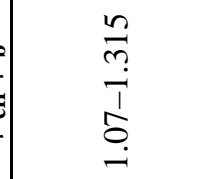 & 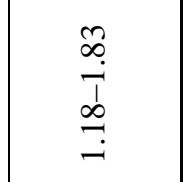 & 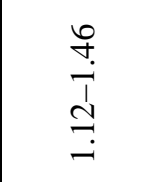 & $\begin{array}{l}n \\
0 \\
0 \\
1 \\
0 \\
0 \\
i\end{array}$ & $\begin{array}{l}0 \\
0 \\
i \\
0 \\
i \\
i\end{array}$ \\
\hline & 1 & \multicolumn{2}{|l|}{$\mid$} & 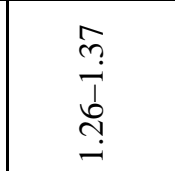 & 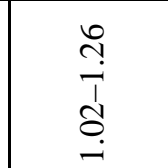 \\
\hline & 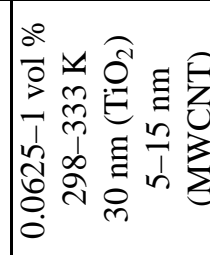 & 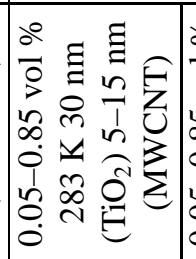 & 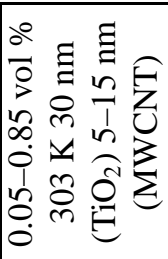 & 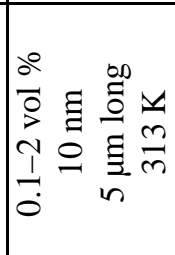 & 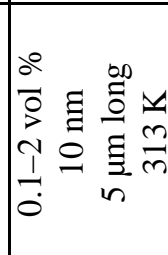 \\
\hline & 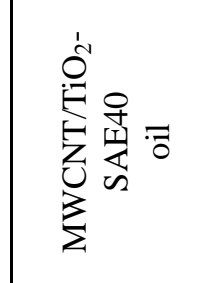 & 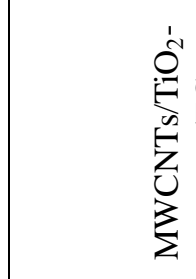 & 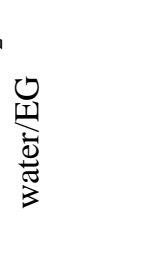 & 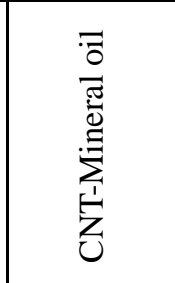 & 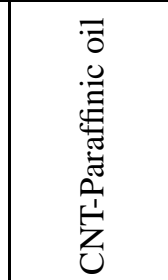 \\
\hline & 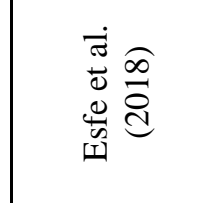 & 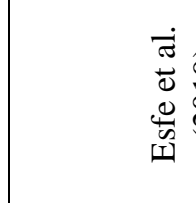 & $\frac{\widehat{\partial}}{\stackrel{d}{d}}$ & & $\frac{\infty}{d}$ \\
\hline
\end{tabular}


of the NPs. Sharifpur et al. (2016) found that the experimentally measured densities of nanofluids $\left(\mathrm{SiO}_{2}\right.$-water, $\mathrm{MgO}$-glycerol, $\mathrm{CuO}$-glycerol, and $\mathrm{SiOx}$-ethylene glycol/water for a range of $1-6$ vol $\%$ as well as a temperature range of $10-40^{\circ} \mathrm{C}$ ) are lower than the predicted values by using Eq. (1).

\subsection{Heat Transfer Characteristics}

Recently, Raja et al. (2016) and Ganvir et al. (2017) conducted comprehensive reviews on heat transfer characteristics of nanofluids. For forced convective heat transfer, Xuan and Li (2003) experimentally investigated flow and convective heat transfer characteristics for $\mathrm{Cu}$-water-based nanofluids through a straight tube with a constant heat flux at the wall. Results showed that the nanofluids give substantial enhancement of the heat transfer rate compared to pure water. Wen and Ding (2004) reported experimental results for the convective heat transfer of $\gamma-\mathrm{Al}_{2} \mathrm{O}_{3}$-waterbased nanofluids flowing through a copper tube in the laminar regime and found that the inclusion of $\mathrm{Al}_{2} \mathrm{O}_{3}$ particles can significantly enhance the convective heat transfer coefficient (HTC). Ding et al. (2006) experimentally investigated the heat transfer performance of CNT nanofluids in a tube, in which the observed HTC enhancement was much higher than the increase in the effective thermal conductivity. Azmi et al. (2013) determined the HTCs and friction factor with $\mathrm{SiO}_{2}$ nanofluid in a tube turbulent flow in the Reynolds number range of $5 \times 10^{3}$ to $27 \times 10^{3}$. It was found that the HTC increased with volume concentration up to $3.0 \%$ and decreased thereafter. Their results showed that the HTC decreases when the viscosity to thermal conductivity enhancement ratio is $>5.0$.

Godson et al. (2014) carried out an experimental study on the heat transfer characteristics of Ag-water nanofluids of concentrations $0.01 \sim 0.04 \%$ in the turbulent regime in a shell and tube heat exchanger. They observed a maximum enhancement in convective HTC of $12.4 \%$ and effectiveness of $6.14 \%$. They attributed the HTC enhancement to the enhanced thermal properties of the nanofluids and delayed development of the boundary layer in the entrance regions due to addition of NPs. A recent review (Hussein et al., 2014) found that most of the numerical studies are in agreement with the results of experimental work, and many of the studies reported enhancements in the forced convective HTC with an increase in the concentration of solid particles.

Figure 2 compares some HTC data extracted from Azmi et al. (2013), Godson et al. (2014), and Kumar et al. (2017). In the experiments of Azmi et al. (2013), $\mathrm{SiO}_{2}$ nanofluids of various concentrations were at $30^{\circ} \mathrm{C}$ bulk temperature, approximately; the nanoparticles were $22 \mathrm{~nm}$ in diameter; and the tube was $0.016 \mathrm{~mm}$ in diameter. The HTC increased with volume concentration up to $3.0 \%$, in which enhancement varied between 29.6 and $38.5 \%$ in the Reynolds number range tested. An apparent increase in the HTC is observed with increasing Ag concentration in water in the experiments of Godson et al. (2014). The increase in the overall HTC is found to be $13.2,12.4$, and $9.2 \%$, respectively, for $0.04,0.03$, and $0.01 \%$ volume concentrations of $\mathrm{Ag}$ NPs. The tube inner diameter was $4 \mathrm{~mm}$. The averaged diameter of $\mathrm{Ag}$ particles was $54 \mathrm{~nm}$. HTC increase with increasing Reynolds number, and NPs concentration was also observed in the results of Kumar et al. (2017) for $\mathrm{Fe}_{3} \mathrm{O}_{4}$-water nanofluids. At a particle concentration of $0.06 \%$, the HTC enhancement is about $9.76 \%$ and $14.7 \%$ at Reynolds number of 16,545 and 28,954, respectively. It should be pointed out that both Godson et al. (2014) and Kumar et al. (2017) showed their data for various NP concentrations at same Reynolds number as the base fluid. As we knew, the Reynolds number depends on kinematic viscosity of fluid in addition to the characteristic length and flow velocity. It is also well known that the addition of NPs in a base

Volume 27, Issue 1, 2020 


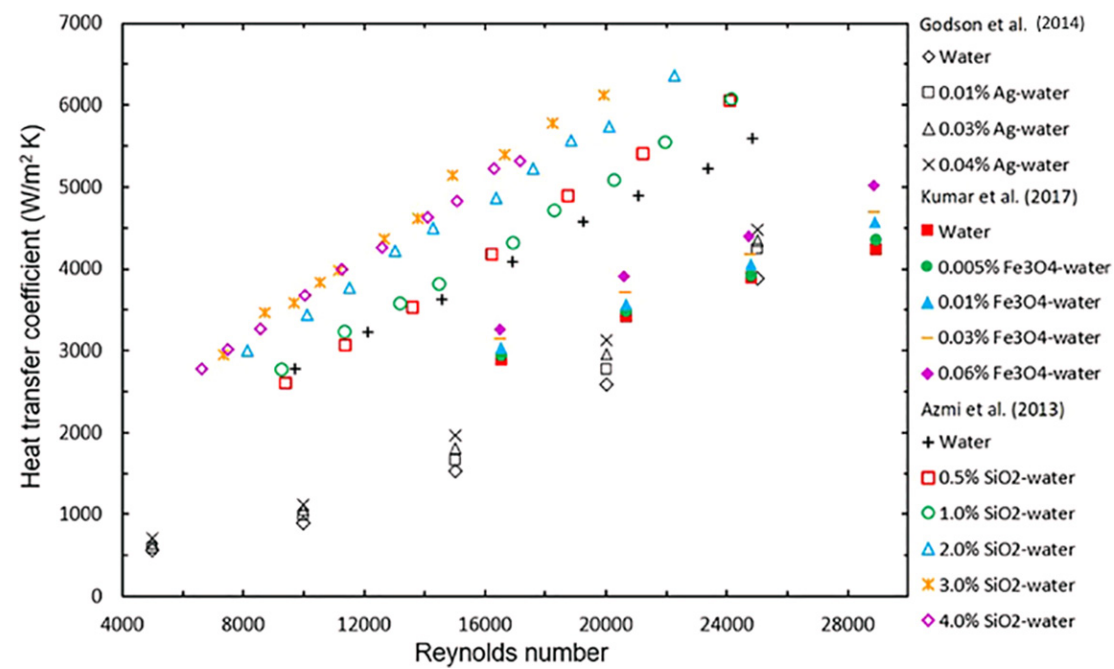

FIG. 2: Forced convective heat transfer coefficients for various nanofluids

fluid will vary the kinematic viscosity. Comparing experimental data at same Reynolds number for the base fluid and nanofluids of various concentrations could have been an error. A similar problem existed in many nanofluid studies presenting Nusselt number in the literature.

For natural convective heat transfer, Mahian et al. (2016) conducted both experimental and theoretical studies of $\mathrm{SiO}_{2}$ nanoparticles of $7 \mathrm{~nm}$ in diameter suspended in water in square and triangular enclosures. They found that the average Nusselt number decreases with an increase in nanofluid concentration at Rayleigh numbers of $10^{5}$ and $10^{6}$. They believed that the enhancement of thermal conductivity and viscosity with increase of nanofluid concentration leads to the reduction of the average Nusselt number, which was obtained through theoretical models. Since the Nusselt number is a ratio of convection heat transfer to conduction heat transfer, the conduction heat transfer increases when the thermal conductivity increases and, hence, the Nusselt number is reduced. Furthermore, an increase in viscosity in nanofluid leads to the reduction of convection heat transfer. Moreover, particle loading results in a decrease in thermal expansion coefficient and heat capacity, which will reinforce the reduction of average Nusselt number.

However, there are some inconsistent reports on nanofluid behavior in convection. Pak and Cho (1998) studied heat transfer performance of $\mathrm{Al}_{2} \mathrm{O}_{3}(13 \mathrm{~nm})$ and $\mathrm{TiO}_{2}(27 \mathrm{~nm})$ water-based nanofluids in a tube. They found that the convective HTC of the nanofluids at 3 vol \% was $12 \%$ lower than that of pure water. A possible reason is that the suspensions have higher viscosity than that of pure water, especially at high particle volume fractions. Yang et al. (2013) showed a much lower increase of convective HTC with respect to the effective thermal conductivity. Putra et al. (2003) presented their experimental observations on natural convection of $\mathrm{Al}_{2} \mathrm{O}_{3}$ and $\mathrm{CuO}$-water nanofluids inside a horizontal cylinder heated from one end and cooled from the other. They found a systematic and definite deterioration of the natural convective heat transfer. The deterioration increased with particle concentration and was more significant for $\mathrm{CuO}$ nanofluids. Wen and Ding (2005a) also found a decrease of natural convective $\mathrm{HTC}$ of $\mathrm{TiO}_{2}$ $(30-40 \mathrm{~nm})$ water nanofluids in a vessel as compared to that of pure water. Haddad et al. (2016) studied natural convection of $\mathrm{SiO}_{2}(20 \mathrm{~nm})$-water nanofluid in an enclosure and found that uncertainties in the predictive models for the effective thermal conductivity and dynamic viscosity 
of nanofluids leads to erroneous evaluation of the convective heat transfer with nanofluids. The heat transfer across the enclosure using different models can be enhanced or deteriorated with respect to the base fluid.

Recent advances in miniaturization and manufacturing bring power densities to increasingly higher levels. Only boiling heat transfer is suitable for such high heat flux removal or rapid cooling. In falling film evaporation, both conductive and convective types of heat transfer take place across the film thickness. Evaporation occurs at the liquid-vapor interface due to convective heat transfer. Nucleate boiling occurs in the liquid-solid interface when the heat flux is increased gradually. An enhanced CHF in pool boiling provides an increase in the safety margin of the thermal system for many applications, such as microelectronics, power electronics, transportation, nuclear engineering, heat pipes, refrigeration, air-conditioning, and heat pump systems.

A dramatic increase $(\sim 200 \%)$ of critical heat flux (CHF) compared to pure water was measured in pool boiling of $\mathrm{Al}_{2} \mathrm{O}_{3}$-water nanofluid (You et al., 2003). Wen and Ding (2005b) found that presence of alumina in the spherical $\mathrm{Al}_{2} \mathrm{O}_{3}$-water nanofluid can enhance the boiling heat transfer by $\sim 40 \%$ for a $1.25 \mathrm{wt} \%$ concentration of the particles. Nguyen et al. (2006) showed enhancement of boiling heat transfer using $\mathrm{Al}_{2} \mathrm{O}_{3}$-nanofluids. The CHF had considerably decreased with increasing particle concentrations. For distilled water, the value of CHF was 1192 $\mathrm{kW} / \mathrm{m}^{2}$, which was quite close to that predicted by using the modified Zuber formula. The corresponding values for nanofluids of $0.5,1$, and $2 \%$ concentration were 744,690 , and $422 \mathrm{~kW} / \mathrm{m}^{2}$, respectively. Thus, the decrease of maximum heat flux was nearly $65 \%$ for $2 \%$ nanofluid as compared to distilled water. Zhou (2004) investigated experimentally the heat transfer characteristics of $\mathrm{Cu}$-acetone based nanofluids with and without acoustic cavitation. In an acoustic field, the boiling heat transfer of nanofluids was enhanced and the boiling hysteresis disappeared. Sarafraz and Hormozi (2016) experimentally investigated the pool boiling heat transfer of aqueous MWCNT nanofluids on both plain and micro-fin modified surfaces. Their results demonstrated that the pool boiling HTC on the plain surface was deteriorated, while for the micro-finned surfaces, it was enhanced up to $56 \%$ and $77 \%$ for 0.1 and $0.3 \mathrm{wt} \%$, respectively. The modified surfaces decreased the rate of fouling in comparison with plain surface, which improved the number of active nucleation sites and bubble formation. In addition, deposition of CNTs on the surface caused some changes in surface characteristics such that the static contact angle value was found to be decreased and surface wettability to be increased as well. In this case, CHF was enhanced up to $95 \%$ (for $0.3 \mathrm{wt} \%$ ).

Balaji et al. (2018) found that quite a few studies have been carried out for understanding nucleate pool boiling of water- and refrigerant-based nanofluids. Park and Jung (2007a) conducted a study on nucleate boiling of R123 and R134a with $1.0 \mathrm{vol} \%$ of CNTs. Up to $36.6 \%$ heat transfer enhancement at low heat flux was observed. Further, no fouling was observed on the surface with CNTs. In another study of Park and Jung (2007b), R22- and water-based CNTs (1.0\%) nanofluids increased boiling HTCs up to $28.7 \%$. With increasing heat flux, however, the enhancement was suppressed due to vigorous bubble generation. Penetration into the thermal boundary layer by CNTs to generate more bubbles at the surface seemed to be the key factor for improved nucleate boiling heat transfer associated with the addition of CNTs. Saidur et al. (2011a) studied the performance of the suspended NPs in refrigerants and lubricating oils. The results indicated that HFC134a and mineral oil with $\mathrm{TiO}_{2}$ NPs performed well and safely in refrigerators, leading to a superior performance. Kim et al. (2012) analyzed the falling film flow of binary nanofluids to determine important parameters such as $\mathrm{SiO}_{2} \mathrm{NP}$ concentration on the distribution stability in the $\mathrm{H}_{2} \mathrm{O} / \mathrm{LiBr}$ nanofluids. Maximum improvement of heat transfer and mass transfer is achieved around 46.8 and $18 \%$, respectively, with $0.005 \mathrm{vol} \%$ concentration of

Volume 27, Issue 1, 2020 
$\mathrm{SiO}_{2}$ NPs. Ruan and Jacobi (2012) investigated the characteristics of heat transfer of MWCNT suspensions in intertube falling film flow. EG-based and water-based nanofluids are prepared at concentrations of $0.05,0.14$, and $0.24 \mathrm{vol} \%$. The results indicated an HTC increase up to $20 \%$.

Pool boiling heat transfer using nanofluids of varying parameters, such as particle size, concentration, and surface roughness, has been a subject of many investigations, and incoherent results-heat transfer enhancement, deterioration, and negligible effect-have been reported in the literature (Trisaksri and Wongwises, 2007, 2009). Das et al. (2003b) carried out an experimental study of pool boiling characteristics of $\mathrm{Al}_{2} \mathrm{O}_{3}$ nanofluids. They found that the inclusion of NPs degraded the boiling performance.

Sarafraz and Hormozi (2015) performed a set of experiments to quantify the pool boiling HTC of dilute $\mathrm{CuO}$-water nanofluids at concentrations of $0.1-0.4 \mathrm{wt} \%$. To stabilize the two-step nanofluids, pH control, stirring, and sonication were utilized. Surfactants of SDS, SDBS, and Triton X-100 were used. Their results showed a significant deterioration of HTC of nanofluids comparing to the base fluid in the absence of surfactants; however, in the presence of surfactant, higher pool boiling HTC was reported. The inconsistencies indicate that the understanding of the boiling heat transfer with nanofluids is poor. It has been realized that the physical properties of nanofluids such as surface tension, liquid thermal conductivity, wettability, viscosity and density, and surface contamination have significant effects on the nanofluid two-phase flow and heat transfer characteristics, but the lack of the accurate knowledge of these physical properties has greatly limited the study in this field.

\section{ENHANCEMENT MECHANISMS}

Nanofluids generally exhibit a substantial increase in thermal conductivity, convective heat transfer coefficient, and critical heat flux compared to the base fluids. Godson et al. (2010) and Pinto and Fiorelli (2016) summarized some common mechanisms for heat transfer enhancement. Table 2 details the enhancement mechanisms proposed by researchers in the field.

TABLE 2: Enhancement mechanisms in nanofluids

\begin{tabular}{|c|c|}
\hline $\begin{array}{c}\text { Brownian } \\
\text { motion }\end{array}$ & $\begin{array}{c}\text { It is the random motion of nanoparticles suspended in a fluid due to } \\
\text { collisions with the moving fluid molecules. Several studies suggest the } \\
\text { Brownian motion of NPs at the molecular and nanoscale level is a key } \\
\text { mechanism governing the thermal behavior of nanofluids (Keblinski et al., } \\
\text { 2002; Jang and Choi, 2004; Koo and Kleinstreuer, 2005; Haddad et al., } \\
\text { 2012; Sheikholeslami, 2018). The model not only captures the } \\
\text { concentration and temperature-dependent conductivity, but also predicts } \\
\text { strongly size-dependent conductivity. }\end{array}$ \\
\hline Thermophoresis & $\begin{array}{c}\text { Thermophoresis is observed when a mixture of two or more types of } \\
\text { motile particles is subjected to the force of a temperature gradient. The } \\
\text { phenomenon is most significant in a natural convection process (Haddad } \\
\text { et al., 2012). The particles travel in the direction of decreasing temperature } \\
\text { and the process of heat transfer increases with a decrease in the bulk } \\
\text { density. Nanofluid properties may vary significantly within the boundary } \\
\text { layer because of the effect of the temperature gradient and thermophoresis } \\
\text { (Buongiorno, 2006). }\end{array}$ \\
\hline
\end{tabular}


TABLE 2: (continued)

\begin{tabular}{|c|c|}
\hline Diffusiophoresis & $\begin{array}{l}\text { Diffusiophoresis occurs when there is a migration of particles from a } \\
\text { lower concentration zone to a higher concentration one. Nanofluids may } \\
\text { lose their non-agglomeration characteristics. Buongiorno (2006) has } \\
\text { stressed that the Brownian motion, thermophoresis and diffusiophoresis } \\
\text { are significant for enhancement. }\end{array}$ \\
\hline Dispersion & $\begin{array}{l}\text { Particles are dispersed in a suspension for long period. Surfactants and } \\
\text { surface functionalization can increase the stability. Pak and Cho (1998) } \\
\text { and Xuan and Li (2000) claimed that the abnormal increase in thermal } \\
\text { conductivity is due to dispersion. Combination of steric stabilization and } \\
\text { electrostatic stabilization is referred to as electrosteric stabilization (Yu } \\
\text { et al., 2017). Xuan and Roetzel (2000) proposed the thermal dispersion } \\
\text { mechanism to explain the enhancement of the HTC using nanofluids. This } \\
\text { dispersion coefficient is related to the properties of the nanofluid } \\
\text { constituents, the flow pattern, the dimension and geometry of the NPs, and } \\
\text { the volumetric fraction. The coefficient is also a consequence of the slip } \\
\text { between the NPs and the base fluid and of the disturbances caused by the } \\
\text { NPs in the flow, due to the micro-turbulent movement of the particles in } \\
\text { the base fluid. }\end{array}$ \\
\hline $\begin{array}{l}\text { Intensified } \\
\text { turbulence }\end{array}$ & $\begin{array}{l}\text { In a turbulent flow, the effective thermal conductivity is many times higher } \\
\text { than the actual value. Similarly in nanofluids, such intensification is } \\
\text { believed to be possible due to the motion of NPs (Xuan and } \mathrm{Li}, 2000) \text {. } \\
\text { Buongiorno (2006) has claimed that due to the particle size, the effects of } \\
\text { both dispersion and intensified turbulence are negligible. }\end{array}$ \\
\hline Interface layer & $\begin{array}{l}\text { A nanofluid is considered analogue to the structure of a composite } \\
\text { material, consisting of a core composed of the NP, an interface layer } \\
\text { containing intermediate properties surrounding this core, and a matrix } \\
\text { composed of the base fluid that immerses these two regions. The } \\
\text { composition of these regions could form a multiphase system in which the } \\
\text { phase superposition would be the main factor responsible for enhancing } \\
\text { the thermal conductivity of the mixture. The work in Keblinski et al. } \\
\text { (2002) showed in favor of this theory, though the formation of an interface } \\
\text { layer can deteriorate the thermal conductivity of a nanofluid because it } \\
\text { brings in a significant thermal resistance. The effect of a nanolayer was } \\
\text { studied by Hentschke (2016) on specific heat and by Sharifpur et al. } \\
\text { (2016) on density. }\end{array}$ \\
\hline Clustering & $\begin{array}{l}\text { The enhancement mechanism of structuring and clustering NPs (Prasher } \\
\text { et al., 2006; Keblinski, 2007) proposes the use of particle clusters with } \\
\text { equivalent thermal conductivity. Ding et al. (2007) found a good } \\
\text { agreement of this model with their experimental results. Nevertheless, } \\
\text { several recent studies presented in Kakaç and Pramuanjaroenkij (2016) } \\
\text { reported that excessive particle clustering in nanofluids deteriorates the } \\
\text { thermal conductivity and an optimum level of clustering must be evaluated } \\
\text { in order to achieve a maximum enhancement obtained by particle } \\
\text { clustering effect. }\end{array}$ \\
\hline
\end{tabular}

Volume 27, Issue 1, 2020 
TABLE 2: (continued)

\begin{tabular}{|c|c|}
\hline & $\begin{array}{l}\text { The ballistic nature of the thermal transport of the NPs was also } \\
\text { considered for thermal conductivity enhancement (Gardellini et al., 2016). } \\
\text { It is significant due to the lack of validity of the thermal diffusion } \\
\text { hypothesis. It states that the NP is so small that the phonon heat transfer } \\
\text { mechanisms assumed in the thermal diffusion change from a randomly } \\
\text { scattered diffusion to a ballistic behavior. The smaller the NPs used in the } \\
\text { composition of the nanofluid are, the higher the ballistic phonon transport } \\
\text { mechanisms are along a nanofluid, so that the validity of any macroscopic } \\
\text { approach to the nanofluids properties is limited by this restriction. }\end{array}$ \\
\hline $\begin{array}{r}\text { Effe } \\
\text { mediun }\end{array}$ & $\begin{array}{l}\text { A nanofluid is a composite material and its properties could be described } \\
\text { by effective medium theories, which were applied in many fields of } \\
\text { science and engineering. Keblinski et al. (2005) found that most of the } \\
\text { thermal conductivity data in nanofluids is reasonably well described by } \\
\text { effective medium theory and the effects of the interface thermal resistance } \\
\text { can be included in effective medium theories. }\end{array}$ \\
\hline $\begin{array}{l}\text { Particle } \\
\text { migration }\end{array}$ & $\begin{array}{l}\text { Migration of NPs and the resulting disturbance of the boundary layer were } \\
\text { proposed to be the main reasons leading to the heat transfer coefficient } \\
\text { enhancement (Wen and Ding, 2004; Ding and Wen, 2005). This migration } \\
\text { would be inducted by the shear stresses formed along the flow, by the } \\
\text { viscosity gradients, and by the Brownian motion, which causes the } \\
\text { migration of particles by diffusion. }\end{array}$ \\
\hline Modified surface & $\begin{array}{l}\text { Bang and Chang (2005) observed enhanced CHF in not only horizontal } \\
\text { but also vertical pool boiling. The surface roughness value of test heaters } \\
\text { submerged in nanofluids is increased with increasing particle } \\
\text { concentration by the deposition of NPs. Das et al. (2003b) found that the } \\
\text { surface roughness considerably decreased because their smooth heater has } \\
\text { a roughness that is much larger than the size of NPs. They contend that } \\
\text { this reduction is the cause of deteriorating the boiling characteristics of the } \\
\text { nanofluid. }\end{array}$ \\
\hline
\end{tabular}

Brownian motion of NPs seems to be responsible for the displacement and for the mixture in the microscopic scale of the nanofluids' components, enabling the enhancement of heat transfer in nanofluids. This is confirmed by Das et al. (2007), who obtained enhancements between two and four times higher for the thermal conductivity in a temperature scale between 20 and $50^{\circ} \mathrm{C}$. However, the weak dependence of the thermal conductivity of nanofluid on the temperature observed in the experiments of Ding et al. (2007) leads one to believe that the Brownian motion has low influence on the thermal conductivity enhancement at low temperatures. Furthermore, Evans et al. (2006) used a kinetic theory based analysis of heat flow in nanofluids to demonstrate that the hydrodynamics effects associated with Brownian motion have only a minor effect on the thermal conductivity of the nanofluid. Their analysis is supported by the results of molecular dynamics (MD) simulations of heat flow in a model nanofluid with well-dispersed particles. They claimed that these findings are consistent with the predictions of the effective medium theory.

Nevertheless, a recent study of natural convection in nanofluids showed that higher heat transfer is formed with the presence of Brownian motion and thermophoresis effect (Haddad 
et al., 2012). The enhancement is more pronounced at low volume fraction of NPs. Brownian motion is considered in $\mathrm{CuO}$-water nanofluid flow due to magnetic field inside a porous medium Sheikholeslami (2018), and both Brownian and thermophoresis phenomena have been utilized in energy and concentration expressions in convective flow of magneto Carreau nanofluid (Hayat et al., 2018). Pinto and Fiorelli (2016) claimed that not a single mechanism has been able to describe the behavior of the nanofluids under general conditions, although Brownian motion of NPs, particle clustering, and the formation of an interface layer around the NPs were widely adopted mechanisms in this area. Especially, the discrepancy in thermal conductivity poses a major challenge.

\section{THERMAL MODELS}

\subsection{Models for Thermal Conductivity}

In the past two decades, a wide experimental investigation on nanofluid thermal conductivity has been carried out. The measurements showed wide discrepancies and inconsistencies due to the difference in nanofluids production and stabilization technique (single step or two steps, with or without surfactants, mechanical stirring, sonication), nanofluids characterization (DLS analysis, Z-potential measurement, $\mathrm{pH}$ test, SEM or TEM analysis, etc.), and thermal conductivity measuring method (transient hot wire, transient plane source, steady-state methods, comparator). However, the experimental results highlight a strong relationship between the nanofluid's thermal conductivity and the following parameters: NP size, shape, and concentration, NP and base fluid thermal conductivity, temperature, surfactants and additives, $\mathrm{pH}$ value, etc. Brownian motion, agglomeration/aggregation, and liquid layering around the NPs also affect the measurement results. To understand the thermophysical properties and heat transfer characteristics of nanofluids with different NPs and base fluids of various concentrations and temperatures, numerical and theoretical investigations have been intensively conducted because experiments are time-consuming and expensive. Models are complementary to the experimental approach. Table 3 lists some typical models and empirical correlations used for predicting the enhancement of thermal conductivity in nanofluids.

Figure 3 compares the thermal conductivity enhancement of some nanofluids between experimental data obtained in recent years and some typical theoretical predictions. It is seen that the enhancement ratio in the Maxwell model (Maxwell, 1873) is mainly determined by the NP volume fraction, and the differences predicted by the Maxwell model among the seven different data sets of various nanofluids are minor. Only for the data of Akilu et al. (2018) for hybrid nanofluids with $80 \% \mathrm{SiO}_{2}, 20 \% \mathrm{CuO} / \mathrm{C}$ composite NPs, and mixed base fluid of $40 \% \mathrm{EG}$ and $60 \%$ glycerol (G), both the Maxwell (1873) and Xuan et al. (2003) models predict closely to the experiment. For the rest of the data, the Maxwell model is not acceptable. The predictions by Xuan et al. (2003) model are also reasonable for the nanofluids of $\mathrm{Al}_{2} \mathrm{O}_{3}$-EG in Kumar et al. (2018b) and of $\mathrm{TiO}_{2}$ NPs in 60\% EG and 40\% water in Krishnakumar et al. (2019), but deviate from the experiments of Said et al. (2016b) and Kumar et al. (2018a) for $\mathrm{Al}_{2} \mathrm{O}_{3} /$ water, Esfe et al. (2015a) for $\mathrm{Al}_{2} \mathrm{O}_{3} / \mathrm{EG}$, and Liu et al. (2011) for $\mathrm{CuO} / \mathrm{EG}$. The prediction by another popular model Koo and Kleinstreuer (2004) matched Liu et al. (2011) data at volume fractions 2-3\%.

\subsection{Models for Viscosity}

Viscosity is an important property of nanofluids. Pumping power, pressure drop, Reynolds number, and convective heat transfer directly depend on the viscosity of a fluid. Some key parameters

Volume 27, Issue 1, 2020 


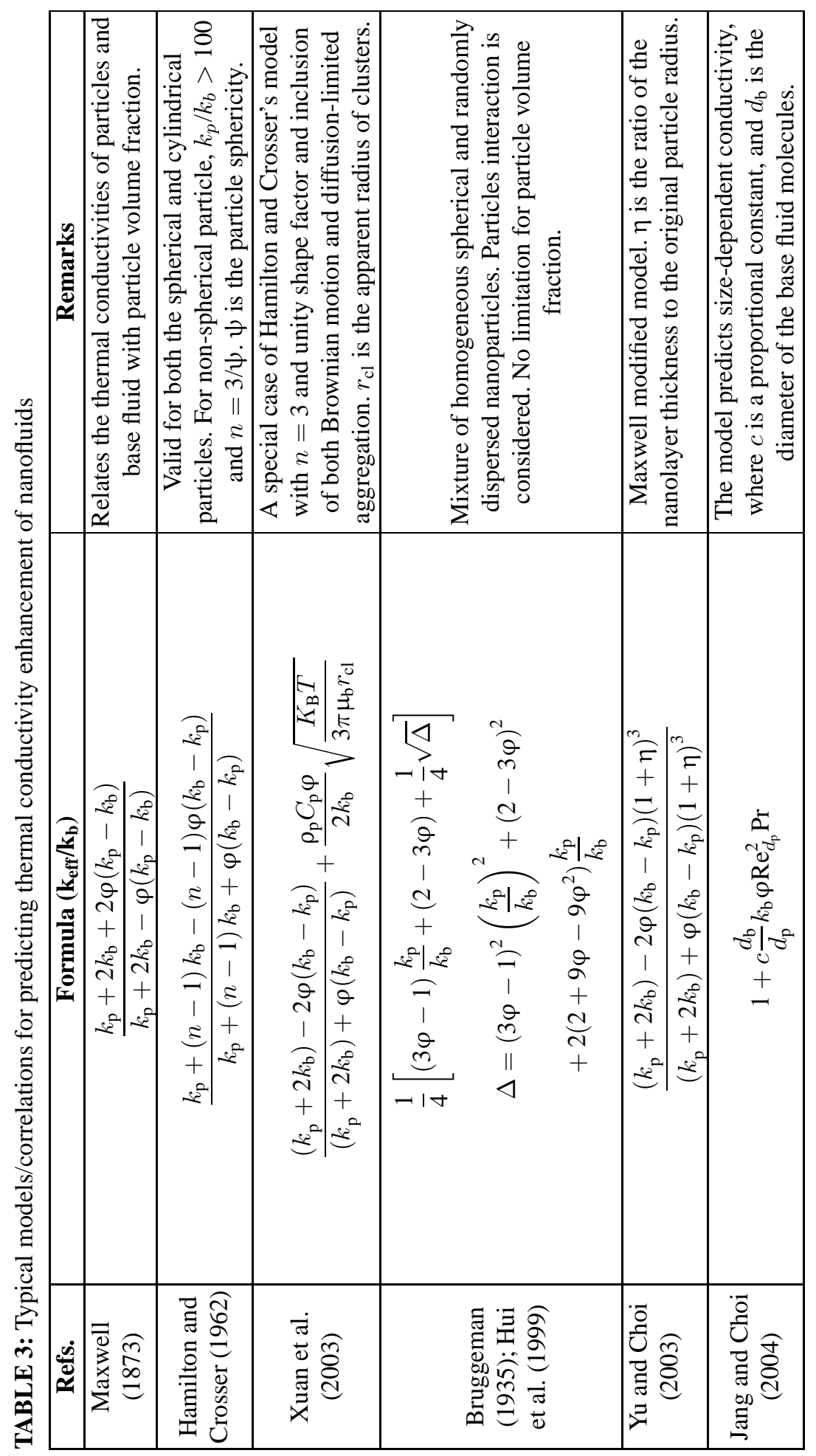




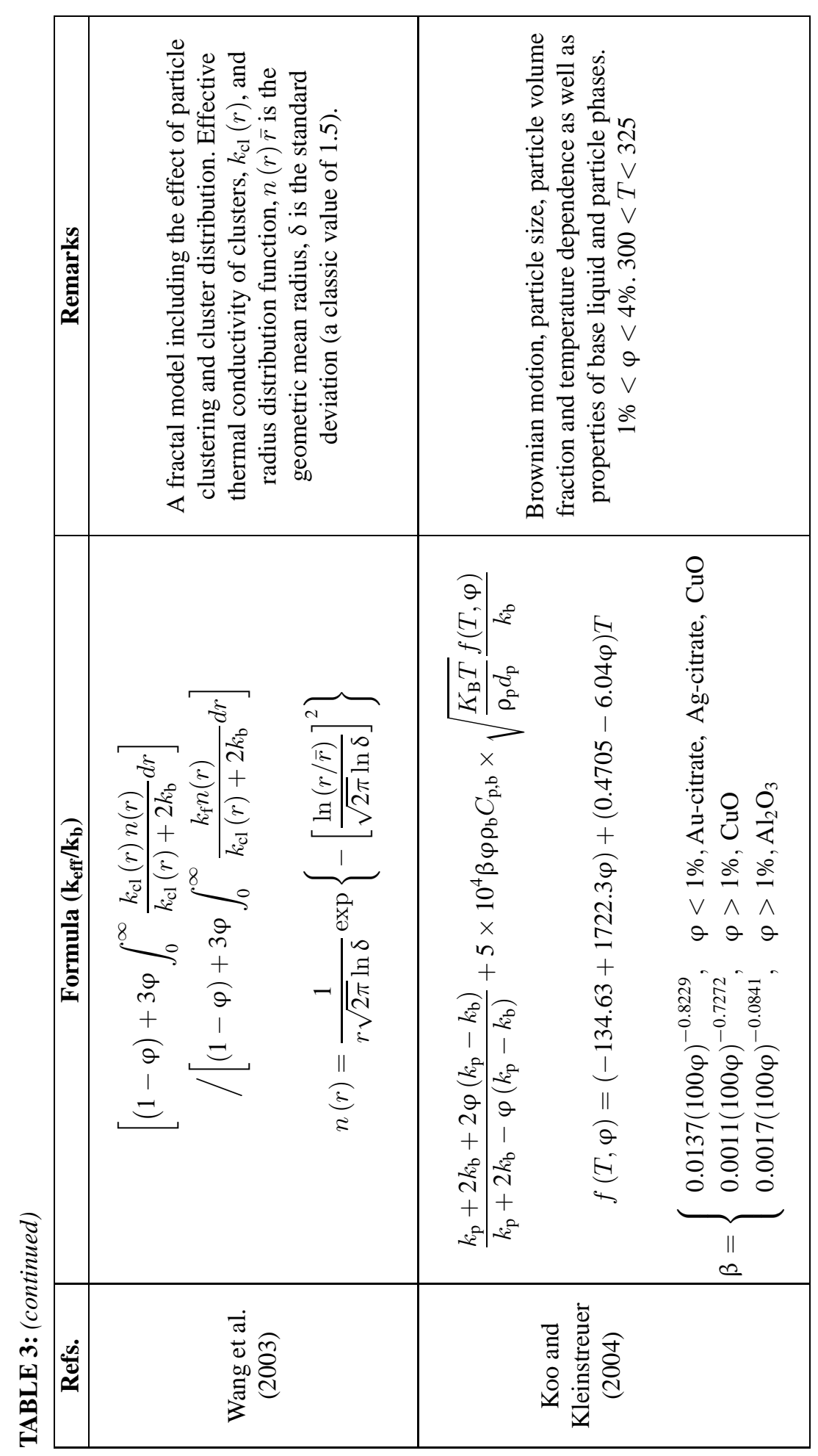

Volume 27, Issue 1, 2020 


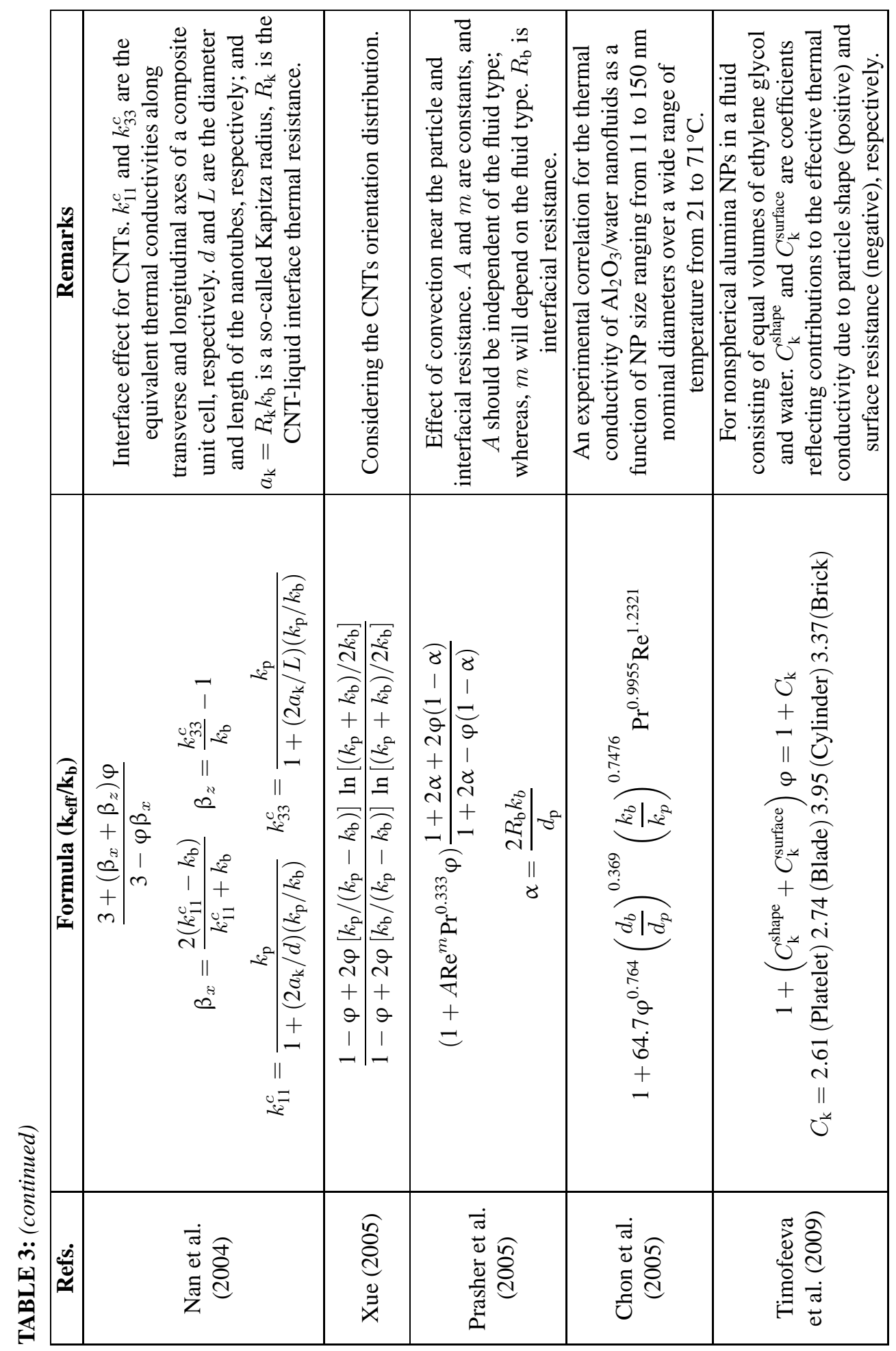




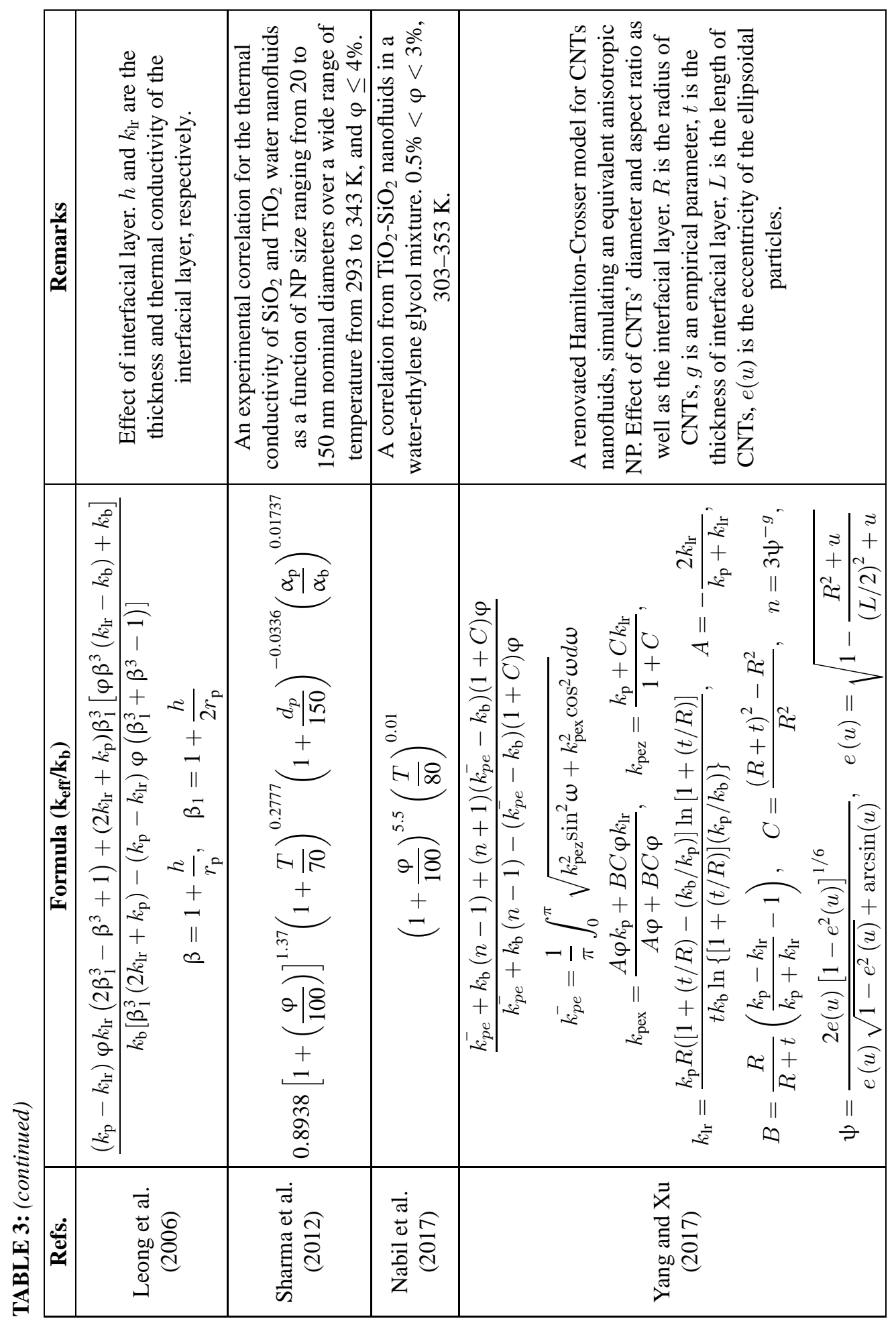

Volume 27, Issue 1, 2020 


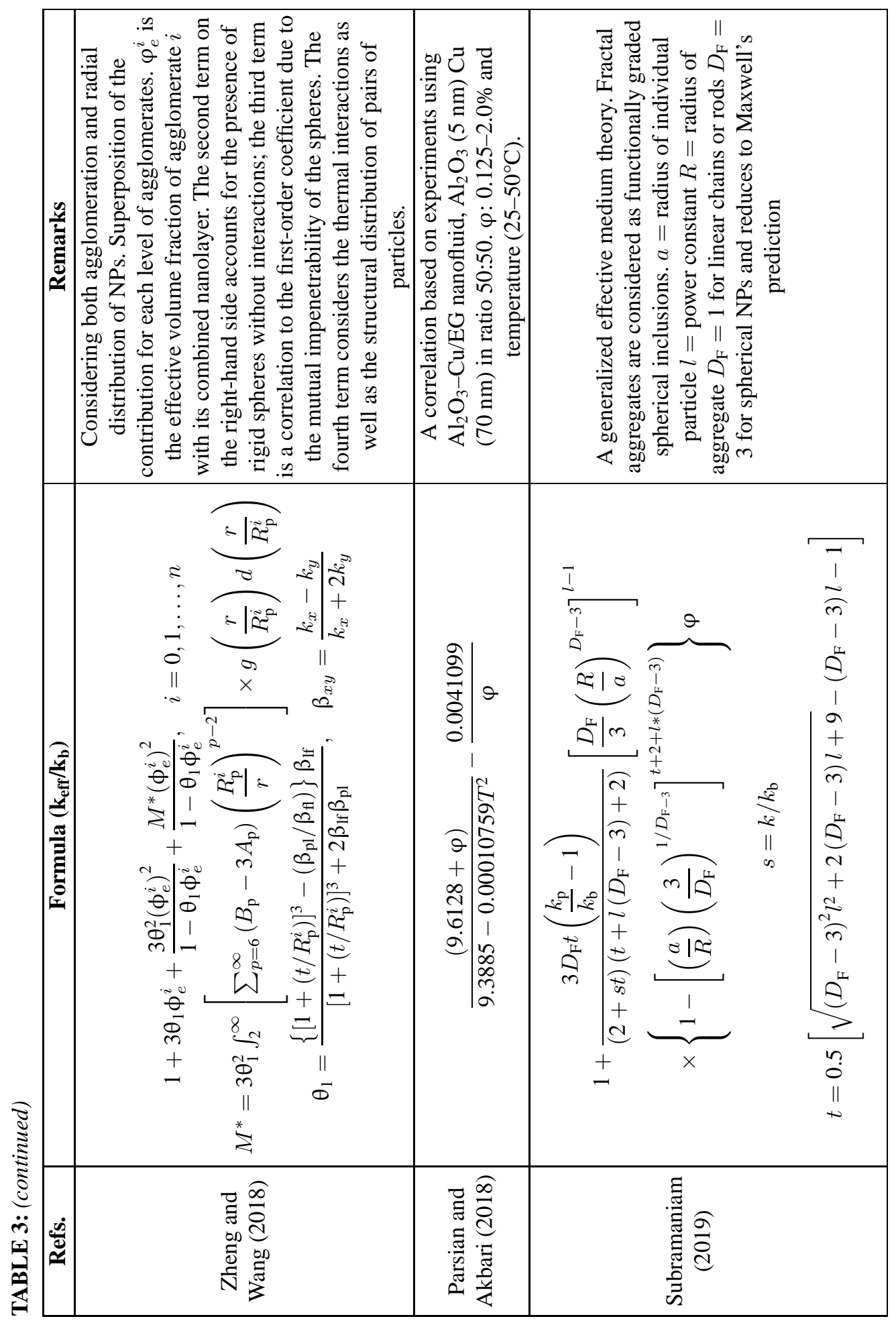




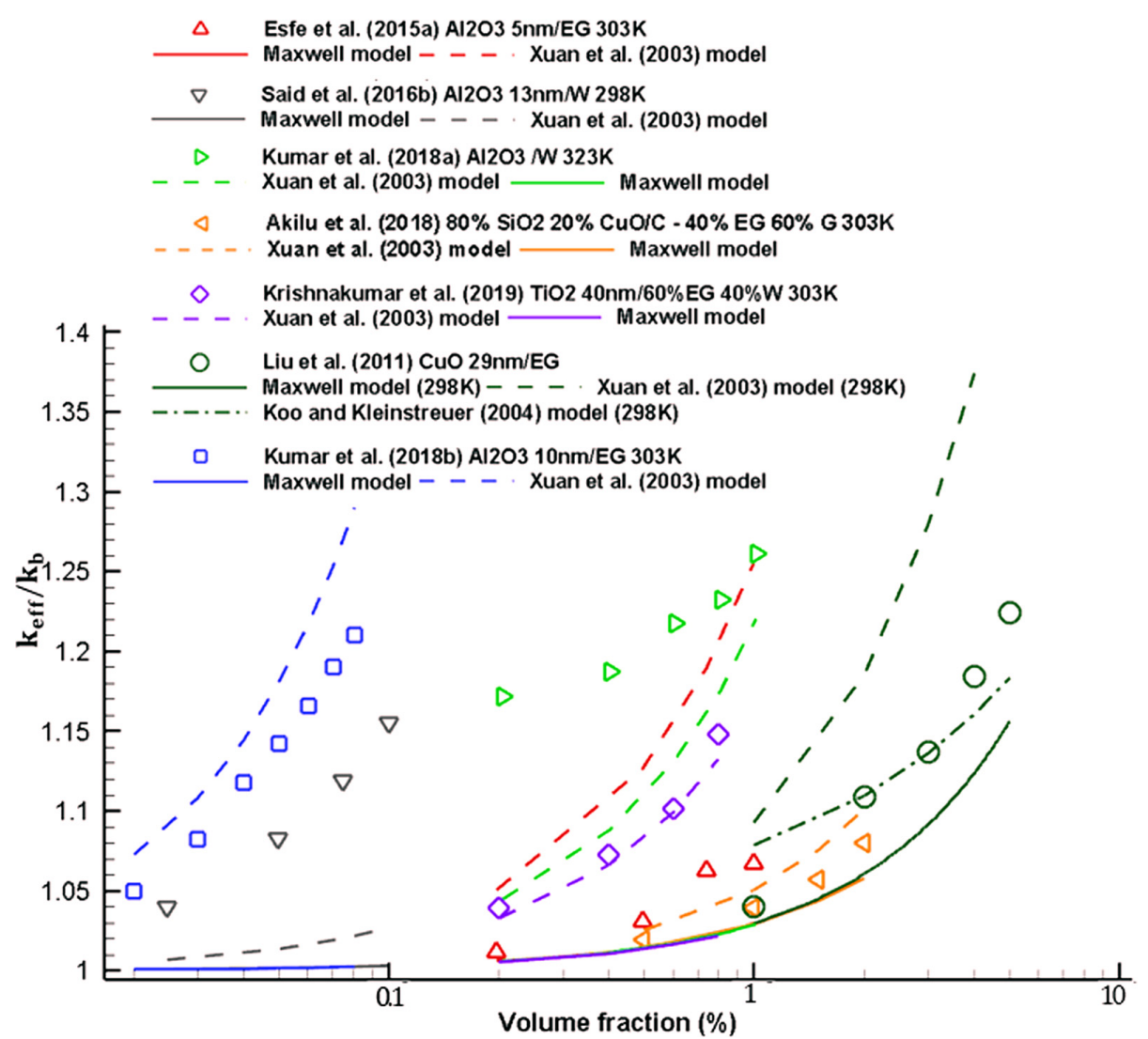

FIG. 3: Comparison of thermal conductivity enhancement between measurements and theoretical models

that influence the viscosity of nanofluids include temperature, volume fraction, particle size and shape, $\mathrm{pH}$ value, aggregation, stability, and shear rate. Regarding the composite of nanofluids, which can consist of different fluid bases and different NPs, different models and/or correlations for different nanofluids need to be developed. Table 4 summarizes some typical models and correlations for predicting viscosity of nanofluids.

Figure 4 shows the comparison between experimental data and models for relative viscosity in nanofluids. Four different data sets are selected for comparison, i.e., hybrid nanofluids with $80 \% \mathrm{SiO}_{2}, 20 \% \mathrm{CuO} / \mathrm{C}$ composite NPs, and base fluid of $40 \% \mathrm{EG}$ and $60 \%$ glycerol (G) mixture (Akilu et al., 2018), ZnO-EG nanofluids (Esfe and Saedodin, 2014), $\mathrm{Al}_{2} \mathrm{O}_{3}$-water nanofluid (Kumar et al., 2018a), and $\mathrm{TiO}_{2}$-EG/water (60:40) nanofluid (Krishnakumar et al., 2019). The traditional Einstein (1906) model depends only on the particle volume fraction (valid for $\varphi<1 \%$ ) and fails to match most of the measurements except for one datum of Akilu et al. (2018) at concentration $0.5 \%$. The prediction by the Maiga et al. (2004) model matched well with the measurement of Kumar et al. (2018a). The prediction by Corcione (2011) model is close to the result of Kumar et al. (2018a) but failed to match the other three data sets. The correlation of Chen et al. (2007) for $\mathrm{TiO}_{2}$-EG nanofluids does not match the result of Krishnakumar et al. (2019) for $\mathrm{TiO}_{2}$-EG/water (60:40) nanofluid, neither for ZnO-EG (Esfe and Saedodin, 2014) or for the hybrid nanofluid (Akilu et al., 2018).

Volume 27, Issue 1, 2020 


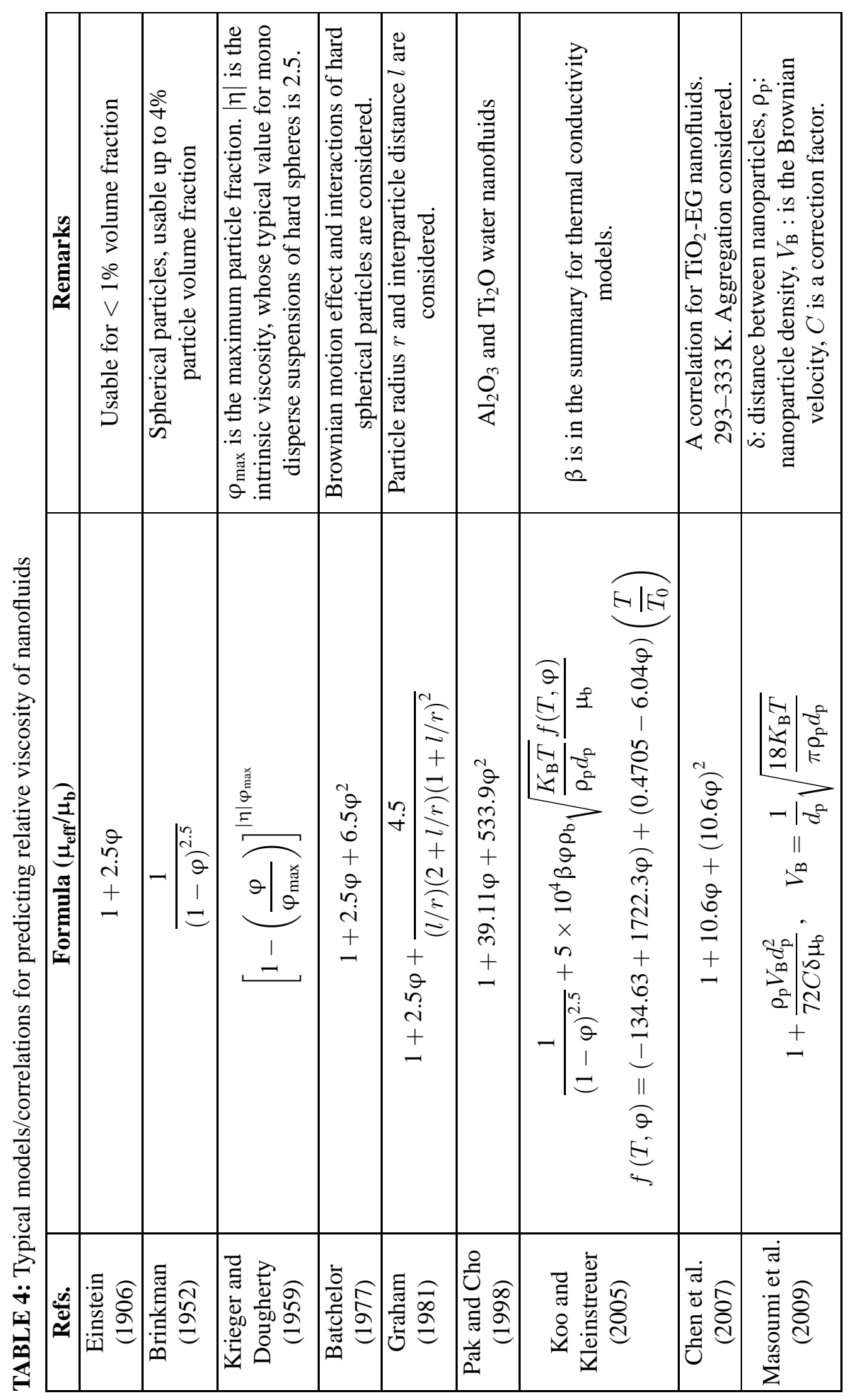




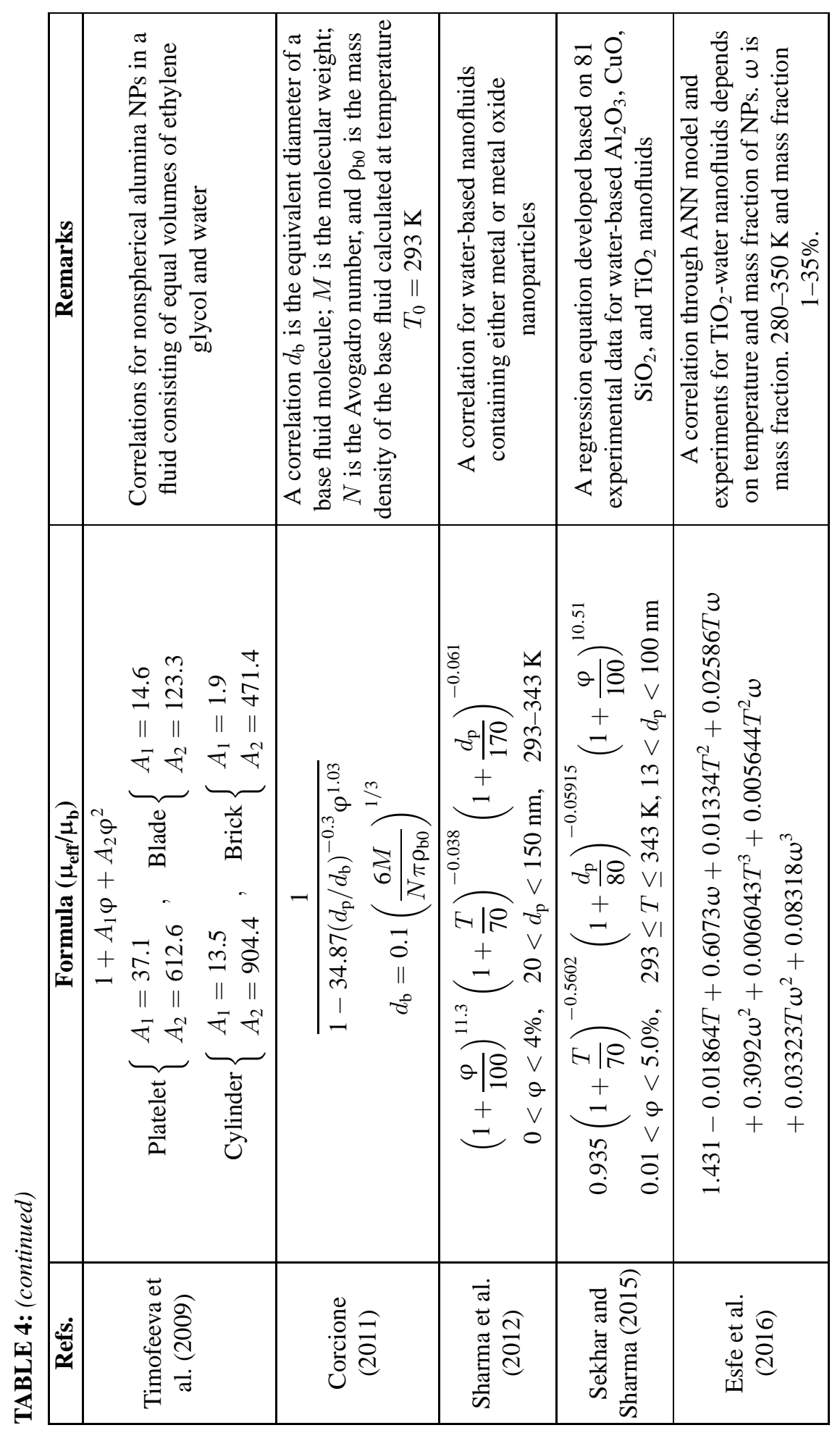

Volume 27, Issue 1, 2020 


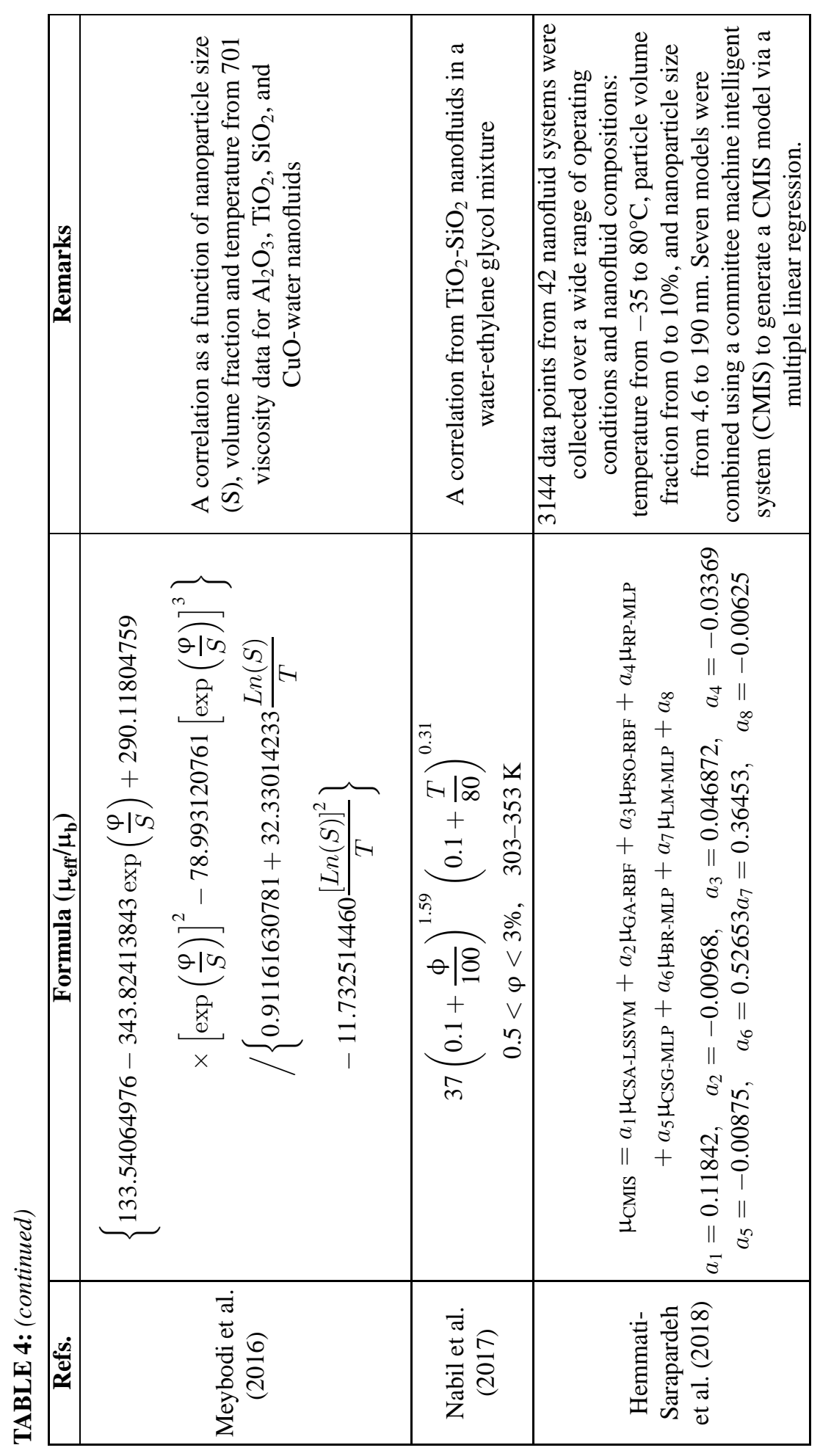




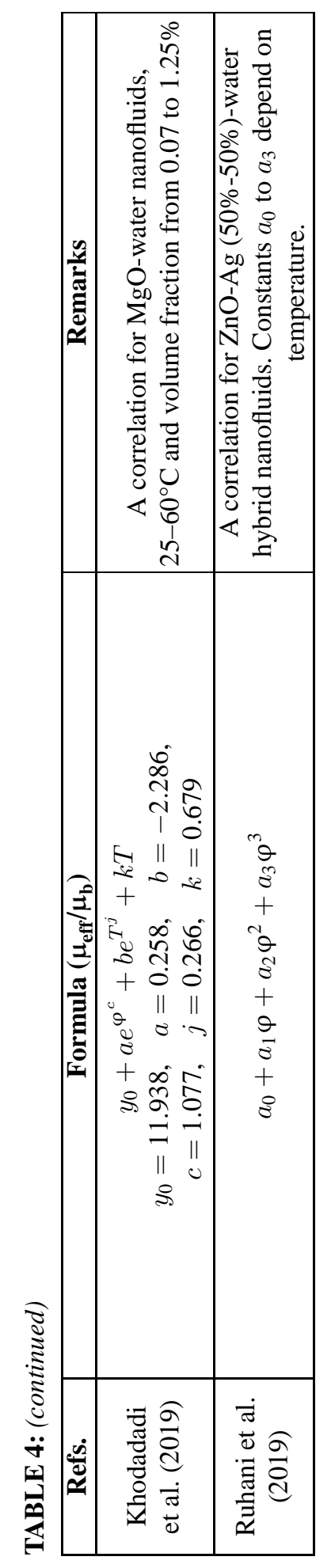

Volume 27, Issue 1, 2020 


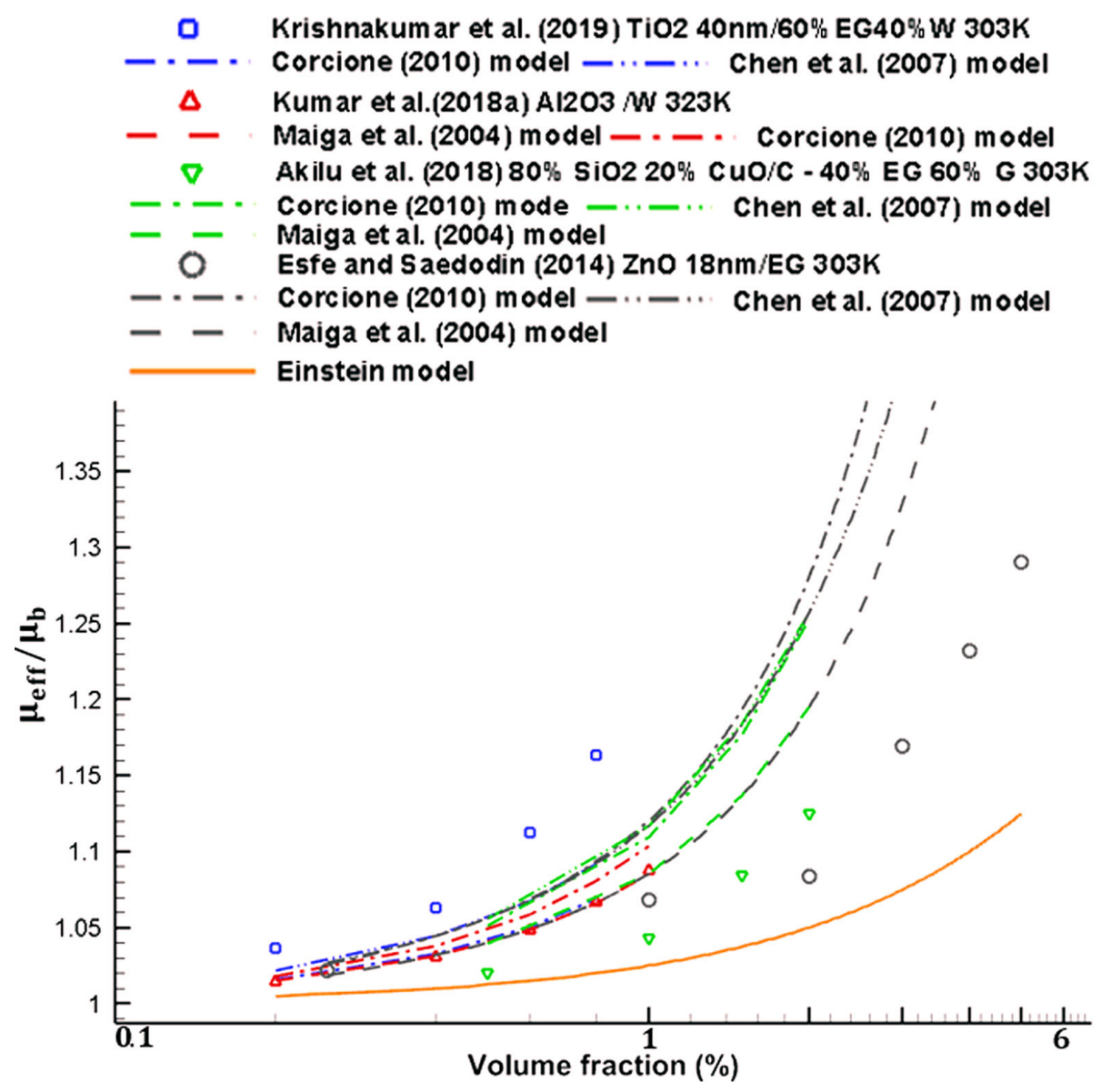

FIG. 4: Comparison of relative viscosity of nanofluids between measurements and theoretical models

\subsection{Models for Specific Heat}

Specific heat is a measure of the amount of thermal energy required to change the temperature of $1 \mathrm{~kg}$ of a substance by $1 \mathrm{~K}$. It also indicates the heat capability stored in a material. As use of nanofluids in solar energy and energy storage systems has increased in recent years, determination of specific heat for nanofluids is becoming critical. Table 5 lists some models and corrections for predicting specific heat capacity for nanofluids.

Figure 5 shows the comparison between experimental data and models for relative specific heat capacity in nanofluids. Six different data sets are compared to the predictions by two popular models. It is seen that the Pak and Cho (1998) model is in close agreement with Sultan (2017) for $\mathrm{TiO}_{2}$-EG/water (60:40) nanofluid but fails to predict the measurements of another five nanofluids. The Xuan and Roetzel (2000) thermal equilibrium model matches with the data for $\mathrm{Al}_{2} \mathrm{O}_{3}$ water nanofluid (Ghaderian and Sidik, 2017), part of the $\mathrm{TiO}_{2}$-EG/water (60:40) nanofluid data in Sultan (2017), and part for $\mathrm{SiO}_{2}$-water nanofluid in Alawi et al. (2019) but fails to estimate the results by Akilu et al. (2018), Selvam et al. (2016), and the Cu-EG nanofluid in Sultan (2017). 


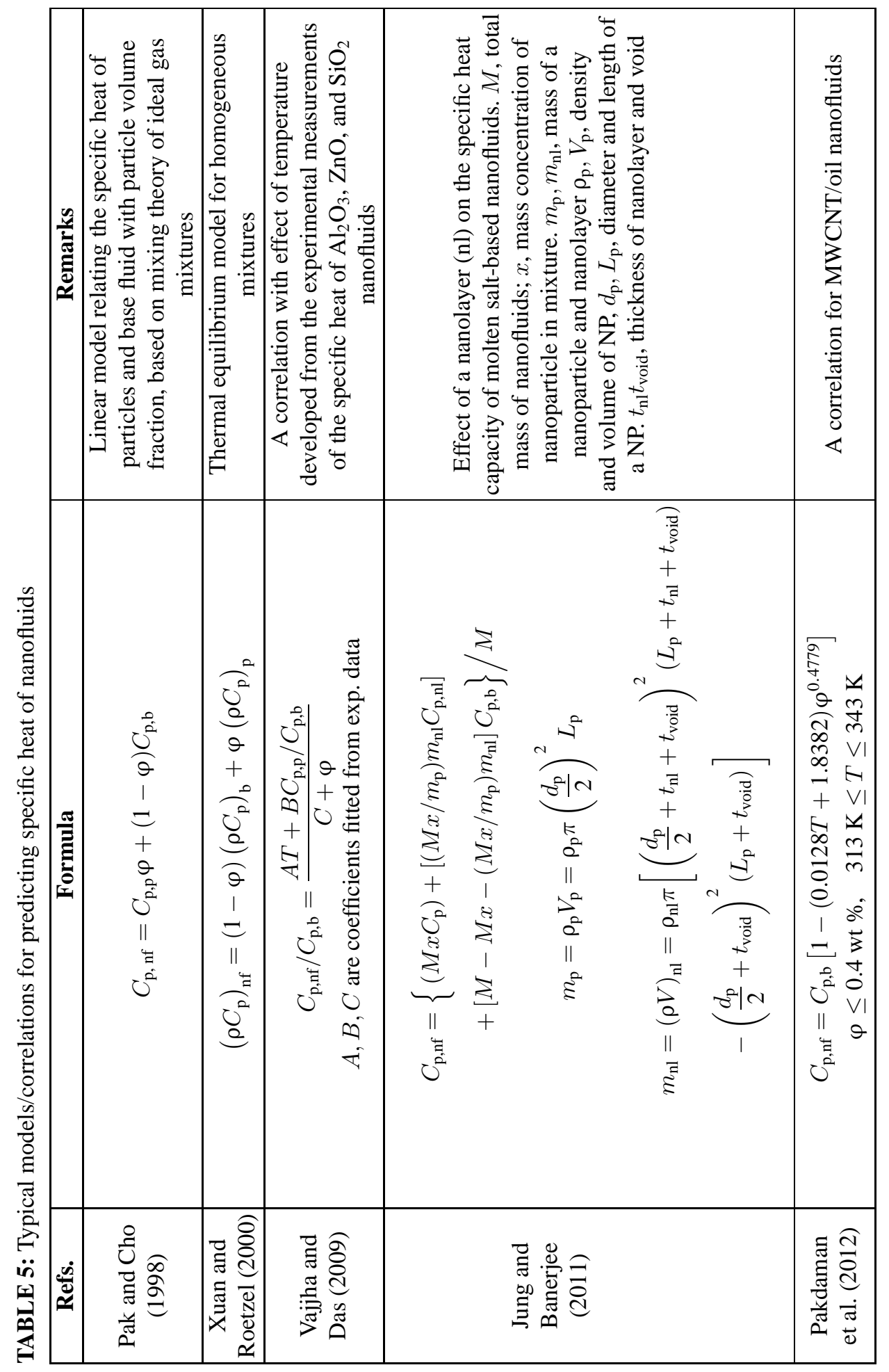

Volume 27, Issue 1, 2020 


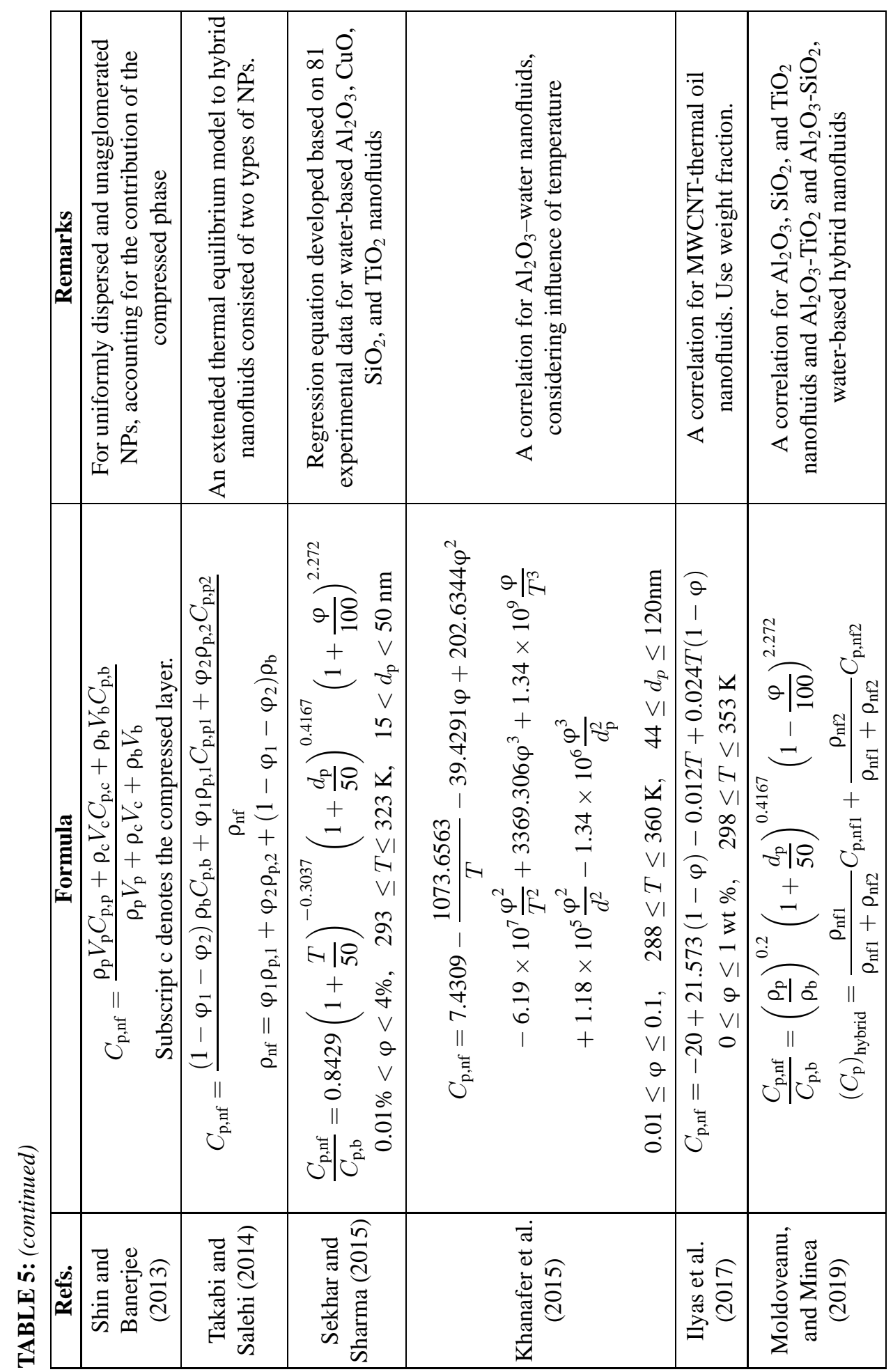




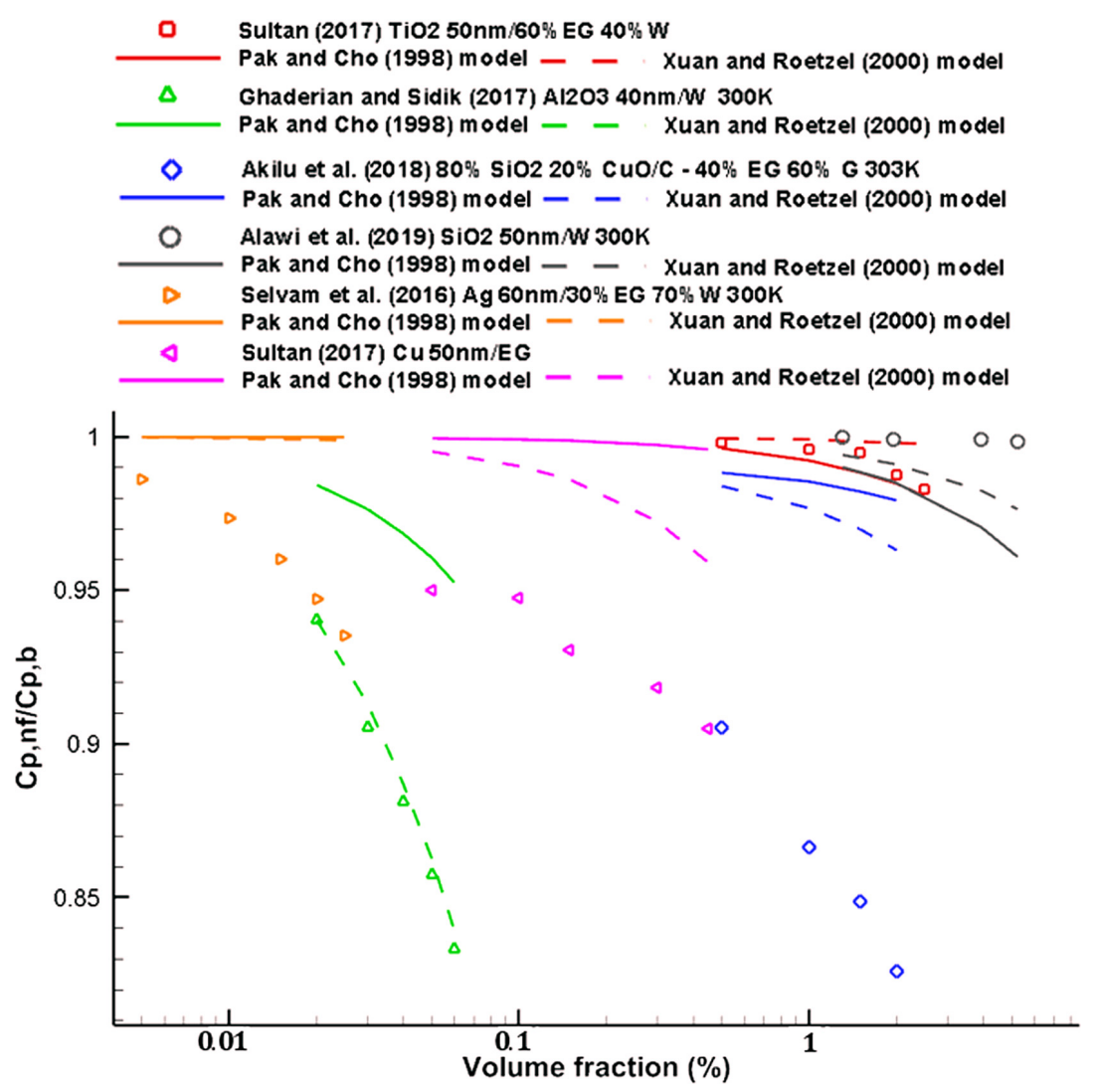

FIG. 5: Comparison of relative specific heat of nanofluids between measurements and theoretical models

\subsection{Modeling of Convective Heat Transfer}

Anomalous enhancement of the convective heat transfer rate of nanofluids has been reported in many numerical studies [see, e.g., Jang and Choi (2006), Yang et al. (2013), and Fard et al. (2018)]. Vanaki et al. (2016) provided a comprehensive review on numerical studies of convective heat transfer of nanofluids and found that most numerical results indicated that the increase of NP volume fraction brings about an increasing trend in forced convective heat transfer of nanofluids and a slight increase in pressure drop. Among the experiments and simulations there are some inconsistencies about the influence of particle concentration on the convective heat transfer, which may be attributed to improper selection of CFD modeling and inaccurate thermal properties models for nanofluids as well as to ignorance of non-Newtonian rheology in the numerical simulations. Vanaki et al. (2016) also pointed out that in practical applications the flow is usually in the turbulent regime, because higher heat transfer can be achieved through turbulent flow; thus, there is much work to be done in understanding the overall effect of various turbulent models on the heat transfer results of nanofluids.

Kakac and Pramuanjaroenkij (2016) reviewed single-phase and two-phase treatments of convective heat transfer enhancement with nanofluids. The single-phase model treats the NPs and base fluid as a single-phase mixture with steady properties. Conventional single-phase modeling has been the most common approach in the majority of numerical studies of convective heat

Volume 27, Issue 1, 2020 
transfer in nanofluids. However, the numerical predictions resulted from this technique may lead to some deviations as compared to the experimental data due to the neglect of slip mechanisms between NP and base fluid. Employing the dispersion model in forced convection studies could improve the results significantly, yet it might not be accurate for predicting natural convection. The two-phase model can provide better views in the nanofluid flow field, since the solid and liquid phases are considered separately. Because of some contradictory results between experiments and modeling, however, it is controversial whether the two-phase approach gives more credible results. The governing equations for the single-phase model are easy to understand for new researchers as well as the less complicated model, which is less time consuming. Vanaki et al. (2016) indicated that Lagrangian-Eulerian and Buongiorno models seem to be more reliable for simulation purposes, as they incorporate Brownian motion and Soret effects as the two migration mechanisms in the boundary layer and, moreover, they are capable to predict nonuniform particle distribution.

Many factors, such as dispersion and random movement of particles, agglomeration and clustering, particle size and shape, affect the convective heat transfer as well as the thermosphysical properties of nanofluids. More experimental and numerical investigations need to be performed by taking these factors into account. More numerical investigation must be done to compare the two-phase model and the homogeneous one in a particular geometry or with a turbulent model. Since numerical models for convective heat transfer are well-documented in the literature, the present review does not list the governing equations of different models. Instead, Table 6 lists some Nusselt number correlations from the literature for convective heat transfer of nanofluids.

It should be pointed out that there is not any agreeable correlation yet that is suitable for nanofluids, just as reflected by the inconsistencies in the models and measurements for thermal properties. From Table 6, it is seen that the Nu correlations differ among different authors and for different nanofluids. Many of the correlations were regressed from limited experimental data. Another key challenge is the accuracy of the dimensionless parameters used. Let us use the correlation of Kumar et al. (2017) in Table 6 for $\mathrm{Fe}_{3} \mathrm{O}_{4}$-water nanofluids as an example. One can see that the correlation contains dimensionless parameters, Re and Pr, in addition to the NPs volume fraction. Kumar et al. (2017) did mention that the parameters were evaluated at mean fluid temperature and listed the properties for $\mathrm{Fe}_{3} \mathrm{O}_{4}$-water suspensions at three temperatures $(20,40$, and $60^{\circ} \mathrm{C}$ ). It could be seen that the Pr was a strong function of temperature, e.g., its value at $60^{\circ} \mathrm{C}$ was just one-third of that at $20^{\circ} \mathrm{C}$; whereas the temperature variation varied in such range during convective heat transfer. How accurate the Pr values used to acquire the correlation were indeed in question. Same question remains with the Re values used. It is known that Re is determined by the viscosity of the nanofluid and the viscosity depends on the volume fraction. However, Kumar et al. (2017) used the same Re values for nanofluids of different volume fractions. As mentioned in Section 1, thousands of research papers are published on nanofluids in a year. Unfortunately, similar latitudes existed in quite a number of studies.

\subsection{Artificial Neural Network Model}

Not a single traditional model for nanofluids is not able to account for all the different parameters and mechanisms affecting the thermal properties and transport. An artificial neural network (ANN) is an interconnected group of artificial neurons that receive input and produce output through patterning and learning from a large amount of sample data. Figure 6 sketches a feedforward ANN example consisting of four inputs, five hidden neurons, and two outputs (e.g., 


\begin{tabular}{|c|c|c|c|c|c|c|c|}
\hline 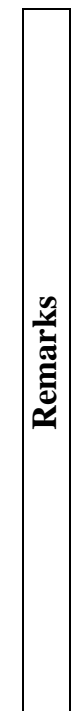 & 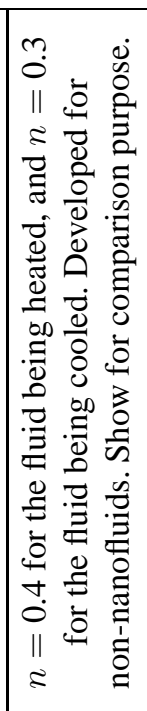 & 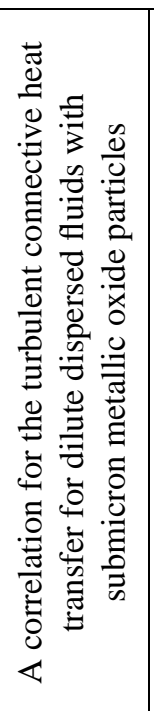 & 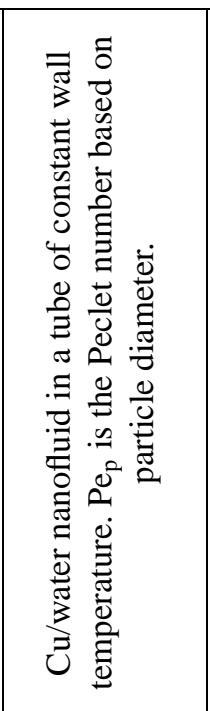 & 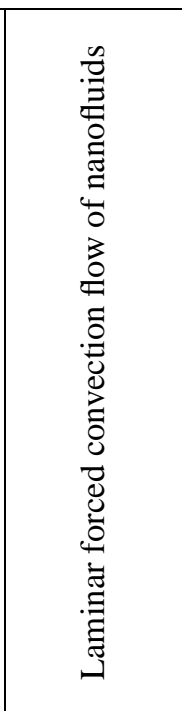 & 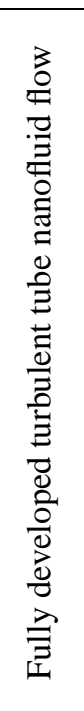 & 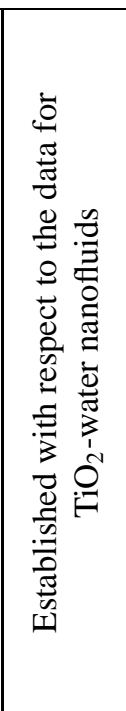 & 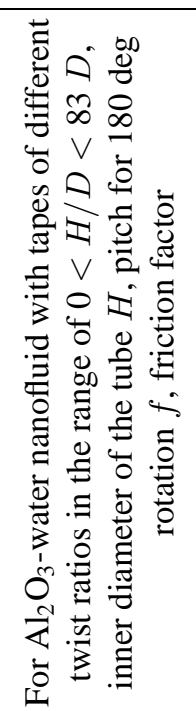 \\
\hline 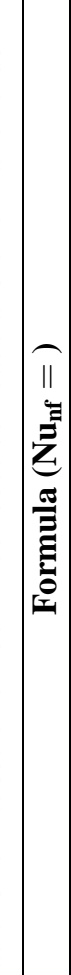 & 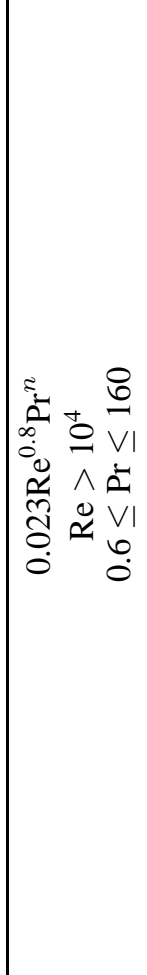 & 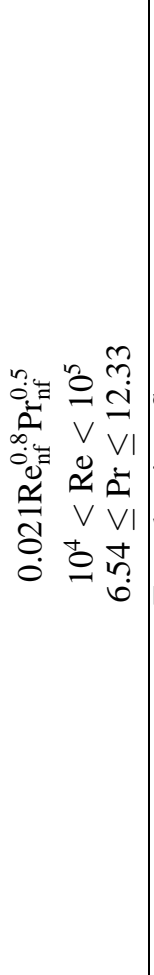 & 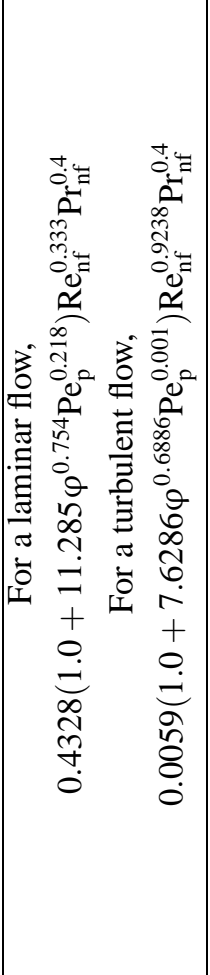 & 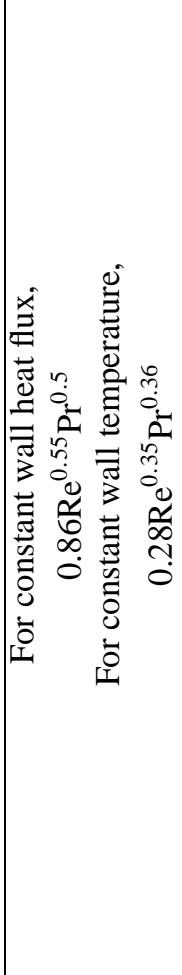 & $\begin{array}{l}n \\
m \\
0 \\
0 \\
0 \\
0 \\
0 \\
\tilde{n} \\
0 \\
0 \\
0\end{array}$ & 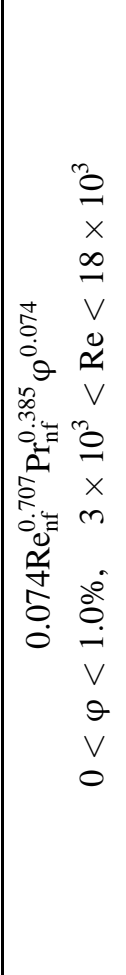 & 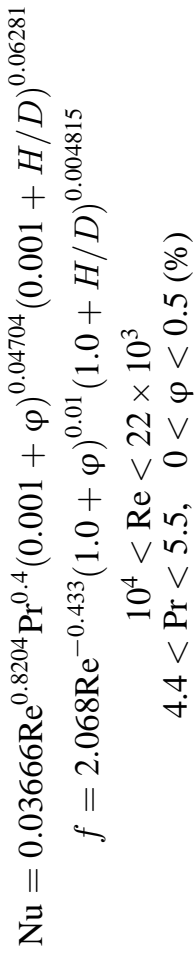 \\
\hline $\begin{array}{l}\frac{\pi}{\tilde{E}} \\
\approx\end{array}$ & 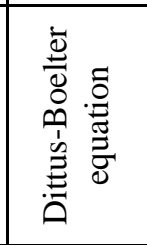 & 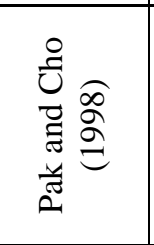 & 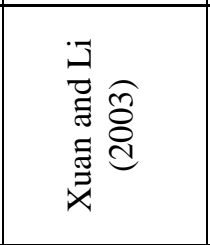 & 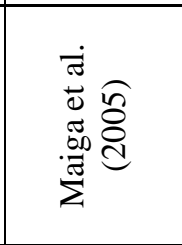 & 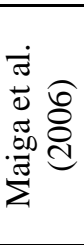 & 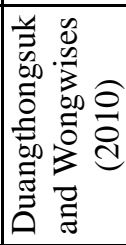 & 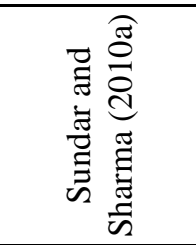 \\
\hline
\end{tabular}




\begin{tabular}{|c|c|c|c|c|c|c|c|c|c|}
\hline 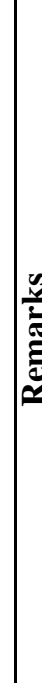 & \multicolumn{4}{|c|}{ 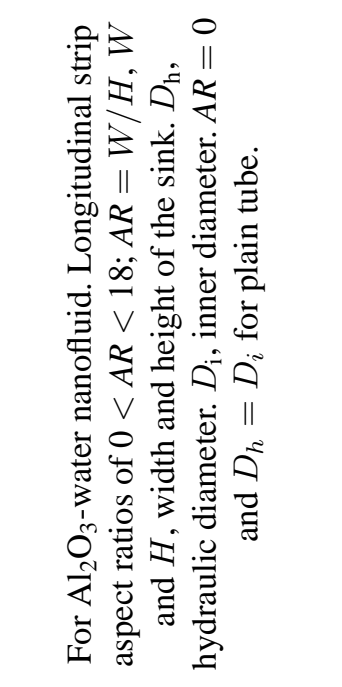 } & 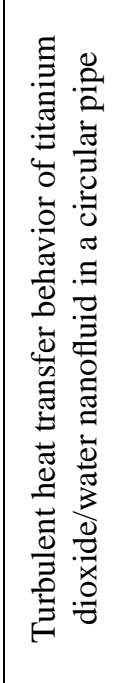 & 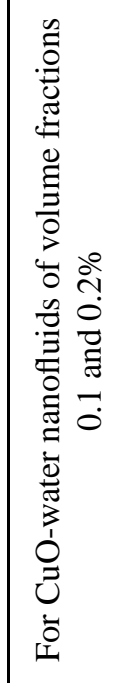 & 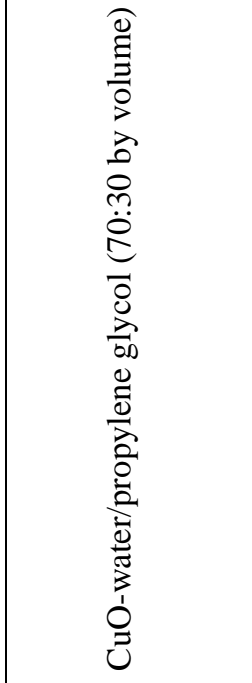 & 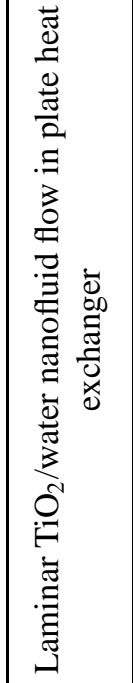 & 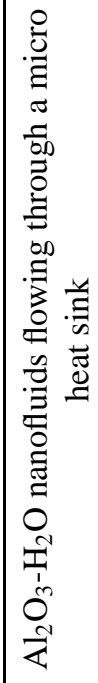 \\
\hline 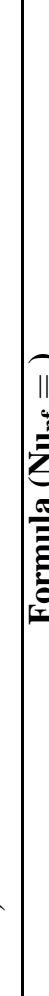 & 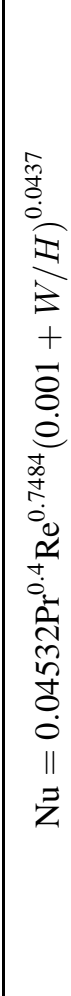 & 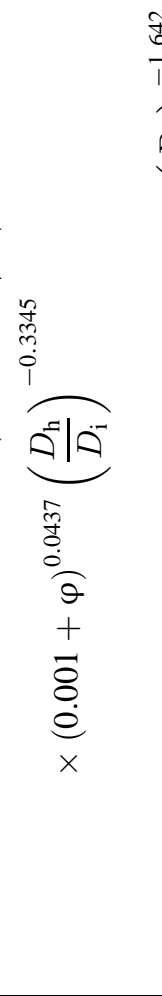 & 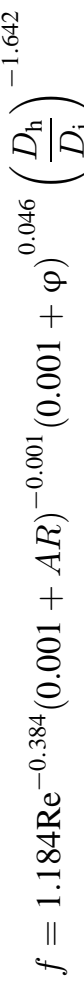 & 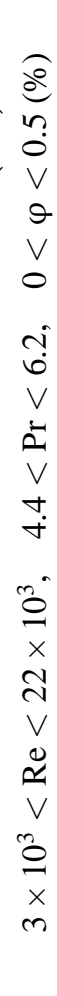 & 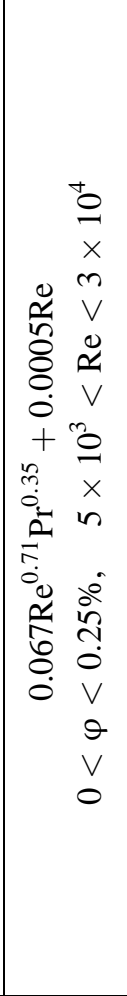 & 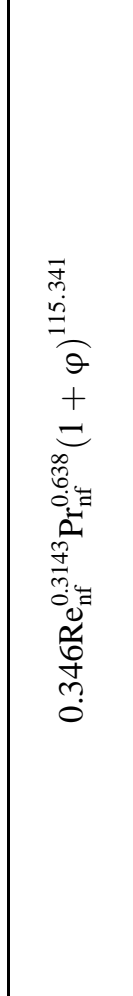 & 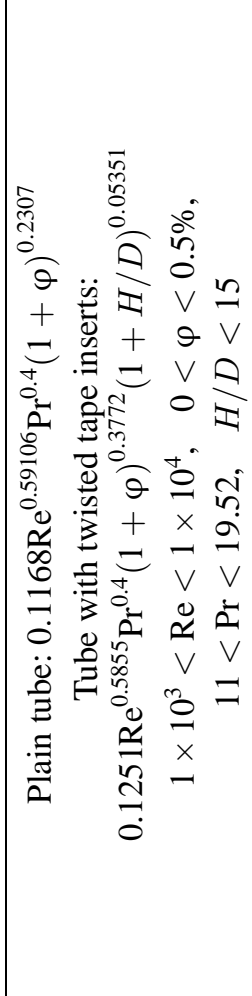 & 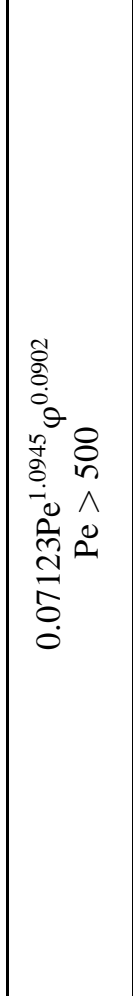 & 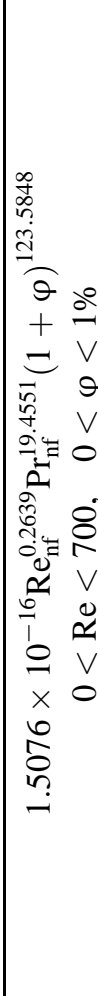 \\
\hline$\simeq$ & & 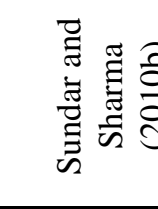 & & & 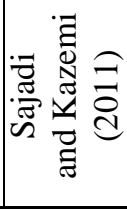 & 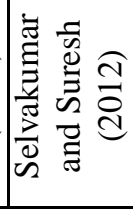 & 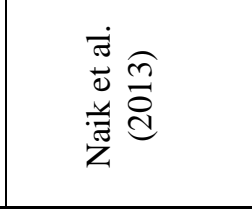 & 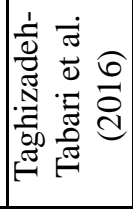 & 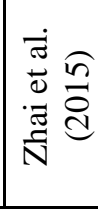 \\
\hline
\end{tabular}




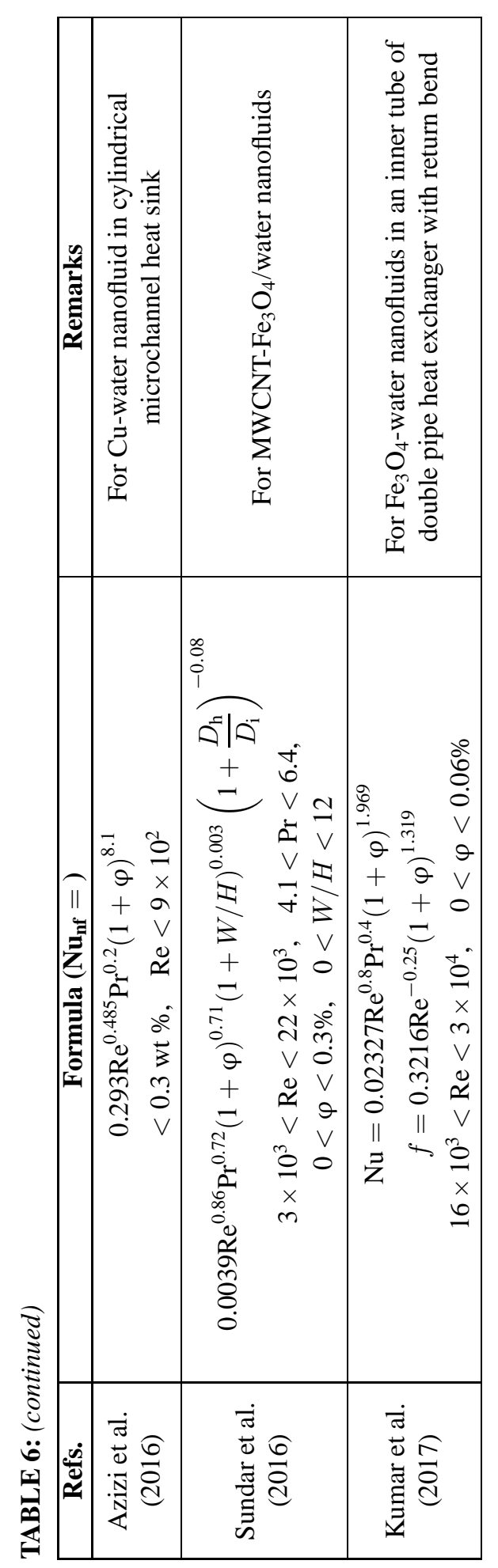

Volume 27, Issue 1, 2020 


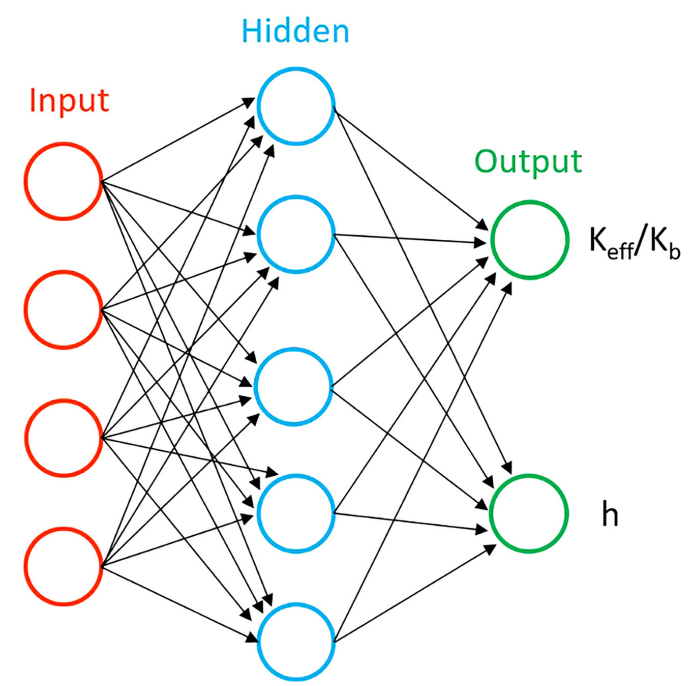

FIG. 6: Schematic of an ANN model

thermal conductivity and HTC of a nanofluid). In feed-forward ANN, there are no cycles or loops, and information moves only in one direction. Neurons are organized into layers: the first layer represents the input neurons (input variables), and the last one contains the output neurons. The network forms by connecting the output of certain neurons to the input of other neurons through a directed, weighted sum. The weights corresponding to the parameters of the model, and the sum are passed through a function known as an activation function. Sometimes a bias term is added to the total weighted sum of inputs to serve as a threshold to shift the activation function. The weights as well as the activation functions can be modified by a process called learning, which is governed by a learning rule. The learning rule is a rule or an algorithm that modifies the parameters of the neural network in order for a given input to the network to produce a favored output. This learning process typically amounts to modifying the weights and thresholds of the variables within the network.

In recent years, the ANN technique has been applied for solving complex engineering problems in different application areas. Sobhanifar et al. (2015) used the ANN technique for the computing convective HTCs. Hojjat et al. (2011) and Longo et al. (2012) used ANN models for the prediction of the thermal conductivity of oxide nanoparticles suspended in water. Esfer et al. $(2014,2015 \mathrm{~b})$ predicted thermal conductivity of nanofluids using thermal conductivity of constituents, diameter of particles, volume fractions, and temperature as input data. Longo et al. (2012) compared the predictions by a three-input model and four-input ANN model. Both models account for the effects of temperature, particle volume fraction, and thermal conductivity; whereas, the four-input model also considered the effect of particle cluster average size. The models have been trained using a set of data obtained by the authors and others. Both models have shown a reasonable agreement in predicting experimental data; the four-input model, albeit applicable only when the cluster average size is known, exhibits better performance. The knowledge of the clustering (agglomeration), usually missing from data presented in literature, seems essential for evaluating nanofluid thermal conductivity.

Figure 7 presents the predicted enhancement of thermal conductivity with the four-input ANN model for $\mathrm{Al}_{2} \mathrm{O}_{3} /$ water and $\mathrm{TiO}_{2} /$ water nanofluids at 1 and $2 \%$ volume fractions in a wide 


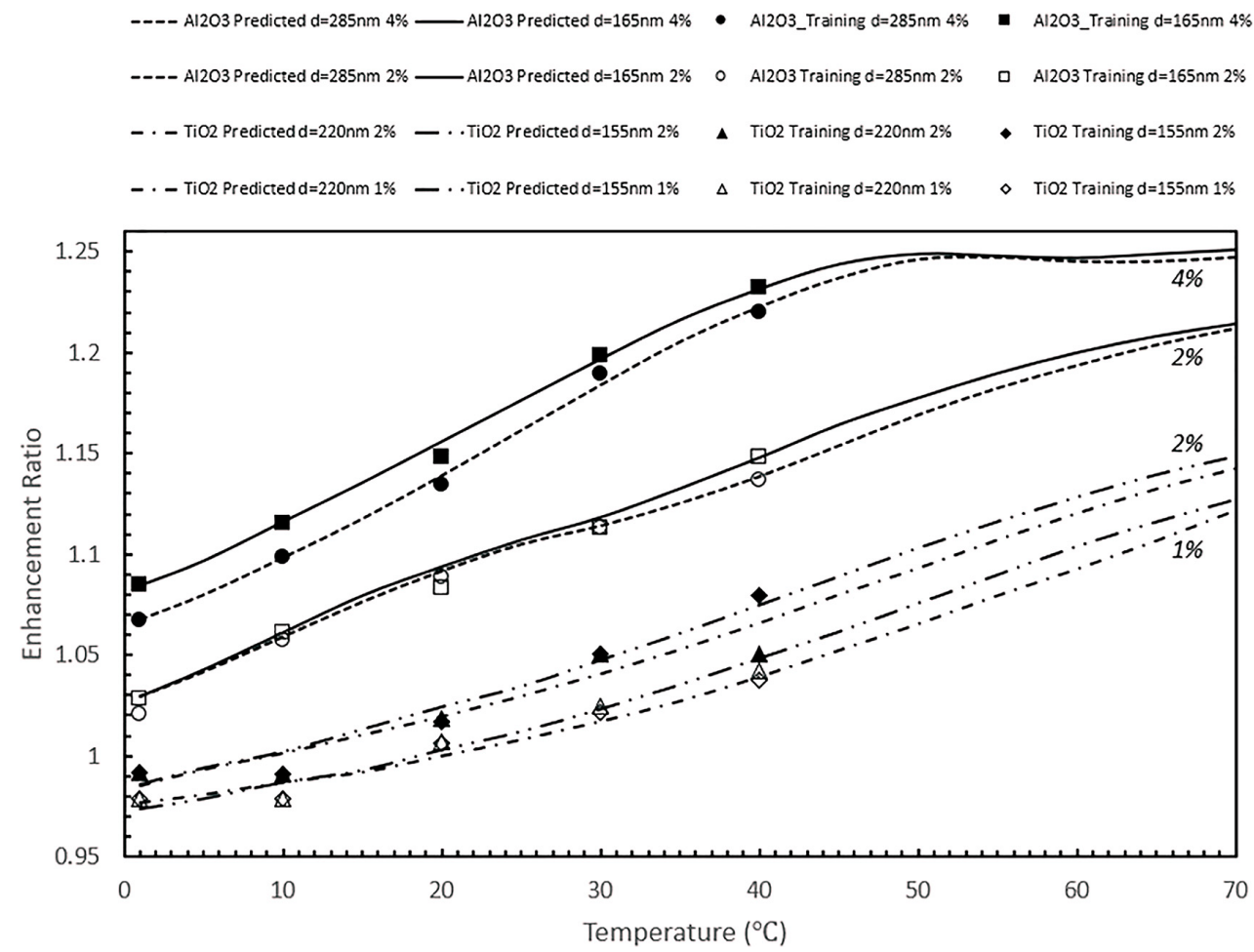

FIG. 7: Predicted enhancement of nanofluid thermal conductivity with the 4-input ANN model

temperature range [data extracted from Longo et al. (2012)]. The $\mathrm{Al}_{2} \mathrm{O}_{3}$ structure is alpha with a purity higher than $99.9 \%$ and average particle diameter of $30 \pm 10 \mathrm{~nm}$. The $\mathrm{TiO}_{2}$ structure is rutile with purity higher than $99.9 \%$ and average particle diameter within $30-50 \pm 10 \mathrm{~nm}$. The nanofluids have been processed in two different ways: by simple stirring (resulting average cluster size: $285 \mathrm{~nm}$ for $\mathrm{Al}_{2} \mathrm{O}_{3} /$ water and $220 \mathrm{~nm}$ for $\mathrm{TiO}_{2} /$ water) and by sonication (average cluster size: $165 \mathrm{~nm}$ for $\mathrm{Al}_{2} \mathrm{O}_{3} /$ water and $155 \mathrm{~nm}$ for $\mathrm{TiO}_{2} /$ water).

\section{APPLICATIONS TO ENHANCED HEAT TRANSFER}

According to areas of application, nanofluids can be organized as heat transfer nanofluids, tribological nanofluids, surfactant nanofluids, chemical nanofluids, environmental nanofluids, pharmaceutical nanofluids, and biomedical nanofluids, etc. Some particles have particular applications. For example, alumina NPs are utilized in fire retardation (Laachachi et al., 2009). CuO NPs have high efficiency and phase stability as nanofluids in heat transfer applications (Chang et al., 2011). Nanofluids with enhanced thermal properties find great potential and wide application in heat transfer processes and thermal systems, covering a spectrum of fields in microelectronics, power and energy industries, chemical engineering and pharmaceutical processes, automobile and aerospace technologies, transportation, building and environmental industry, nuclear technology, defense technology, machining, and manufacturing. Applications extend to the areas of cooling of automobile engines; cooling of electronics; cooling of transformer oil, improving diesel generator efficiency; cooling of heat exchanging devices, improving heat transfer

Volume 27, Issue 1, 2020 
efficiency of chillers and domestic refrigerator-freezers; and cooling in machining and drilling (Saidur et al., 2011a). Godson et al. (2010) reviewed applications to microchannel heat sink (MCHS) and heat pipes. Kakac and Pramuanjaroenkij (2016) briefed several review articles involving applications. Next, we provide a detailed review on several areas of heat transfer applications with nanofluids.

\subsection{Cooling Applications}

Recent studies have indicated that substitution of conventional coolants by nanofluids appears promising (Saidur et al., 2011b; Khoshvaght-Aliabadi et al., 2017; Ahmed et al., 2018; Subhedar et al., 2018). Routbort et al. (2009) stated that use of nanofluids for industrial cooling could save energy, increase energy efficiency, and reduce emissions and pollution. For the U.S. industry, the replacement of cooling and heating water with nanofluids has the potential to conserve one trillion Btus of energy. For the U.S. electric power industry, using nanofluids in closed-loop cooling cycles could save about 10-30 trillion Btu per year (Wong and De Leon, 2010).

Chang et al. (2012) analyzed the influence of NP volume fraction on spray cooling with $\mathrm{Al}_{2} \mathrm{O}_{3}$-water nanofluids. They indicated that nanofluids with a high volume fraction are incompatible for spray cooling; whereas, those with a low volume fraction $(0.001 \mathrm{vol} \%)$ showed significant improvement in spray cooling efficiency. On the basis of the characteristics of the nanofluid suspension, NPs easily deposit on the solid surface especially after heating and cooling repeatedly, clogging the nozzle and increasing the thermal contact resistance. As one of the solutions, a dispersing agent could be added to the liquid for improving the stability of nanofluid.

The studies in spray cooling with nanofluids are still in the preliminary stage, and the relevant conclusions have not obtained consistency (Bellerová et al., 2012; Hsieh et al., 2015; Ravikumar et al., 2015). Anyhow, nanofluids produced positive results in the transient heat transfer of spray cooling (Nayak and Mishra, 2019). Manoj et al. (2019) indicated that nanofluid spray impingement cooling (NSIC) has a huge potential of being used as lubricant and coolant in machining processes due to its excellent lubricating properties and high heat removal capacity. They carried out a study to improve the machining performance during turning of AISI 316 SS using uncoated carbide inserts under a bio-oil based NSIC environment. Different volume fractions of Karanja oil-based $\mathrm{TiO}_{2}$ nanofluid were applied. Their results indicate that the application of bio-oil based $\mathrm{TiO}_{2}$ decreased the peak tool temperatures by $52 \%$ as compared to a dry turning environment. There was a noticeable increase in surface finish quality. As Cheng et al. (2016) pointed out, the potential of nanofluids is worth exploring. More appropriate pairing of NP-fluid and stable nanofluids should be developed and considered in spray cooling.

Nguyen et al. (2007) used $\mathrm{Al}_{2} \mathrm{O}_{3}$-water nanofluid for cooling of microprocessors or other electronic components. Experimental data, obtained for turbulent flow regime, have clearly shown that the inclusion of NPs into distilled water has produced a considerable enhancement of the cooling block convective HTC. For a particular nanofluid with $6.8 \%$ particle volume concentration, HTC has been found to increase as much as $40 \%$ compared to that of the base fluid. An $\mathrm{Al}_{2} \mathrm{O}_{3}(1 \%$ )-water nanofluid showed an average improvement in thermal performance of $26 \%$ over that of pure water for a given pumping power in a double-layered microchannel heat sink (Hung and Yan, 2012). Khoshvaght-Aliabadi et al. (2017) found that adding 0.1 and 0.4 wt \% $\alpha-\mathrm{Al}_{2} \mathrm{O}_{3}$ NPs in water as coolant causes an increase in the range of $4.8-13.3 \%$ for the HTC and $3.3-9.6 \%$ for the pressure drop. A noticeable average performance factor of 2.68 was obtained for the simultaneous utilization of corrugated minichannels and $\mathrm{Al}_{2} \mathrm{O}_{3}$ /water nanofluid inside a heat sink (Khoshvaght-Aliabadi and Sahamiyan, 2016). 
Tariq et al. (2019) investigated the thermal performance of a micro-hole cellular structure using $\mathrm{Al}_{2} \mathrm{O}_{3}$-water and $\mathrm{CuO}$-water nanofluids with 0.67 and $0.4 \mathrm{vol} \%$, respectively. The thermal conductivities of $\mathrm{Al}_{2} \mathrm{O}_{3}$ and $\mathrm{CuO}$ nanofluids were enhanced by 2 and $1.19 \%$, respectively, as compared to the pure water. Using $\mathrm{Al}_{2} \mathrm{O}_{3}$ nanofluids, they achieved the minimum base temperature of 24.5 and $26.6^{\circ} \mathrm{C}$ numerically and experimentally, respectively; whereas with $\mathrm{CuO}$ nanofluids, the respective values are 25.5 and $27.7^{\circ} \mathrm{C}$. The lowest base temperature of 26.6 and $27.7^{\circ} \mathrm{C}$ in experiments using $\mathrm{Al}_{2} \mathrm{O}_{3}$-water and $\mathrm{CuO}$-water nanofluids, respectively, is about 17.6 and $14.5 \%$ lower than the lowest temperature value of $32.3^{\circ} \mathrm{C}$ using water.

It is predicted that the next generation of computer chips will produce localized heat flux over $10 \mathrm{MW} / \mathrm{m}^{2}$, with the total power exceeding $300 \mathrm{~W}$ (Ma et al., 2006a,b). Pulsating heat pipes (PHPs) are heat transfer devices that are widely utilized in electronic devices and energy systems. In combination with thin-film evaporation, the nanofluid PHP cooling system can serve as a next-generation cooling device that will be able to handle the heat dissipation coming from new technology (Ma et al., 2006a). Lin et al. (2008) investigated nanofluids in PHP using Ag NPs. The silver nanofluid improved heat transfer characteristics of the heat pipes. Xing et al. (2017) experimentally investigated the thermal performance of vertical closed PHP using pure water and hydroxylated MWNTs nanofluids. Their results showed that the heat transfer performance of PHP can be significantly improved by applying the nanofluids at the lower concentration and the MWNTs nanofluid PHP exhibits better start-up characteristics than water. The thermal resistance of $0.1 \mathrm{wt} \%$ nanofluid PHP is decreased by $34 \%$ in comparison to pure water when the input power increases up to $100 \mathrm{~W}$. Nazari et al. (2018) used four concentrations of graphene oxide $(0.25,0.5,1$, and $1.5 \mathrm{~g} / \mathrm{l})$ in water in experimental study in a PHP and showed that adding graphene oxide sheets increased thermal conductivity and viscidity of the base fluid, and decreased thermal resistance of PHP up to $42 \%$.

Use of nanofluids as coolants would allow for smaller size and better positioning of the automobile radiators (Akash et al., 2019), leading to a reduction in the frontal area of the radiator by up to $10 \%$ (Singh et al., 2006). Coolant pumps could be shrunk, and truck engines could be operated at higher temperatures, allowing for more horsepower while still meeting stringent emission standards. It was determined that copper nanofluid produces a higher wear rate than the base fluid, and this is possibly due to oxidation of copper nanoparticles. A lower wear and friction rate was seen for alumina nanofluids in comparison to the base fluid. Kulkarni et al. (2008) used $\mathrm{Al}_{2} \mathrm{O}_{3}$ nanofluid as a coolant in a diesel-electric generator. Ahmed et al. (2018) experimentally studied enhancement of a car engine radiator using $\mathrm{TiO}_{2}$-water nanofluid as coolant. $\mathrm{TiO}_{2}$-water nanofluid with $0.2 \%$ concentration can enhance the effectiveness of a car radiator by $47 \%$ as compared to 0.1 and $0.3 \%$ concentrations and pure water as a coolant. Subhedar et al. (2018) used $\mathrm{Al}_{2} \mathrm{O}_{3}$ /water-mono EG nanofluids as a coolant for car radiators. Experimental results showed that the nanofluid with $0.2 \%$ volume fraction had a $30 \%$ rise in heat transfer. Also, the reduction in the frontal area of the radiator if the base fluid is replaced by nanofluid is estimated to make a lighter cooling system, produce less drag, and save fuel costs. Future engines that are designed using nanofluids' cooling properties would be able to run at more optimal temperatures, allowing for increased power output. With a nanofluids engine, components would be smaller and weigh less, allowing for better gas mileage, saving consumers money and resulting in fewer emissions for a cleaner environment.

Kumar et al. (2018a) experimentally studied the application of $\mathrm{Al}_{2} \mathrm{O}_{3}$-water nanofluids (oleic acid as a surfactant) as a coolant in an automotive car radiator. Figure 8 shows their experimental measurements on thermal conductivity and viscosity at $80^{\circ} \mathrm{C}$, and output temperature of the nanofluids for different NPs volume fractions at inlet temperature of $80^{\circ} \mathrm{C}$ with two different

Volume 27, Issue 1, 2020 


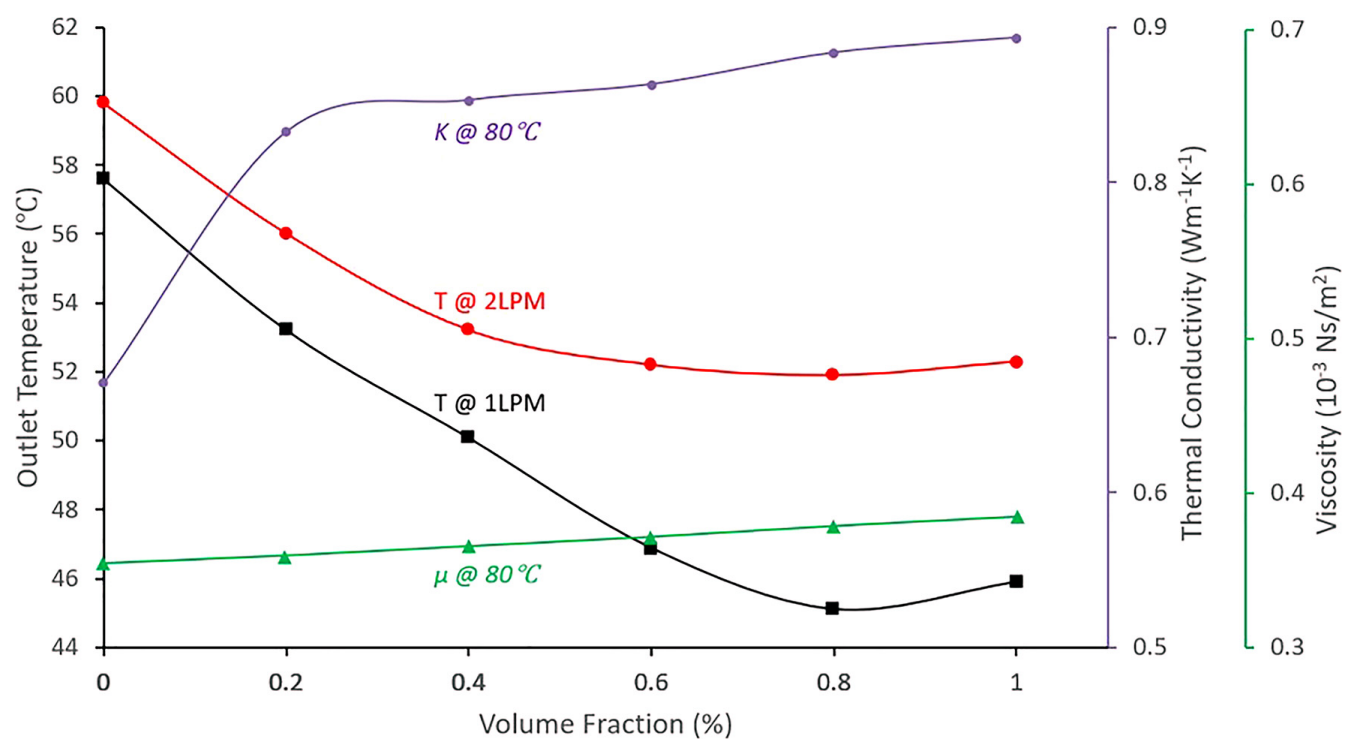

FIG. 8: Measured thermal conductivity, dynamic viscosity, and output temperature versus particle volume fraction in the coolant application of $\mathrm{Al}_{2} \mathrm{O}_{3}$-water nanofluids with oleic acid as a surfactant in a radiator [based on the data from Kumar et al. (2018a)]

volume flow rates. It is seen that both the thermal conductivity and viscosity of the nanofluid increase with an increase in the concentration of NPs. The outlet temperature decreases with increase of the NPs to $0.8 \mathrm{vol} \%$ and then upward with further increasing concentration. The lower the outlet temperature is, the better the thermal performance is. For $1 \mathrm{LPM}$ and $80^{\circ} \mathrm{C}$ with $0.8 \mathrm{vol} \%$ nanofluid, the outlet temperature is reduced by $21.7 \%$ as compared to water. For low volume fractions, an increased thermal conductivity of the nanofluid enhances the heat transfer and hence decreases the outlet temperature. As the concentration of the nanofluid increased, the viscosity of the nanofluid increases, which in turn increases the thermal boundary layer thickness, leading to a reduction in heat transfer and increase in the outlet temperature. Hence at higher volume fractions, the viscous effect becomes dominant over the increase in the thermal conductivity.

The use of nanofluids in nuclear power plants seems like a potential future application (Kim et al., 2007; Boungiorno et al., 2008; Sharma and Pandey, 2018). Cooling down fuel rods is the critical technical challenge in nuclear reactors. Many pressurized water-cooled nuclear power systems are CHF-limited, but the application of nanofluid can greatly improve the CHF of the coolant so that there is a bottom-line economic benefit while also raising the safety standard of the power plant system. Another possible application of nanofluids in nuclear systems is the alleviation of postulated severe accidents during which the core melts and relocates to the bottom of the reactor vessel. If such accidents were to occur, it is desirable to retain the molten fuel within the vessel by removing the decay heat through the vessel wall (Buongiorno et al., 2009). Saadati et al. (2018) investigated the effects of selecting water/silver nanofluids as both a coolant and a reactivity controller during the first operating cycle of a light water nuclear reactor. The results showed that the maximum required level of Ag NPs is $1.3 \mathrm{vol} \%$ at the beginning of the cycle; this value drops to zero at the end of cycle. Due to substitution of water/boric acid with water/Ag nanofluid, reactor operation time at maximum power extends to 357.3 days, 
and the energy generation increases by $\sim 27.3 \%$. Several significant gaps in knowledge are evident at this time, including demonstration of the nanofluid thermal-hydraulic performance at prototypical reactor conditions and the compatibility of the nanofluid chemistry with the reactor materials.

Conventional cryopreservation protocols for slow-freezing or vitrification involve cell injury due to ice formation/cell dehydration or toxicity of high cryoprotectant concentrations, respectively. Since higher cooling rates lower the cryoprotectant concentration required to achieve vitrification, He et al. (2008) were interested in further decreasing the amount of cryoprotectant required for vitrification via heat transfer enhancement either inside the cryopreservation solution or on the boundary between the micro-capillary and the cryogenic fluid. They developed a novel ultrafast vitrification approach for cryopreservation of sensitive mammalian cells using a small quartz micro-capillary. Enhancing heat transfer inside the cryopreservation solution could be achieved by dispersing nanoparticles in the cryopreservation solutions to form nanofluids. Additionally, the enhancement of heat transfer during the warming step of a vitrification protocol is essential since critical warming rates to avoid devitrification are generally higher than critical cooling rates to achieve vitrification. Manuchehrabadi et al. (2017) improved tissue cryopreservation using inductive heating of magnetic nanoparticles.

Nanofluids can also be used for safer surgery by producing effective cooling around the surgical region and thereby enhancing the patient's chance of survival and reducing the risk of organ damage. Cryosurgery is a procedure that uses freezing to destroy undesired tissues. Yan and Liu (2008) proposed a surgical term, nanocryosurgery, for efficient tumor treatment through combining cyrosurgery and nanotechnology. Intentional loading of nanoparticles with high thermal conductivity into the target tissues can reduce the final temperature, increase the maximum freezing rate, and enlarge the ice volume obtained in the absence of nanoparticles. Additionally, NP-enhanced freezing could make conventional cyrosurgery more flexible in many aspects, such as artificially interfering in the size, shape, image, and direction of ice ball formation. Recently, Akbar et al. (2016) studied the antibacterial applications for a new thermal conductivity model in arteries with CNT suspended nanofluid. Khademi et al. (2019) found that the nanofluid injection locally increases the thermal conductivity and decreases the heat capacity of the biological tissue; hence, the tissue significantly becomes more sensitive to temperature changes. With respect to the choice of particle for enhancing freezing, magnetite $\left(\mathrm{Fe}_{3} \mathrm{O}_{4}\right)$ and diamond are perhaps the most popular and appropriate because of their good biological compatibility.

\subsection{Applications to Renewable Energy and Energy Systems}

A recent editorial (Liu and Guo, 2018) pointed out that pursuing ideal energy or its utilization ways has never been so urgent as it was because the energy and environmental problems are becoming increasingly serious. Thus far, tremendous efforts in the research of energy science and technologies have been conducted. However, there still exists a gap between research and needs. This indicates that new energy or revolutionary technologies over existing ones should be fully explored. In the renewable energy industry, nanofluids could be employed to enhance heat transfer from solar collectors to energy storage tanks. When extracting energy (geothermal, fossil fuels) from the earth's crust that varies in length between 5 and $10 \mathrm{~km}$ and temperature between 500 and $1000^{\circ} \mathrm{C}$, nanofluids can be employed to cool the pipes, machinery, and equipment working in a high-friction and high-temperature environment (Ahmadi et al., 2018).

Geothermal energy exists in rock and trapped liquid or vapor that can be applied for heating and generating electricity. Geothermal energy is one of the most suitable sources of energy since

Volume 27, Issue 1, 2020 
it is possible to use it continuously for generating power and providing heat. The cumulative capacity of geothermal power plants in the world has increased from $10.34 \mathrm{GW}$ in 2007 to 14.30 GW in 2017. According to the International Energy Agency, Technology Roadmap Geothermal Heat and Power 2011, it is expected to reach 1400 TWh electricity generation per year by using geothermal sources by 2050 . In addition, geothermal heat has the ability to contribute $3.9 \%$ of final energy for heat by 2050, which means $1600 \mathrm{TWh}$ thermal energy. Enhancement of heat transfer with nanofluids leads to improved efficiency of the geothermal energy systems (Bobbo et al., 2016). Using nanofluid as heat carrier resulted in reduction of thermal resistance on a borehole heat exchanger (Diglio et al., 2018). By considering both heat transfer and pressure drop, it was concluded that using $\mathrm{Cu}$-based nanofluids led to the most reduction in the length of a borehole heat exchanger.

Jamshidi and Mosaffa (2018) numerically investigated the performance of a geothermal heat exchanger and the effects of utilizing nanofluids in extracted heat. Their results showed that, employing the NPs in $0.5 \mathrm{vol} \%$ could lead to a $\sim 18 \%$ increase in obtained energy from the earth. The extracted heat from the earth in geothermal systems depends on the thermophysical properties of the applied nanofluid, such as specific heat, dynamic viscosity, and thermal conductivity, as well as the flow rate and well specification. As Ahmadi et al. (2018) pointed out, there are some concerns using nanofluids in heat exchangers of geothermal systems though it improves the heat transfer and efficiency. NP sedimentation can deteriorate heat transfer and performance of the systems. There are some suggestions to overcome the problem. According to Sun et al. (2018), in the case of static fluid in shut-down condition, accumulation of NPs appeared in the bottom of borehole after sedimentation for many hours. Relatively high velocity of the fluid can remove the accumulated particles, which may lead to reliable performance of nanofluidic heat exchangers in geothermal systems.

Solar energy is renewable and green. Although the amount of solar irradiation on the Earth's surface is enormous, approximately $3 \times 10^{24}$ joules/yr, most of it remains unused because of challenges such as high cost and low electricity conversion efficiency at present. NP-based direct absorption solar collectors, which utilize the high radiation absorption property of nanoparticles suspended in a working fluid, are proposed to increase the efficiency of solar systems. Figure 9 shows the increase of collector efficiency with use of various nanofluids to the use of base fluid. It is seen that addition of CNT NPs (6-20 nm diameter, 1-5 $\mu \mathrm{m}$ length) from 0.05 to $1 \%$ in water (Otanicar et al., 2010) increased the efficiency by $>50 \%$, and the enhancement increased with increasing volume fraction until $0.5 \%$. Suspensions of graphite NPs (C, $30 \mathrm{~nm}$ diameter) in water are more efficient than the CNT-based nanofluids of same volume fraction up to $0.5 \%$. Two Agwater nanofluids with different NP sizes at same volume fraction $(0.25 \%)$ were also compared by Otanicar et al. (2010). From Fig. 9, it is observed that the smaller Ag NPs (20 nm diameter) are more efficient than the larger NPs (40 nm diameter). In the study of Arikan et al. (2018), the effect of $\mathrm{Al}_{2} \mathrm{O}_{3}$-water and $\mathrm{ZnO}$-water nanofluids, with and without $\mathrm{EG}$, on the efficiency of a flat plate solar collector was investigated. The volume fraction of the NPs and EG were 0.25 and $25 \%$, respectively. The study was conducted on three mass flow rates, $0.05,0.07$, and 0.09 $\mathrm{kg} / \mathrm{s}$, respectively. Figure 9 only extracted the data for $0.09 \mathrm{~kg} / \mathrm{s}$. The efficiency of the system was compared to distilled water (base fluid). Their results showed that an increase in the mass flow rate and use of the EG increased efficiency. Figure 9 also shows the data for $\mathrm{Al}_{2} \mathrm{O}_{3}$-water by Yousefi et al. (2012) and for ZnO-water by Babu and Raja (2016), respectively. Zhang et al. (2014) showed that Au-water nanofluids at very low volume fraction $(<0.0006 \%)$ could increase the efficiency substantially, using $6 \mathrm{ppm}$ aqueous gold nanofluid could enhance the photothermal conversion efficiency by $\sim 78 \%$. 


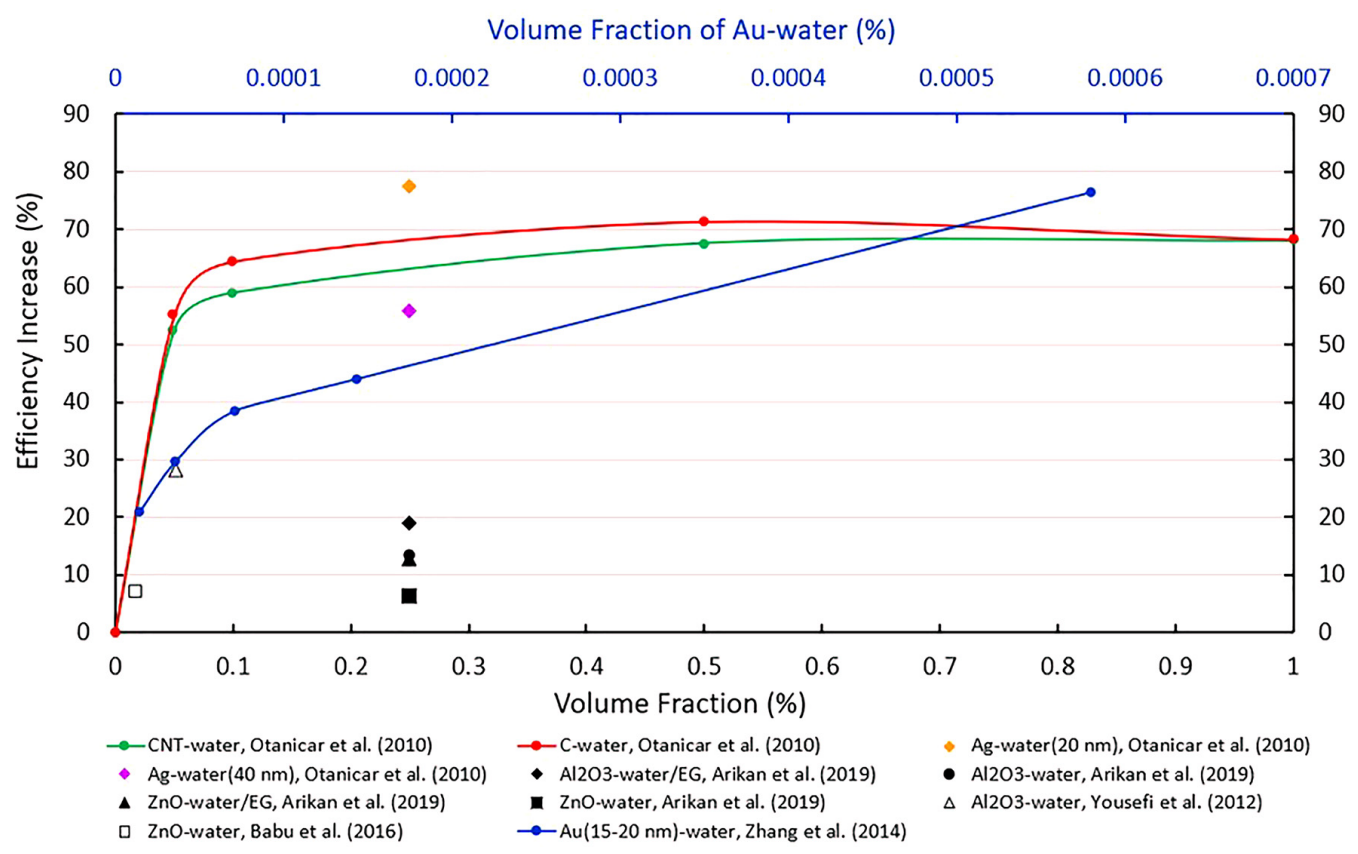

FIG. 9: Solar collector efficiency increase with use of nanofluids

An enhancement of $144 \%$ in the in the stored thermal energy can be obtained at the peak temperature for a particle concentration of $6.5 \mathrm{ppm}$ silver aqueous nanofluid (Bandarra Filho et al., 2014). Zeng and Xuan (2018) modeled binary nanofluid containing MWCNTs and $\mathrm{SiO}_{2} / \mathrm{Ag}$ plasmonic nanoparticles for enhancing solar energy absorption and photothermal conversion because different NPs have different spectrally absorptive features. Zeiny et al. (2018) performed a well-controlled experiment for three different categorized nanofluids, i.e., $\mathrm{Au}, \mathrm{Cu}$, carbon black nanofluids, and their hybrids. Photothermal conversation efficiencies, specific absorption rates, and cost of a unit thermal power generation were calculated from the recorded temperature rise of different nanofluids. They found that adding NPs to water enhanced the photothermal conversation efficiency, and this enhancement is linearly proportional to the concentration of NPs. Considering both photothermal conversion efficiency and potential economic cost, carbon black nanofluid is a suitable candidate; whereas, gold is not due to its high cost.

Parabolic trough collectors (PTCs) are widely used in concentrated solar power plants. Thermal oil, water, and EG have been extensively utilized as the working fluids in solar thermal electric plants with PTCs. However, their operating temperature limitation or environmental pollution have caused employing alternative working fluids. To overcome such issues, use of nanofluids as a working fluid has been considered and its effect is reviewed by Akbarzadeh and Valipour (2018). There are some drawbacks in the context of using nanofluids such as the high price and the instability of the mixture. Furthermore, the increased pressure drop with nanofluids over base fluid flow is a concern.

Some investigations have combined nanofluids with passive techniques to improve heat transfer. Waghole et al. (2014) experimentally investigated the effect of Ag nanofluids on the thermal performance and pressure drop of a PTC with twisted tape. Chougule and Sahu (2016) proved that the pressure drop with the use of helical inserts was significantly more than the use of

Volume 27, Issue 1, 2020 
nanofluids in a PTC. But the heat transfer enhancement with simultaneous effects of turbulators and nanofluids was much higher than using a nanofluid alone. Nusselt number enhancement for $\mathrm{CNT} /$ water nanofluid was $\sim 33.58 \%$; whereas, it was $215.55 \%$ with simultaneous use of both nanofluid and helical tape inserts of a twist ratio 1.5. Combination other passive methods like wavy tubes and fins with nanofluids have also been investigated.

Nanofluids were also applied to solar cells, solar stills, solar water heaters, etc. In arid remote regions in the world, the provision of fresh water is more critical. In these regions, solar desalination systems can solve part of the problem where solar energy is available (Kianifar et al., 2012). Gnanadason et al. (2012) investigated the effects of adding CNTs to the water inside a single basin solar still and revealed that adding nanofluids increases the efficiency by $50 \%$. Mahian et al. (2017) studied experimentally and theoretically the performance of a solar still equipped with a heat exchanger using nanofluids through three key parameters, i.e., freshwater yield, energy efficiency, and exergy efficiency. The results reveal that using the heat exchanger at temperatures $<60^{\circ} \mathrm{C}$ is not advantageous and the corresponding yield is smaller than that of solar still without the heat exchanger; although in such a case, using nanofluids as the working fluid in the heat exchanger can enhance the performance indices by $\sim 10 \%$. At higher temperatures $\left(\right.$ e.g., $70^{\circ} \mathrm{C}$ ), the use of a heat exchanger is beneficial; however, using nanofluids instead of water can augment the performance indices marginally, i.e., by $\sim 1 \%$. Cooling of solar cells to improve the efficiency of such solar devices (Elmir et al., 2012). Hjerrild et al. (2019) experimentally tested spectrum splitting nanofluids for three cells: c-Si, GaAs, and Ge solar cells. The nanofluids were composed of combinations of core-shell silver-silica $\left(\mathrm{Ag}-\mathrm{SiO}_{2}\right)$ nanoplates as visible light absorbers and silica-coated gold and gold-copper nanorods as infrared absorbers. The nanofluid paired with a c-Si PV cell delivered the highest combined efficiency, which indicates that this PV-nanofluid combination is a strong candidate for a low-cost, high-efficiency spectrum splitting technology.

Thermal energy storage can be used to enhance energy efficiency and improve energy conservation and management. Latent heat storage uses phase-change material (PCM), which is widely used for solar energy storage, industrial waste energy storage, etc. Thermal energy storage PCM utilizes the heat absorption and release of substances during phase transition processes to store and release thermal energy. Organic PCMs are one of the most preferred forms for thermal energy storage because they have a proper phase-change temperature range, little or no super cooling, lower vapor pressure, nontoxicity, noncorrosivity, and excellent thermal stability. Fatty acids and paraffin wax (PW) are good organic PCMs due to their desirable characteristics, such as high latent heat of fusion, negligible super cooling, low vapor pressure in the melt, and thermal stability. Wang et al. (2014) dispersed $\mathrm{TiO}_{2} \mathrm{NPs}(20 \mathrm{~nm})$ in the form of anatase into a PW matrix without any surfactant to make PCMs for energy storage. The melting temperature and latent heat capacity were measured using a differential scanning calorimetric instrument. The thermal conductivity was measured by a transient short hot-wire method. A significant increase in both the latent heat capacity and thermal conductivity is found at $\sim 0.7 \mathrm{wt} \% \mathrm{TiO}_{2} \mathrm{NP}$ loading. The latent heat includes both the solid-solid phase change and solid-liquid phase change. There are at least two opposite factors that cause the latent capacity change in the PCM: (i) the interaction between the PW molecules and $\mathrm{TiO}_{2}$ particles will increase the latent capacity of the composites and (ii) the addition of the $\mathrm{TiO}_{2}$ particles would reduce the latent heat capacity because the replacement of nanoparticles for the PW molecules could lead to absorbing or releasing more energy during composite melting or solidification processes. Thus, the latent heat capacity of the composite would increase if the first factor were stronger than the second one and vice versa. The polarizing optical microscope analysis illustrated that $\mathrm{TiO}_{2}$ particles aggregated with increasing 
particle loading. Aggregation of NPs increases interfacial thermal resistance between the NPs and the matrix molecules and decreases thermal conductivity.

Wang et al. (2019) prepared organic PCMs for enhanced energy storage in water heaters by adding $\mathrm{SiO}_{2}$ particles into molten palmitic acid (PA). They found that the $\mathrm{SiO}_{2}-\mathrm{PA}$ water heater responds faster and has a larger volume ratio of hot water output to water heater size. Rueda-Garcia et al. (2018) investigated electrochemical energy storage in a $\mathrm{LiFePO}_{4} /$ reduced graphene oxide aqueous nanofluid and demonstrated the possible application of electroactive nanofluid electrodes in alternative flow batteries. Sidik et al. (2018) recently provided a review on performance enhancement of a cold thermal energy storage system using nanofluid PCMs. Cold thermal energy storage plays a vital role in many industrial applications such as central air-conditioning in large buildings, high-powered electronic cooling applications, waste heat recovery, food processing, and restoring the electrical power imbalance between daytime need and night-time abundance.

\subsection{Applications to Building Technology}

There are unending situations where an augmentation in heat transfer effectiveness can be beneficial to the quality, quantity, and cost of a product or process. In many of these situations, nanofluids are good candidates for accomplishing the enhancement in heat transfer performance and hence improving the energy efficiency. "Energy efficiency is a low-cost way to save money, support job growth, reduce pollution, and improve the competitiveness of our businesses. Our homes, offices, schools, hospitals, restaurants, and stores consume a lot of energy and money. We spend more than $\$ 400$ billion each year to power our homes and commercial buildings, consuming approximately $74 \%$ of all electricity used in the United States, about $40 \%$ of our nation's total energy bill. And much of this energy and money is wasted-over $30 \%$ on average. If we cut the energy use of U.S. buildings by $20 \%$, we could save approximately $\$ 80$ billion annually on energy bills and help create jobs" (U.S. DoE, 2019).

Use of thermal energy storage PCMs to the floor, wall, and ceiling to absorb environmental energy can keep the temperature of buildings at a healthy range (Khudhair and Farid, 2004). Such an application would save energy in a heating, ventilating, and air conditioning system while providing environmental benefits. Adding NPs into PCMs can enhance the thermal performance. To prevent leakage during the melting process, micro-/nanoencapsulation of PCMs has aroused increasing interests of research (Liu et al., 2018). CNTs grafted with stearyl alcohol (CNTs-SA) were used in synthesizing phase-change microcapsules (MicroPCMs) in order to enhance the thermal conductivities of the microcapsules. The thermal conductivity of MicroPCMs/CNTsSA with $4 \%$ of CNTs increased by $79.2 \%$ compared to MicroPCMs (Li et al., 2014). Amin et al. (2017) tested beeswax/graphene with various mass fractions of NPs with the objective of investigating the thermal properties of this nano-PCM to reduce energy consumption in buildings. The addition of graphene nanoplatelets increased the thermal conductivity, latent heat, heat capacity, and viscosity of nano-PCM.

Strandberg and Das (2010) analyzed the performance of nanofluids in the hydronic heating system of buildings. The base fluid used in the analysis was a solution comprised of $60 \%$ ethylene glycol and $40 \%$ water (by weight). In cold climates like those found in Alaska, Canada, and other circumpolar regions, heat transfer fluids regularly encounter very low temperatures on the order of $-40^{\circ} \mathrm{C}$. It is a common practice to use this mixed fluid as a heat transfer fluid. The nanofluids were prepared with $\mathrm{CuO}$ NPs dispersed in the same base fluid with volumetric particle concentration ranging up to $4 \%$. The results showed that a higher convective heat transfer

Volume 27, Issue 1, 2020 
coefficient was achieved at higher temperatures for a nanofluid. Kulkarni et al. (2009) performed experiments using $\mathrm{CuO}, \mathrm{AlO}$, and $\mathrm{SiO}_{2}$ nanofluids for heating buildings and reducing pollution. Solar-based radiant heating systems represent a sustainable, and relatively low-cost, technology to raise the temperature of the interior thermal mass of our buildings. Mesgari et al. (2018) investigated MWCNT nanofluids for solar-assisted radiant heating systems, focusing on the effects of exposure time and temperature on stability, optical absorbance properties, the extent of functionalization, and the photothermal conversion performance of UV-ozone-treated MWCNT nanofluids. No agglomeration or degradation of the MWCNTs was observed at elevated temperatures (up to $150^{\circ} \mathrm{C}$ ), highlighting the stability of proposed nanofluids.

Dr. Madamopoulos at City College of New York and the present author proposed together to National Science Foundation the nanofluid-filled hollow prismatic glass louver concept shown in Fig. 10, which serves for dual purpose: improved daylighting and solar thermal energy harvesting. The innovative louver will utilize solar energy rather than "block" sunlight like traditional louvers. The prismatic glass shape can transmit visible light and redirect the collimated (direct) irradiation to the ceiling or through scattering in the nanofluids to eliminate the "glare effect" (Vlachokostas and Madamopoulos, 2015, 2017), such that daylighting quality and comfortableness can be improved. The absorbed solar energy (Cai and Guo, 2018, 2019), mostly infrared and ultraviolet, in the glass and nanofluid can be stored as thermal energy and harvested via the flowing nanofluid (Nan et al., 2020).

\section{CHALLENGES AND FUTURE RESEARCH}

Significant progress on heat transfer enhancement research and development using nanofluids has been made. In general, dilute suspensions with well-dispersed highly conductive NPs enhance thermal performance over base fluid. Nevertheless, key issues linger with regard to
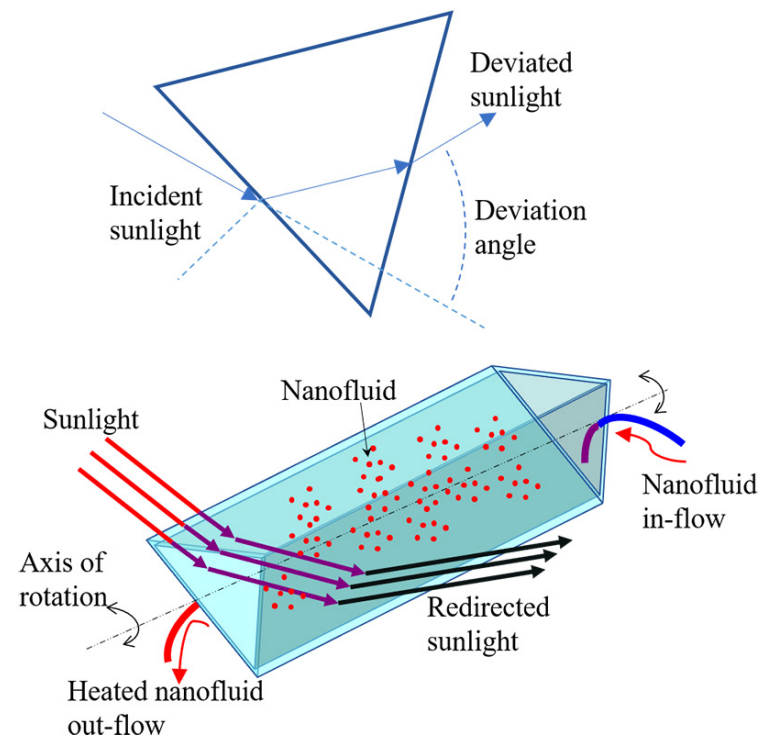

FIG. 10: Concept of nanofluid-filled prismatic louver installed behind a window for dual-purpose: (1) improving daylighting via redirection of direct light through prism effect to ceiling to increase diffuse light and (2) and solar energy harvesting via the nanofluid 
enhancement mechanisms and consistency in results of measurements and predictions. In particular, controversial results exist. Clearly, it will be necessary to consider not only one possible mechanism but combine several mechanisms, as well as to take into account the differences of experimental conditions (such as measurement instrument, accuracy and repeatability, temperature and concentration control, personnel experience) and characteristics of nanofluids (such as NPs-fluid pairing, NPs size profile and morphology, NP surface functionalization, addition of surfactant, NPs agglomeration, $\mathrm{pH}$ value, stability, etc.).

There are several important issues that need to be solved to enable broad applications of nanofluids as heat transfer media in engineering and technology, namely:

- Long-term stability of nanofluids is a key issue for both scientific research and practical engineering applications. Stability of nanofluids under quiescent as well as flow conditions in thermal systems should be systematically studied and evaluated. Researchers need to understand better how the stability of a nanofluid affects its thermophysical properties. To date, long-term stability of most nanofluids in working conditions and real equipment is not confirmed and much effort is required for improving the stability of nanofluids. It was pointed out that the stability of a nanofluid is affected by a number of factors, such as preparation technique, $\mathrm{pH}$ value, NP concentration, particles type, particle morphology, particle size, fluid temperature, etc. Use of different stability techniques or stabilizers could result in inconsistency in thermal properties and performance evaluation, as revealed in previous studies. Robust techniques for large-scale production of stable nanofluids are needed.

- Most studies used mechanical stirring or sonication to prepare for nanofluids without controlling the temperature of the fluid or the mechanical force. The preparation approach could be very important because it might result in completely different $\mathrm{pH}$ values, settling behavior, particles agglomeration, and thus, thermophysical properties. Additionally, using an ultrasonic device, for fabricating nanofluids, will increase the temperature of the fluid gradually but is strongly affected by the ambient temperature where the sample is prepared, meaning that various locations or different weather conditions might likely result in producing a diverse nanofluid and lead to inconsistent test results.

- Use of important dimensionless parameters, such as Reynolds number, Prandtl number, and Nusselt number, is encouraged in heat transfer research. However, unclarity existed in many studies with regard to how to evaluate these dimensionless parameters. Thermal properties of nanofluids are usually a strong function of temperature. Temperature dependence is not clear in many previous studies. Some previous results compared convective heat transfer results of various nanofluids and base fluid under the same Reynolds number to similar flow control conditions. Variation due to addition of NPs on dimensionless parameters might not have been properly incorporated in some previous studies. A uniform standard in experiments, analyses, and evaluations is required.

- Enhanced cooling efficiency using nanofluids as coolants has gained tremendous interest among the researchers. Most of the studies have been performed with oxides of metals. Heat transfer enhancement is much higher in the case of metallic nanoparticles, and enhancement is large even at very low volume fraction. Therefore, exhaustive studies on low volume concentration, nanofluids with metallic nanoparticles, detailed characterization of nanoparticles sizes, distribution, additives, and stabilizers (if used) are required to be done.

Volume 27, Issue 1, 2020 
- The factors influencing enhancement of thermal properties of nanofluids need to be investigated systematically. From a theoretical perspective, the mechanism of thermal conductivity enhancement is still not very clear. One of the possible explanations is the particle motion in the form of Brownian motion. Another possible concept is nano-convection of fluid around the particles due to their motion; in this concept, the particles transport some of the amount of heat transferred through agitation in the liquid. This concept seems to be a potential explanation for NPs behavior. Yet another concept of liquid layering around the particle may give a path for rapid thermal conduction. Currently, a liquid shell around the particles behaves like solids, is assumed, then adjustable parameters of shell thickness and shell conductivity are to be thought of.

- Particle motion induced by inter particles and other forces could be significant at the nanometer scale and can be explored further, as such motions may contribute significantly to energy transport at this scale. There is an urgent need for an atomic and nanoscale level understanding of heat transfer in nanofluids.

- Rheology of nanofluids is as important as thermal conductivity. Non-Newtonian behavior of some nanofluids has been revealed, and this will further complicate the study. Moreover, many industrial processes are operated at turbulent conditions. It would be interesting to have more deeper discussions on the effect of turbulence on nanofluids' heat transfer.

- There is always a concern that NPs sedimentation can deteriorate heat transfer and thermal performance of a system. Nevertheless, relatively high velocity of the nanofluid can remove the accumulated particles, which may lead to reliable performance of nanofluidic heat exchangers as revealed in some previous studies. Fouling effect due to NPs deposition on pipe surface as well as similar wettability property as nanocoating can be explored. It was reported that nanocoating has the advantage of reducing the surface roughness, which strongly influences the shear stress at the boundary.

- In many situations, the right ratio of NPs to base fluid should be found to obtain the highest effective thermal conductivity as well as the lowest possible effective viscosity from the fabricated nanofluid. This is important to meet the applications of heat transfer and to overcome the pressure drop in the same time. Additional research inputs are needed to develop very precise correlations to predict thermal properties and performance.

- Use of intelligent computing techniques for predictive analysis is presently in its infancy, but quite suitable for exploring the complex thermophysical properties of various nanofluids as low-cost solutions. A nanofluid database of thermophysical properties is needed; it should include NPs composition, concentration, size, preparation method, additives (if used), and temperature.

\section{ACKNOWLEDGMENTS}

This material is based on work supported by the National Science Foundation under Grant No. ECCS-1505706. My graduate students, Yi Nan, Xu Huang, and Hang Zhang, have helped in preparing the tables and figures. 


\section{REFERENCES}

Abbood, S.A., Wang, J., Wu, Z., and Sunden, B., Analysis of Natural Convection of Cu and $\mathrm{TiO}_{2} \mathrm{Nanofluids}$ inside Nonconventional Enclosures, J. Enhanced Heat Transf., vol. 25, pp. 315-332, 2018.

Abdollahi, A., Darvanjooghi, M.H.K., Karimipour, A., and Safaei, M.R., Experimental Study to Obtain the Viscosity of CuO-Loaded Nanofluid: Effects of Nanoparticles' Mass Fraction, Temperature and Basefluid's Types to Develop a Correlation, Meccanica, vol. 53, no. 15, pp. 3739-3757, 2018.

Ahmadi, M.H., Ramezanizadeh, M., Nazari, M.A., Lorenzini, G., Kumar, R., and Jilte, R., Applications of Nanofluids in Geothermal: A Review, Math. Modell. Eng. Prob., vol. 5, pp. 281-285, 2018.

Ahmed, S.A., Ozkaymak, M., Sözen, A., Menlik, T. and Fahed, A., Improving Car Radiator Performance by Using $\mathrm{TiO}_{2}$-Water Nanofluid, Eng. Sci. Technol., vol. 21, no. 5, pp. 996-1005, 2018.

Akash, A.R., Pattamatta, A., and Das, S.K., Experimental Study of the Thermohydraulic Performance of Water/Ethylene Glycol-Based Graphite Nanocoolant in Vehicle Radiators, J. Enhanced Heat Transf., vol. 26, pp. 345-363, 2019.

Akbar, N.S., Raza, M., and Ellahi, R., Anti-Bacterial Application for New Thermal Conductivity Model in Arteries with CNT Suspended Nanofluid, J. Mech. Med. Biol., vol. 16, no. 5, p. 1650063, 2016.

Akbarzadeh, S. and Valipour, M.S., Heat Transfer Enhancement in Parabolic Trough Collectors: A Comprehensive Review, Renew. Sustain. Energy Rev., vol. 92, pp. 198-218, 2018.

Akilu, S., Baheta, A.T., Said, M.A.M., Minea, A.A., and Sharma, K.V., Properties of Glycerol and Ethylene Glycol Mixture based $\mathrm{SiO}_{2}-\mathrm{CuO} / \mathrm{C}$ Hybrid Nanofluid for Enhanced Solar Energy Transport, Sol. Energy Mater. Sol. Cells, vol. 179, pp. 118-128, 2018.

Alawi, O.A., Mallah, A.R., Kazi, S.N., Sidik, N.A.C., and Najafi, G., Thermophysical Properties and Stability of Carbon Nanostructures and Metallic Oxides Nanofluids, J. Therm. Anal. Calorim., vol. 135, no. 2, pp. 1545-1562, 2019.

Alva, G., Lin, Y., and Fang, G., An Overview of Thermal Energy Storage Systems, Energy, vol. 144, pp. 341-378, 2018.

Amin, M., Putra, N., Kosasih, E.A., Prawiro, E., Luanto, R.A., and Mahlia, T.M.I., Thermal Properties of Beeswax/Graphene Phase Change Material as Energy Storage for Building Applications, Appl. Therm. Eng., vol. 112, pp. 273-280, 2017.

Arikan, E., Abbasoglu, S., and Gazi, M., Experimental Performance Analysis of Flat Plate Solar Collectors Using Different Nanofluids, Sustainability, vol. 10, p. 1794, 2018.

Arulprakasajothi, M., Elangovan, K., Chandrasekhar, U., and Suresh, S., Experimental Study of a WaterBased Titanium Oxide Nanofluid in a Circular Pipe with Transition Flow and Conical Strip Inserts, Heat Transf. Res., vol. 49, pp. 439-456, 2018.

Azizi, Z., Alamdari, A., and Malayeri, M.R., Thermal Performance and Friction Factor of a Cylindrical Microchannel Heat Sink Cooled by Cu-Water Nanofluid, Appl. Therm. Eng., vol. 99, pp. 970-978, 2016.

Azizian, R., Doroodchi, E., and Moghtaderi, B., Influence of Controlled Aggregation on Thermal Conductivity of Nanofluids, J. Heat Transf., vol. 138, p. 021301, 2016.

Azmi, W.H., Sharma, K.V., Mamat, R., Najafi, G., and Mohamad, M.S., The Enhancement of Effective Thermal Conductivity and Effective Dynamic Viscosity of Nanofluids-A Review, Renew. Sustain. Energy Rev., vol. 53, pp. 1046-1058, 2016.

Azmi, W.H., Sharma, K.V., Sarma, P.K., Mamat, R., Anuar, S., and Rao, V.D., Experimental Determination of Turbulent Forced Convection Heat Transfer and Friction Factor with $\mathrm{SiO}_{2}$ Nanofluid, Exp. Fluid Sci., vol. 51, pp. 103-111, 2013.

Babu, S.A. and Raja, M., An Experimental Investigation on the Effect of $\mathrm{ZnO} /$ Water Nanofluid on the Efficiency of Flat-Plate Solar Collector, Adv. Nat. Appl. Sci., vol. 7, pp. 40-48, 2016.

Volume 27, Issue 1, 2020 
Balaji, D., Velraj, R., and Murthy, M.R., A Review of the Role of Passive Techniques on Heat Transfer Enhancement of Horizontal Tube Falling Film and Flooded Evaporators, J. Enhanced Heat Transf., vol. 25, pp. 239-282, 2018.

Bandarra Filho, E.P., Mendoza, O.S.H., Beicker, C.L.L., Menezes, A., and Wen, D., Experimental Investigation of a Silver Nanoparticle-Based Direct Absorption Solar Thermal System, Energy Convers. Manage., vol. 84, pp. 261-267, 2014.

Bang, I.C. and Chang, S.H., Boiling Heat Transfer Performance and Phenomena of $\mathrm{Al}_{2} \mathrm{O}_{3}-$ Water NanoFluids from a Plain Surface in a Pool, Int. J. Heat Mass Transf., vol. 48, pp. 2407-2419, 2005.

Bashirnezhad, K., Bazri, S., Safaei, M.R., Goodarzi, M., Dahari, M., Mahian, O., Dalkilica, A.S., and Wongwises, S., Viscosity of Nanofluids: A Review of Recent Experimental Studies, Int. Commun. Heat Mass Transf., vol. 73, pp. 114-123, 2016.

Batchelor, G.K., The Effect of Brownian Motion on the Bulk Stress in a Suspension of Spherical Particles, J. Fluid Mech., vol. 83, no. 1, pp. 97-117, 1977.

Bellerová, H., Tseng, A.A., Pohanka, M., and Raudensky, M., Spray Cooling by Solid Jet Nozzles Using Alumina/Water Nanofluids, Int. J. Therm. Sci., vol. 62, pp. 127-137, 2012.

Bellos, E., Tzivanidis, C., and Tsimpoukis, D., Enhancing the Performance of Parabolic Trough Collectors Using Nanofluids and Turbulators, Renew. Sustain. Energy Rev., vol. 91, pp. 358-375, 2018.

Bergles, A.E. and Manglik, R.M., Current Progress and New Development in Enhanced Heat and Mass Transfer, J. Enhanced Heat Transf., vol. 20, pp. 1-15, 2013.

Bergles, A.E., ExHFT for Fourth Generation Heat Transfer Technology, Exp. Thermal Fluid Sci., vol. 26, pp. 335-344, 2002.

Bergles, A.E., Jensen, M.K., Somerscales, E.F.C., and Manglik, R.M., Literature Review of Heat Transfer Enhancement Technology for Heat Exchangers in Gas-Fired Applications, Gas Research Institute, Chicago, IL, Tech. Rep. ACRC TR-105, 1991.

Bergles, A.E., Nirmalan, V., Junkhan, G.H., and Webb, R.L., Bibliography on Augmentation of Convective Heat and Mass Transfer-II, Iowa State University, Ames, IA, Tech. Rep. ISU-ERI-AMES-84221, 1983.

Bergles, A.E., Recent Developments in Enhanced Heat Transfer, Heat Mass Transf., vol. 47, pp. 10011008, 2011.

Bergles, A.E., Techniques to Enhance Heat Transfer, Handbook of Heat Transfer, W.M. Rohsenow, J.P. Hartnett, and Y.I. Cho, Eds., New York, NY: McGraw-Hill, pp. 11.1-11.76, 1998.

Bhuiyan, M.H.U., Saidur, R., Amalina, M.A., and Mostafizur, R.M., Measurement of Latent Heat of Vaporization of Nanofluids Using Calorimetric Technique, J. Therm. Anal. Calorim., vol. 122, pp. 1341-1346, 2015.

Bianco, V., Marchitto, A., Scarpa, F., and Tagliafico, L.A., Computational Fluid Dynamics Modeling of Developing Forced Laminar Convection Flow of $\mathrm{Al}_{2} \mathrm{O}_{3}$-Water Nanofluid in a Two-Dimensional Rectangular Section Channel, J. Enhanced Heat Transf., vol. 25, pp. 387-398, 2018.

Bobbo, S., Colla, L., Barizza, A., Rossi, S., Fedele, L., and Nazionale, C., Characterization of Nanofluids Formed by Fumed $\mathrm{Al}_{2} \mathrm{O}_{3}$ in Water for Geothermal Applications, Int. Compress Eng. Refrig. Air Cond. High Perform. Build. Conf., pp. 1-9, 2016.

Brinkman, H.C., The Viscosity of Concentrated Suspensions and Solutions, J. Chem. Phys., vol. 20, no. 4, p. $571,1952$.

Bruggeman, V.D., Berechnung Verscheidener Physikalischer Konstanten von Heterogenen Substanzen, Annal. Phys., vol. 416, no. 7, pp. 636-664, 1935.

Buongiorno, J., Convective Transport in Nanofluids, J. Heat Transf., vol. 128, pp. 240-250, 2006.

Buongiorno, J., Hu, L.W., Apostolakis, G., Hannink, R., Lucas, T., and Chupin, A., A Feasibility Assessment of the Use of Nanofluids to Enhance the In-Vessel Retention Capability in Light-Water Reactors, 
Nucl. Eng. Des., vol. 239, no. 5, pp. 941-948, 2009.

Buongiorno, J., Hu, L.-W., Kim, S.J., Hannink, R., Truong, B., and Forrest, E., Nanofluids for Enhanced Economics and Safety of Nuclear Reactors: An Evaluation of the Potential Features Issues, and Research Gaps, Nucl. Technol., vol. 162, no. 1, pp. 80-91, 2008.

Cai, Y.M. and Guo, Z., Spectral Monte Carlo Simulation of Collimated Solar Irradiation Transfer in a Water-Filled Prismatic Louver, Appl. Opt., vol. 57, pp. 3021-3030, 2018.

Cai, Y.M. and Guo, Z., Spectral Investigation of Solar Energy Absorption and Light Transmittance in a Water-Filled Prismatic Glass Louver, Sol. Energy, vol. 179, pp. 164-173, 2019.

Cao, Y.D. and Faghri, A., A Review on Micro/Miniature Heat Pipes, J. Enhanced Heat Transf., vol. 24, pp. 473-482, 2017.

Chamra, L.M. and Webb, R.L., A Review on Condensation and Evaporation in Micro-Fin Tubes at Equal Saturation Temperatures, J. Enhanced Heat Transf., vol. 24, pp. 399-409, 2017.

Chang, T.B., Syu, S.C., and Yang, Y.K., Effects of Particle Volume Fraction on Spray Heat Transfer Performance of $\mathrm{Al}_{2} \mathrm{O}_{3}$-Water Nanofluids, Int. J. Heat Mass Transf., vol. 55, pp. 1014-1021, 2012.

Chang, M.H., Liu, H.S., and Tai, C.Y., Preparation of Copper Oxide Nanoparticles and Its Application in Nanofluid, Powder Technol., vol. 207, pp. 378-382, 2011.

Chen, H., Ding, Y., He, Y., and Tan., C., Rheological Behaviour of Ethylene Glycol based Titania Nanofluids, Chem. Phys. Lett., vol. 444, pp. 333-337, 2007.

Chen, L., Xie, H., Li, Y., and Yu, W., Nanofluids Containing Carbon Nanotubes Treated by Mechanochemical Reaction, Thermochim. Acta, vol. 477, nos. 1-2, pp. 21-24, 2008.

Cheng, L.X., Bandarra Filho, E.P., and Thome, J.R., Nanofluid Two-Phase Flow and Thermal Physics: A New Research Frontier of Nanotechnology and Its Challenges, J. Nanosci. Nanotech., vol. 8, pp. 33153332, 2008.

Cheng, W.-L., Zhang, W.W., Chen, H., and Hu, L., Spray Cooling and Flash Evaporation Cooling: The Current Development and Application, Renew. Sustain. Energy Rev., vol. 55, pp. 614-628, 2016.

Chien, R. and Chuang, J., Experimental Microchannel Heat Sink Performance Studies Using Nanofluids, Int. J. Therm. Sci., vol. 46, pp. 57-66, 2007.

Chitra, S.R., Sendhilnathan, S., and Suresh, S., Investigation of Heat Transfer Characteristics of Mgmnni/Diw-Based Nanofluids for Quenching in Industrial Applications, J. Enhanced Heat Transf., vol. 22, pp. 1-28, 2015.

Choi, S.U.S. and Eastman, J.A., Enhancing Thermal Conductivity of Fluids with Nanoparticles, International Mechanical Engineering Congress and Exhibition, San Francisco, USA, November 12-17, 1995.

Choi, S.U.S., Zhang, Z.G., Yu, W., Lockwood, F.E., and Grulke, E.A., Anomalous Thermal Conductivity Enhancement in Nanotube Suspensions, Appl. Phys. Lett., vol. 79, p. 2252, 2001.

Chon, C.H., Kihm, K.D., Lee, S.P., and Choi, S.U., Empirical Correlation Finding the Role of Temperature and Particle Size for Nanofluid $\left(\mathrm{Al}_{2} \mathrm{O}_{3}\right)$ Thermal Conductivity Enhancement, Appl. Phys. Lett., vol. 87, p. $153107,2005$.

Chougule, S.S. and Sahu, S.K., Comparative Study on Heat Transfer Enhancement of Low Volume Concentration of $\mathrm{Al}_{2} \mathrm{O}_{3}$-Water and Carbon Nano-Tube-Water Nano-Fluids in Transition Regime Using Helical Screw Tape Inserts, Exp. Heat Transf., vol. 29, pp. 1-20, 2016.

Corcione, M., Empirical Correlating Equations for Predicting the Effective Thermal Conductivity and Dynamic Viscosity of Nanofluids, Energy Convers. Manage., vol. 52, no. 1, pp. 789-793, 2011.

Das, S.K., Choi, S.U.S., Yu, W., and Pradeep, T., Nanofluids: Science and Technology, NJ: Wiley, Hoboken, 2007.

Das, S.K., Putra, N., and Roetzel, W., Pool Boiling Characteristics of Nano-Fluids, Int. J. Heat Mass Transf., vol. 46, pp. 851-862, 2003b.

Volume 27, Issue 1, 2020 
Das, S.K., Putra, N., Thiesen, P., and Roetzel, W., Temperature Dependence of Thermal Conductivity Enhancement for Nanofluids, J. Heat Transf., vol. 125, no. 4, pp. 567-574, 2003 a.

Dehghani, M.S., Toghraie, D., and Mehmandoust, B., Mixed-Convection Nanofluid Flow through a Grooved Channel with Internal Heat Generating Solid Cylinders in the Presence of an Applied Magnetic Field, Heat Transf. Res., vol. 50, pp. 287-309, 2019.

Diaz, R. and Guo, Z., Enhanced Conduction and Pool Boiling Heat Transfer on Single-Layer GrapheneCoated Substrates, J. Enhanced Heat Transf., vol. 26, pp. 127-143, 2019.

Diglio, G., Roselli, C., Sasso, M., and Jawali, C.U., Borehole Heat Exchanger with Nanofluids as Heat Carrier, Geothermics, vol. 72, pp. 112-123, 2018.

Ding, Y., Alias, H., Wen, D., and Williams, R.A., Heat Transfer of Aqueous Suspensions of Carbon Nanotubes (CNT Nanofluids), Int. J. Heat Mass Transf., vol. 49, nos. 1-2, pp. 240-250, 2006.

Ding, Y. and Wen, D.S., Particle Migration in a Flow of Nanoparticle Suspensions, Powder Technol., vol. 149, pp. 84-92, 2005.

Ding, Y., Chen, H., Wang, L., Yang, C.Y., He, Y., Yang, W., Lee, W.P., Zhang, L., and Huo, R., Heat Transfer Intensification Using Nanofluids, KONA Powder Particle J., vol. 25, pp. 23-38, 2007.

Dong, F., Cao, T., Hou, L., and Ni, J., Optimization Study of Artificial Cavities on Subcooled Flow Boiling Performance of Water in a Horizontal Simulated Engine Cooling Passage, J. Enhanced Heat Transf., vol. 26, pp. 37-57, 2019.

Donghyun, S. and Debjyoti, B., Enhancement of Specific Heat Capacity of High-Temperature SilicaNanofluids Synthesized in Alkali Chloride Salt Eutectics for Solar Thermal-Energy Storage Applications, Int. J. Heat Mass Transf., vol. 54, pp. 1064-1070, 2011.

Duangthongsuk, W. and Wongwises, S., An Experimental Study on the Heat Transfer Performance and Pressure Drop of $\mathrm{TiO}_{2}$-Water Nanofluids Flowing under a Turbulent Flow Regime, Int. J. Heat Mass Transf., vol. 53, pp. 334-344, 2010.

Eastman, J.A., Choi, S.U.S., Li, S., Yu, W., and Thompson, L.J., Anomalously Increased Effective Thermal Conductivities of Ethylene Glycol-Based Nanofluids Containing Copper Nanoparticles, Appl. Phys. Lett., vol. 78, p. 718, 2001.

Einstein, A., A New Determination of Molecular Dimensions, Ann. Phys., vol. 324, no. 2, pp. 289-306, 1906.

Elias, M.M., Mahbubul, I.M., Saidur, R., Sohel, M.R., Shahrul, I.M., Khaleduzzaman, S.S., and Sadeghipour, S., Experimental Investigation on the Thermo-Physical Properties of $\mathrm{Al}_{2} \mathrm{O}_{3}$ Nanoparticles Suspended in Car Radiator Coolant, Int. Commun. Heat Mass Transf., vol. 54, pp. 48-53, 2014.

Elmir, M., Mehdaoui, R., and Mojtabi, A., Numerical Simulation of Cooling a Solar Cell by Forced Convection in the Presence of a Nanofluid, Energy Procedia, vol. 18, pp. 594-603, 2012.

Esfe, M.H., Ahangar, M.R.H., Rejvani, M., Toghraie, D., and Hajmohammad, M.H., Designing an Artificial Neural Network to Predict Dynamic Viscosity of Aqueous Nanofluid of $\mathrm{TiO}_{2}$ Using Experimental Data, Int. Commun. Heat Mass Transf., vol. 75, pp. 192-196, 2016.

Esfe, M.H. and Saedodin, S., An Experimental Investigation and New Correlation of Viscosity of ZnOEG Nanofluid at Various Temperatures and Different Solid Volume Fractions, Exp. Therm. Fluid Sci., vol. 55, pp. 1-5, 2014.

Esfe, M.H., Arani, A.A.A., and Esfandeh, S., Experimental Study on Rheological Behavior of Monograde Heavy-Duty Engine Oil Containing CNTs and Oxide Nanoparticles with Focus on Viscosity Analysis, J. Mol. Liq., vol. 272, pp. 319-329, 2018.

Esfe, M.H., Karimipour, A., Yan, W.M., Akbari, M., Safaei, M.R., and Dahari, M., Experimental Study on Thermal Conductivity of Ethylene Glycol-Based Nanofluids Containing $\mathrm{Al}_{2} \mathrm{O}_{3}$ Nanoparticles, Int. J. Heat Mass Transf., vol. 88, pp. 728-734, 2015a. 
Esfe, M.H., Raki, H.R., Emami, M.R.S., and Afrand, M., Viscosity and Rheological Properties of Antifreeze based Nanofluid Containing Hybrid Nano-Powders of MWCNTs and $\mathrm{TiO}_{2}$ under Different Temperature Conditions, Powder Technol., vol. 342, pp. 808-816, 2019.

Esfe, M.H., Saedodin, S., Bahiraei, M., Toghraie, D,. Mahian, O., and Wongwises, S., Thermal Conductivity Modeling of MgO/EG Nanofluids Using Experimental Data and Artificial Neural Network, J. Therm. Anal. Calorim., vol. 118, pp. 287-294, 2014.

Esfe, M.H., Saedodin, S., Sina, N., Afrand, M., and Rostami, S., Designing an Artificial Neural Network to Predict Thermal Conductivity and Dynamic Viscosity of Ferromagnetic Nanofluid, Int. Commun. Heat Mass Transf., vol. 68, pp. 50-57, 2015b.

Evans, W., Fish, J., and Keblinski, P., Role of Brownian Motion Hydrodynamics on Nanofluid Thermal Conductivity, Appl. Phys. Lett., vol. 88, p. 093116, 2006.

Fard, A.M., Mirjalily, S.A.A., and Ahrar, A.J., Influence of Carbon Nanotubes on Pressure Drop and Heat Transfer Rate of Water in Helically Coiled Tubes, J. Enhanced Heat Transf., vol. 26, pp. 217-233, 2018.

Fedele, L., Colla, L., Bobbo, S., Barison, S., and Agresti, F., Experimental Stability Analysis of Different Water-Based Nanofluids, Nano. Res. Lett., vol. 6, p. 300, 2011.

Ganvir, R.B., Wale, P.V., and Kriplani, V.M., Heat Transfer Characteristics in Nanofluid-A Review, Renew. Sustain. Energy Rev., vol. 75, pp. 451-460, 2017.

Gardellini, A., Fasano, M., Bigdeli, M.B., Chiavazzo, E., and Asinari, P., Thermal Transport Phenomena in Nanoparticle Suspensions, J. Phys.: Cond. Matt., vol. 28, p. 483003, 2016.

Ghaderian, J. and Sidik, N.A.C., An Experimental Investigation on the Effect of $\mathrm{Al}_{2} \mathrm{O}_{3}$ /Distilled Water Nanofluid on the Energy Efficiency of Evacuated Tube Solar Collector, Int. J. Heat Mass Transf., vol. 108, pp. 972-987, 2017.

Gnanadason, M.K., Kumar, P.S., Rajakumar, S., and Yousuf, M.H.S., Effect of Nanofluids in a Vacuum Single Basin Solar Still, Int. J. Sci. Eng. Res., vol. 3, pp. 303-309, 2012.

Godson, L., Deepak, K., Enoch, C., Jefferson, B., and Raja, B., Heat Transfer Characteristics of Silver/Water Nanofluids in a Shell and Tube Heat Exchanger, Arch. Civil Mech. Eng., vol. 14, no. 3, pp. 489-496, 2014.

Godson, L., Raja, B., Lal, D.M., and Wongwises, S., Enhancement of Heat Transfer Using Nanofluids-An Overview, Renew. Sustain. Energy Rev., vol. 14, pp. 629-641, 2010.

Graham, A.L., On the Viscosity of Suspensions of Solid Spheres, Appl. Sci. Res., vol. 37, nos. 3-4, pp. 275$286,1981$.

Guo, W.W., Li, G.N., Zheng, Y., and Dong, C., Measurement of the Thermal Conductivity of $\mathrm{SiO}_{2 b v}$ Nanofluids with an Optimized Transient Hot Wire Method, Thermochim. Acta, vol. 661, pp. 84-97, 2018.

Guo, Z., Heat Transfer Enhancement-A Brief Review of 2018 Literature, J. Enhanced Heat Transf., vol. 26, pp. 429-449, 2019.

Haddad, Z., Abid, C., Mohamad, A.A., Rahli, O., and Bawazer, S., Natural Convection of Silica-Water Nanofluids based on Experimental Measured Thermophysical Properties: Critical Analysis, Heat Mass Transf., vol. 52, pp. 1649-1663, 2016.

Haddad, Z., Abu-Nada, E., Oztop, H.F., and Mataoui, A., Natural Convection in Nanofluids: Are the Thermophoresis and Brownian Motion Effects Significant in Nanofluid Heat Transfer Enhancement?, Int. J. Therm. Sci., vol. 57, pp. 152-162, 2012.

Hamid, K.A., Azmi, W.H., Nabil, M.F., Mamat, R., and Sharma, K.V., Experimental Investigation of Thermal Conductivity and Dynamic Viscosity on Nanoparticle Mixture Ratios of $\mathrm{TiO}_{2}-\mathrm{SiO}_{2} \mathrm{Nanofluids}$ Int . J. Heat Mass Transf., vol. 116, pp. 1143-1152, 2018.

Hamilton, R.L. and Crosser, O.K., Thermal Conductivity of Heterogeneous Two Component Systems, Ind. Eng. Chem. Fundam., vol. 1, no. 3, pp. 187-191, 1962.

Volume 27, Issue 1, 2020 
Han, H., Zhang, Y., Wang, N., Samani, M.K., Ni, Y., Mijbil, Z.Y., Edwards, M., Xiong, S., Sääskilahti, K., Murugesan, M., and Fu, Y., Functionalization Mediates Heat Transport in Graphene Nanoflakes, Nature Commun., vol. 7, p. 11281, 2016.

Han, T.C., Bai, X., Thong, J.T., Li, B., and Qiu, C.-W., Full Control and Manipulation of Heat Signatures: Cloaking, Camouflage and Thermal Metamaterials, Adv. Mater., vol. 26, pp. 1731-1734, 2014.

Hassan, M., Marin, M., Ellahi, R., and Alamri, S.Z., Exploration of Convective Heat Transfer and Flow Characteristics Synthesis by $\mathrm{Cu}-\mathrm{Ag}$ /Water Hybrid-Nanofluids, Heat Transf. Res., vol. 49, no. 18, pp. 1837-1848, 2018.

Hayat, T., Qayyum, S., Alsaedi, A., and Shafiq, A., Theoretical Aspects of Brownian Motion and Thermophoresis on Nonlinear Convective Flow of Magneto Carreau Nanofluid with Newtonian Conditions, Results Phys., vol. 10, pp. 521-528, 2018.

He, Q., Zeng, S., and Wang, S., Experimental Investigation on the Efficiency of Flat-Plate Solar Collectors with Nanofluids, Appl. Therm. Eng., vol. 88, pp. 165-171, 2015.

He, X., Park, E.Y.H., Fowler, A., Yarmush, M.L., and Toner, M., Vitrification by Ultra-Fast Cooling at a Low Concentration of Cryoprotectants in a Quartz Micro-Capillary: A Study Using Murine Embryonic Stem Cells, Cryobiology, vol. 56, no. 3, pp. 223-232, 2008.

Hemmati-Sarapardeh, A., Varamesh, A., Husein, M.M., and Karan, K., On the Evaluation of the Viscosity of Nanofluid Systems: Modeling and Data Assessment, Renew. Sustain. Energy Rev., vol. 81, pp. 313329, 2018.

Hentschke, R., On the Specific Heat Capacity Enhancement in Nanofluids, Nanoscale Res. Lett., vol. 11, p. 88, 2016.

Hjerrild, N.E., Crisostomo, F., Chin, R.L., Scott, J.A., Amal, R., and Taylor, R.A., Experimental Results for Tailored Spectrum Splitting Metallic Nanofluids for C-Si, Gaas, and Ge Solar Cells, IEEE J. Photovoltaics, vol. 9, pp. 385-390, 2019.

Hojjat, M., Etemad, S.Gh., Bagheri, R., and Thibault, J., Thermal Conductivity of Non-Newtonian Nanofluids: Experimental Data and Modeling Using Neural Network, Int. J. Heat Mass Transf., vol. 54, pp. 1017-1023, 2011.

Hsieh, S.S., Leu, H.Y., and Liu, H.H., Spray Cooling Characteristics of Nanofluids for Electronic Power Devices, Nanoscale Res. Lett., vol. 10, p. 139, 2015.

Huang, K. and Deng, X., Enhanced Heat and Mass Transfer of Falling Liquid Films in Vertical Tubes, $J$. Enhanced Heat Transf., vol. 25, no. 1, pp. 79-96, 2018.

Hui, P.M., Zhang, X., Markworth, A.J., and Stroud, D., Thermal Conductivity of Graded Composites: Numerical Simulations and an Effective Medium Approximation, J. Mater. Sci., vol. 34, no. 22, pp. 5497$5503,1999$.

Hung, T.-C. and Yan, W.-M., Enhancement of Thermal Performance in Double-Layered Microchannel Heat Sink with Nanofluids, Int. J. Heat Mass Transf., vol. 55, pp. 3225-3238, 2012.

Hussein, A.M., Sharma, K.V., Bakar, R.A., and Kadirgama, K., A Review of Forced Convection Heat Transfer Enhancement and Hydrodynamic Characteristics of a Nanofluid, Renew. Sustain. Energy Rev., vol. 29, pp. 734-743, 2014.

Hwang, Y., Lee, J.K., Lee, C.H., Jung, Y.M., Cheong, S.I., Lee, C.G., Ku, B.C., and Jang, S.P., Stability and Thermal Conductivity Characteristics of Nanofluids, Thermochim. Acta, vol. 455, nos. 1-2, pp. 70-74, 2007.

Iasiello, M., Cunsolo, S., Bianco, N., Chiu, W.K., and Naso, V., Fully Developed Convection Heat Transfer in Open-Cell Foams, J. Enhanced Heat Transf., vol. 25, nos. 4-5, pp. 333-346, 2018.

Ibrahim, N.I., Al-Sulaiman, F.A., Rahman, S., Yilbas, B.S., and Sahin, A.Z., Heat Transfer Enhancement of Phase Change Materials for Thermal Energy Storage Applications: A Critical Review, Renew. Sustain. Energy Rev., vol. 74, pp. 26-50, 2017. 
Ilyas, S.U., Pendyala, R., and Marneni, N., Preparation, Sedimentation, and Agglomeration of Nanofluids, Chem. Eng. Technol., vol. 37, no. 12, pp. 2011-2021, 2014.

Ilyas, S.U., Pendyala, R., and Narahari, M., Stability and Thermal Analysis of MWCNT-Thermal Oil-Based Nanofluids, Colloids Surf. A, vol. 527, pp. 11-22, 2017.

Inoue, T., Teruya, Y., and Monde, M., Enhancement of Pool Boiling Heat Transfer in Water and Ethanol/Water Mixtures with Surface-Active Agent, Int. J. Heat Mass Transf., vol. 47, pp. 5555-5563, 2004.

Ismael, M.A., Armaghani, T., and Chamkha, A.J., Mixed Convection and Entropy Generation in a LidDriven Cavity Filled with a Hybrid Nanofluid and Heated by a Triangular Solid, Heat Transf. Res., vol. 49, no. 17, pp. 1645-1665, 2018.

Jamshidi, N. and Mosaffa, A., Investigating the Effects of Geometric Parameters on Finned Conical Helical Geothermal Heat Exchanger and Its Energy Extraction Capability, Geothermics, vol. 76, pp. 177-189, 2018.

Jang, S.P. and Choi, S.U.S., Cooling Performance of a Microchannel Heat Sink with Nanofluids, Appl. Therm. Eng., vol. 26, pp. 2457-2463, 2006.

Jang, S.P. and Choi, S.U.S., Role of Brownian Motion in the Enhanced Thermal Conductivity of Nanofluids, Appl. Phys. Lett., vol. 84, no. 21, pp. 4316-4318, 2004.

Jung, S. and Banerjee, D.J., A Simple Analytical Model for Specific Heat of Nanofluid with Tube Shaped and Disc Shaped Nanoparticles, ASME/JSME 2011 8th Thermal Engineering Joint Conf., p. T30023, 2011.

Kakac, S. and Pramuanjaroenkij, A., Review of Convective Heat Transfer Enhancement with Nanofluids, Int. J. Heat Mass Transf., vol. 52, pp. 3187-3196, 2009.

Kakac, S. and Pramuanjaroenkij, A., Single-Phase and Two-Phase Treatments of Convective Heat Transfer Enhancement with Nanofluids-A State-of-the-Art Review, Int. J. Therm. Sci., vol. 100, pp. 75-97, 2016.

Karami, M. and Akhavan-Behabadi, M.A., Thermo-Optical Properties of Copper Oxide Nanofluids for Direct Absorption of Solar Radiation, Sol. Energy Mater. Sol. Cells, vol. 144, pp. 136-142, 2016.

Kasaeian, A., Azarian, R.D., Mahian, O., Kolsi, L., Chamkha, A.J., Wongwises, S., and Pop, I., Nanofluid Flow and Heat Transfer in Porous Media: A Review of the Latest Developments, Int. J. Heat Mass Transf., vol. 107, pp. 778-791, 2017.

Kaya, H., Ekiciler, R., and Arslan, K., Entropy Generation Analysis of Forced Convection Flow in a Semicircular Microchannel with $\mathrm{TiO}_{2} /$ Water Nanofluid, Heat Transf. Res., vol. 50, no. 4, pp. 335-348, 2019.

Keblinski, P., Eastman, J.A., and Cahill, D.G., Nanofluids for Thermal Transport, Mater. Today, vol. 8, pp. 36-44, 2005.

Keblinski, P., Nanofluids for Enhanced Thermal Transport: Understanding and Controversy, Symposium II Nanoscale Heat Transport-From Fundamentals to Devices, Materials Research Soc. Spring Symp., San Francisco, USA, pp. 10-13, 2007.

Keblinski, P., Phillpot, S.R., Choi, S.U.S., and Eastman, J.A., Mechanisms of Heat Flow in Suspensions of Nano-Sized Particles (Nanofluids), Int. J. Heat Mass Transf., vol. 45, pp. 855-863, 2002.

Khademi, R., Mohebbi-Kalhori, D., and Razminia, A., Thermal Analysis of a Tumorous Vascular Tissue during Pulsed-Cryosurgery and Nano-Hyperthermia Therapy: Finite Element Approach, Int. J. Heat Mass Transf., vol. 137, pp. 1001-1013, 2019.

Khalil, W., Mohamed, A., Bayoumi, M., and Osman, T.A., Thermal and Rheological Properties of Industrial Mineral Gear Oil and Paraffinic Oil/CNTs Nanolubricants, Iranian J. Sci. Tachnol., vol. 42, no. 4, pp. 355-361, 2018.

Khanafer, K., Tavakkoli, F., Vafai, K., and AlAmiri, A., A Critical Investigation of the Anomalous Behavior of Molten Salt-Based Nanofluids, Int. Commun. Heat Mass Transf., vol. 69, pp. 51-58, 2015.

Volume 27, Issue 1, 2020 
Khanlari, A., Sözen, A., Variyenli, H.I., and Metin, G.Ü.R.Ü., Comparison between Heat Transfer Characteristics of $\mathrm{TiO}_{2}$ /Deionized Water and Kaolin/Deionized Water Nanofluids in the Plate Heat Exchanger, Heat Transf. Res., vol. 50, no. 5, pp. 435-450, 2019.

Khodadadi, H., Toghraie, D., and Karimipour, A., Effects of Nanoparticles to Present a Statistical Model for the Viscosity of MgO-Water Nanofluid, Powder Technol., vol. 342, pp. 166-180, 2019.

Khoshvaght-Aliabadi, M., and Sahamiyan, M., Performance of Nanofluid Flow in Corrugated Minichannels Heat Sink (CMCHS), Energy Convers. Manage., vol. 108, pp. 297-308, 2016.

Khoshvaght-Aliabadi, M., Hassani, S.M., Mazloumi, S.H., and Nekoei, M., Effects of Nooks Configuration on Hydrothermal Performance of Zigzag Channels for Nanofluid-Cooled Microelectronic Heat Sink, Microelectron. Reliab., vol. 79, pp. 153-165, 2017.

Khudhair, A.M. and Farid, M.M., A Review on Energy Conservation in Building Applications with Thermal Storage by Latent Heat Using Phase Change Materials, Energy Convers. Manage., vol. 45, pp. 263$275,2004$.

Kianifar, A., Heris, S.Z., and Mahian, O., Exergy and Economic Analysis of a Pyramid-Shaped Solar Water Purification System: Active and Passive Cases, Energy, vol. 38, pp. 31-36, 2012.

Kim, H.J., Bang, I.C., and Onoe, J., Characteristic Stability of Bare Au-Water Nanofluids Fabricated by Pulsed Laser Ablation in Liquids, Opt. Lasers Eng., vol. 47, no. 5, pp. 532-538, 2009.

Kim, H., Jeong, J., and Kang, Y.T., Heat and Mass Transfer Enhancement for Falling Film Absorption Process by $\mathrm{SiO}_{2}$ Binary Nanofluids, Int. J. Refrig., vol. 35, pp. 645-651, 2012.

Kim, N.-H., Steam Condensation Enhancement and Fouling in Titanium Corrugated Tubes, J. Enhanced Heat Transf., vol. 26, pp. 59-74, 2019.

Kim, S.J., Bang, I.C., Buongiorno J., and Hu, L.W., Surface Wettability Change during Pool Boiling of Nanofluids and Its Effect on Critical Heat Flux, Int. J. Heat Mass Transf., vol. 50, nos. 19-20, pp. 41054116, 2007.

Koo, J. and Kleinstreuer, C., A New Thermal Conductivity Model for Nanofluids, J. Nanopart. Res., vol. 6, pp. 577-588, 2004.

Koo, J. and Kleinstreuer, C., Impact Analysis of Nanoparticle Motion Mechanisms on the Thermal Conductivity of Nanofluids, Int. Commun. Heat Mass Transf., vol. 32, no. 9, pp. 1111-1118, 2005.

Krieger, I.M. and Dougherty, T.J., A Mechanism for Non-Newtonian Flow in Suspensions of Rigid Spheres, Trans. Soc. Rheol., vol. 3, pp. 137-152, 1959.

Krishnakumar, T.S., Sheeba, A., Mahesh, V., and Prakash, M.J., Heat Transfer Studies on Ethylene Glycol/Water Nanofluid Containing $\mathrm{TiO}_{2}$ Nanoparticles, Int. J. Refrig., vol. 102, pp. 55-61, 2019.

Kulkarni, D.P., Das, D.K., and Vajjha, R.S., Application of Nanofluids in Heating Buildings and Reducing Pollution, Appl. Energy, vol. 86, no. 12, pp. 2566-2573, 2009.

Kulkarni, D.P., Vajjha, R.S., Das, D.K., and Oliva, D., Application of Aluminum Oxide Nanofluids in Diesel Electric Generator as Jacket Water Coolant, Appl. Therm. Eng., vol. 28, pp. 1774-1781, 2008.

Kumar, N.R., Bhramara, P., Addis, B.M., Sundar, L.S., Singh, M.K., and Sousa, A.C., Heat Transfer, Friction Factor and Effectiveness Analysis of $\mathrm{Fe}_{3} \mathrm{O}_{4}$ /Water Nanofluid Flow in a Double Pipe Heat Exchanger with Return Bend, Int. Commun. Heat Mass Transf., vol. 81, pp. 155-163, 2017.

Kumar, N., Sonawane, S.S., and Sonawane, S.H., Experimental Study of Thermal Conductivity, Heat Transfer and Friction Factor of $\mathrm{Al}_{2} \mathrm{O}_{3}$ based Nanofluid, Int. Commun. Heat Mass Transf., vol. 90, pp. 1-10, 2018 b.

Kumar, S., Dinesha, P., Gaggad, A., and Mehrotra, K., Performance of an Automotive Car Radiator Operated with Nanofluid-Based Coolant, Heat Transf. Res., vol. 49, no. 16, $2018 \mathrm{a}$.

Kumar, S., Kothiyal, A.D., Bisht, M.S., and Kumar, A., Effect of Nanofluid Flow and Protrusion Ribs on Performance in Square Channels: An Experimental Investigation, J. Enhanced Heat Transf., vol. 26, 
no. 1, pp. 75-100, 2019.

Kuzma-Kichta, Y. and Leontiev, A., Choice and Justification of the Heat Transfer Intensification Methods, J. Enhanced Heat Transf., vol. 25, pp. 465-564, 2018.

Laachachi, A., Ferriol, M., Cochez, M., Lopez Cuesta, J.M., and Ruch, D., A Comparison of the Role of Boehmite $(\mathrm{AlOOH})$ and Alumina $\left(\mathrm{Al}_{2} \mathrm{O}_{3}\right)$ in the Thermal Stability and Flammability of poly(methyl methacrylate), Polym. Degrad. Stab., vol. 94, pp. 1373-1378, 2009.

Lee, J. and Mudawar, I., Assesment of the Effectiveness of Nanofluids for Single Phase and Two-Phase Heat Transfer in Microchannels, Int. J. Heat Mass Transf., vol. 50, pp. 452-463, 2007.

Lee, J.H., Han, K., and Koo, J., A Novel Method to Evaluate Dispersion Stability of Nanofluids, Int. J. Heat Mass Transf., vol. 70, pp. 421-429, 2014.

Lee, S., Taylor, R.A., Dai, L., Prasher, R., and Phelan, P.E., The Effective Latent Heat of Aqueous Nanofluids, Mater. Res. Express, vol. 2, p. 065004, 2015.

Lemes, M.A., Rabelo, D., and De Oliveira, A.E., A Novel Method to Evaluate Nanofluid Stability Using Multivariate Image Analysis, Anal. Methods, vol. 9, no. 39, pp. 5826-5833, 2017.

Leong, K.C., Yang, C., and Murshed, S.M.S., A Model for the Thermal Conductivity of Nanofluids-The Effect of Interfacial Layer, J. Nanopart. Res., vol. 8, pp. 245-254, 2006.

Li, C.H. and Peterson, G.P., Experimental Investigation of Temperature and Volume Fraction Variations on the Effective Thermal Conductivity of Nanoparticle Suspensions (Nanofluids), J. Appl. Phys., vol. 99, no. 8, p. 084314, 2006.

Li, D. and Kaner, R.B., Processable Stabilizer-Free Polyaniline Nanofiber Aqueous Colloids, Chem. Commun., vol. 14, no. 26, pp. 3286-3288, 2005.

Li, M., Chen, M., and Wu, Z., Enhancement in Thermal Property and Mechanical Property of Phase Change Microcapsule with Modified Carbon Nanotube, Appl. Energy, vol. 127, pp. 166-171, 2014.

Li, X., Zhu, D., and Wang, X., Evaluation on Dispersion Behavior of the Aqueous Copper NanoSuspensions, J. Colloid Interface Sci., vol. 310, no. 2, pp. 456-463, 2007.

Li, Z.X., Sheikholeslami, M., and Bhatti, M.M., Effect of Lorentz Forces on Nanofluid Flow inside a Porous Enclosure with a Moving Wall Using Various Shapes of CuO Nanoparticles, Heat Transf. Res., vol. 50, no. 7, pp. 697-715, 2019.

Ligrani, P., McInturff, P., Suzuki, M., and Nakamata, C., Winglet-Pair Target Surface Roughness Influences on Impingement Jet Array Heat Transfer, J. Enhanced Heat Transf., vol. 26, pp. 15-35, 2019.

Lin, Y.-H., Kang, S.-W., and Chen, H.-L., Effect of Silver Nano-Fluid on Pulsating Heat Pipe Thermal Performance, Appl. Therm. Eng., vol. 28, nos. 11-12, pp. 1312-1317, 2008.

Lin, Y., Jia, Y., Alva, G., and Fang, G., Review on Thermal Conductivity Enhancement, Thermal Properties and Applications of Phase Change Materials in Thermal Energy Storage, Renew. Sustain. Energy Rev., vol. 82, pp. 2730-2742, 2018.

Liu, J. and Guo, Z., Unconventional Energy: Seeking the Ways to Innovate Energy Science and Technology, Frontiers Energy, vol. 12, no. 2, pp. 195-197, 2018

Liu, M., Lin, M.C., and Wang, C., Enhancements of Thermal Conductivities with $\mathrm{Cu}, \mathrm{CuO}$, and Carbon Nanotube Nanofluids and Application of MWNT/Water Nanofluid on a Water Chiller System, Nano. Res. Let., vol. 6, no. 1, p. 297, 2011.

Liu, Z., Yu, Z., Yang, T., Qin, D., Li, S., Zhang, G., Haghighat, F., and Joybari, M.M., A Review on MacroEncapsulated Phase Change Material for Building Envelope Applications, Build. Environ., vol. 144, pp. 281-294, 2018.

Longo, G.A., Zilio, C., Ceseracciu, E., and Reggiani, M., Application of Artificial Neural Network (ANN) for the Prediction of Thermal Conductivity of Oxide-Water Nanofluids, Nano Energy, vol. 1, pp. 290296, 2012.

Volume 27, Issue 1, 2020 
Luo, Z., Wang, C., Wei, W., Xiao, G., and Ni, M., Performance Improvement of a Nanofluid Solar Collector based on Direct Absorption Collection (DAC) Concepts, Int. J. Heat Mass Transf., vol. 75, pp. 262-271, 2014.

Ma, H.B., Wilson, C., and Borgmeyer, B., Effect of Nanofluid on the Heat Transport Capability in an Oscillating Heat Pipe, Appl. Phys. Lett., vol. 88, p. 143116, 2006 a.

Ma, H.B., Wilson, C., Yu, Q., Park, K., Choi, S.U.S., and Tirumala, M., An Experimental Investigation of Heat Transport Capability in a Nanofluid Oscillating Heat Pipe, J. Heat Transf.. vol. 128, no. 11, pp. 1213-1216, 2006b.

Mageshbabu, D., Kabeel, A.E., Sathyamurthy, R., El-Agouz, S.A., Chamkha, A.J., Girija, M.S., and Madhu, B., Enhancing the Thermal Performance of a Micro Finned Tube with $\mathrm{TiO}_{2}$-Water Nanofluids Using Twisted Tape Inserts, Heat Transf. Res., vol. 50, no. 9, pp. 851-863, 2019.

Mahbubul, I.M., Elcioglu, E.B., Saidur, R., and Amalina, M.A., Optimization of Ultrasonication Period for Better Dispersion and Stability of $\mathrm{TiO}_{2}-$ Water Nanofluid, Ultrason. Sonochem., vol. 37, pp. 360-367, 2017.

Mahian, O., Kianifar, A., Heris, S.Z., and Wongwises, S., Natural Convection of Silica Nanofluids in Square and Triangular Enclosures: Theoretical and Experimental Study, Int. J. Heat Mass Transf., vol. 99, pp. 792-804, 2016.

Mahian, O., Kianifar, A., Heris, S.Z., Wen, D., Sahin, A.Z., and Wongwises, S., Nanofluids Effects on the Evaporation Rate in a Solar Still Equipped with a Heat Exchanger, Nano Energy, vol. 36, pp. 134-155, 2017.

Maiga, S.E.B., Nguyen, C.T., Galanis, N., and Roy, G., Heat Transfer Behaviours of Nanofluids in a Uniformly Heated Tube, Superlattices Microst., vol. 35, nos. 3-6, pp. 543-557, 2004.

Maiga, S.E.B., Nguyen, C.T., Galanis, N., Roy, G., Mare, T., and Coqueux, M., Heat Transfer Enhancement in Turbulent Tube Flow Using $\mathrm{Al}_{2} \mathrm{O}_{3}$ Nanoparticles Suspension, Int. J. Numer. Methods Heat Fluid Flow, vol. 16, pp. 275-292, 2006.

Maiga, S.E.B., Palm, S.J., Nguyen, C.T., Roy, G., and Galanis, N., Heat Transfer Enhancement by Using Nanofluids in Forced Convection Flows, Int. J. Heat Fluid Flow, vol. 26, no. 4, pp. 530-546, 2005.

Manoj, U., Mishra, P.C., Sahoo, A.K., and Subhashree, P., Experimental Investigation of Bio-Oil based Nanofluid Spray Cooling during AISI 316 SS Turning, Advances in Interdisciplinary Engineering, M. Kumar, R. Pandey, and V. Kumar, Eds., Singapore: Springer, 2019.

Manuchehrabadi, N., Gao, Z., Zhang, J.J., Ring, H.L., Shao, Q., Liu, F., McDermott, M., Fok, A., Rabin, Y., Brockbank, K.G., and Garwood, M., Improved Tissue Cryopreservation Using Inductive Heating of Magnetic Nanoparticles, Sci. Trans. Med., vol. 9, no. 379, p. eaah4586, 2017.

Martínez, V.A., Vasco, D.A., and García-Herrera, C.M., Transient Measurement of the Thermal Conductivity as a Tool for the Evaluation of the Stability of Nanofluids Subjected to a Pressure Treatment, Int. Commun. Heat Mass Transf., vol. 91, pp. 234-238, 2018.

Masoumi, N., Sohrabi, N., and Behzadmehr, A., A New Model for Calculating the Effective Viscosity of Nanofluids, J. Phys. D, vol. 42, no. 5, p. 055501, 2009.

Matysiak, L. and Platek, R., Analytical, Numerical, and Experimental Study of a Robot Controller with a Forced Cooling System, Heat Transf. Res., vol. 50, no. 2, pp. 195-216, 2019.

Maxwell, J.C., A Treatise on Electricity and Magnetism, London, UK: Oxford University Press, 1873.

Mehrali, M., Sadeghinezhad, E., Rosen, M.A., Akhiani, A.R., Latibari, S.T., Mehrali, M., and Metselaar, H.S.C., Heat Transfer and Entropy Generation for Laminar Forced Convection Flow of Graphene Nanoplatelets Nanofluids in a Horizontal Tube, Int. Commun. Heat Mass Transf., vol. 66, pp. 23-31, 2015.

Mesgari, S., Hjerrild, N., Arandiyan, H., and Taylor, R.A., Carbon Nanotube Heat Transfer Fluids for Solar 
Radiant Heating of Buildings, Energy Build., vol. 175, pp. 11-16, 2018.

Meybodi, M.K., Daryasafar, A., Koochi, M.M., Moghadasi, J., Meybodi, R.B., and Ghahfarokhi, A.K., A Novel Correlation Approach for Viscosity Prediction of Water based Nanofluids of $\mathrm{Al}_{2} \mathrm{O}_{3}, \mathrm{TiO}_{2}, \mathrm{SiO}_{2}$, and $\mathrm{CuO}$, J. Taiwan Inst. Chem. Eng., vol. 58, pp. 19-27, 2016.

Michael, J.J. and Iniyan, S., Performance of Copper Oxide/Water Nanofluid in a Flat Plate Solar Water Heater under Natural and Forced Circulations, Energy Convers. Manage., vol. 95, pp. 160-169, 2015.

Missana, T. and Adell, A., On the Applicability of DLVO Theory to the Prediction of Clay Colloids Stability, J. Colloid Interface Sci., vol. 230, no. 1, pp. 150-156, 2000.

Mohammadi, M., Dadvar, M., and Dabir, B., $\mathrm{TiO}_{2} / \mathrm{SiO}_{2}$ Nanofluids as Novel Inhibitors for the Stability of Asphaltene Particles in Crude Oil: Mechanistic Understanding, Screening, Modeling, and Optimization, J. Mol. Liq., vol. 238, pp. 326-340, 2017.

Moldoveanu, G.M. and Minea, A.A., Specific Heat Experimental Tests of Simple and Hybrid Oxide-Water Nanofluids: Proposing New Correlation, J. Mol. Liq., vol. 279, pp. 299-305, 2019.

Mondragon, R., Julia, J.E., Cabedo, L., and Navarrete, N., On the Relationship between the Specific Heat Enhancement of Salt-Based Nanofluids and the Ionic Exchange Capacity of Nanoparticles, Sci. Rep., vol. 8, no. 1, p. 7532, 2018.

Nabil, M.F., Azmi, W.H., Hamid, K.A., Mamat, R., and Hagos, F.Y., An Experimental Study on the Thermal Conductivity and Dynamic Viscosity of $\mathrm{TiO}_{2}-\mathrm{SiO}_{2}$ Nanofluids in Water: Ethylene Glycol Mixture, Int. Comm. Heat Mass Transf., vol. 86, pp. 181-189, 2017.

Nagasaka, Y. and Nagashima, A., Absolute Measurement of the Thermal Conductivity of Electrically Conducting Liquids by the Transient Hot-Wire Method, J. Phys. E, vol. 14, pp. 1435-1440, 1981.

Naik, M.T., Janardana, G.R., and Sundar, L.S., Experimental Investigation of Heat Transfer and Friction Factor with Water-Propylene Glycol based $\mathrm{CuO}$ Nanofluid in a Tube with Twisted Tape Inserts, Int. Comm. Heat Mass Transf., vol. 46, pp. 13-21, 2013.

Nan, C.W., Liu, G., Lin, Y., and Li, M., Interface Effect on Thermal Conductivity of Carbon Nanotube Composites, Appl. Phys. Lett., vol. 85, no. 16, pp. 3549-3551, 2004.

Nan, Y., Cai, Y.M., and Guo, Z., Heat Transfer and Fluid Flow in a Water-Filled Glass Louver Subject to Solar Irradiation, Heat Transf. Res., vol. 51, pp. 25-39, 2020.

Nandakrishnan, S.L., Deepu, M., and Shine, S.R., Numerical Investigation of Heat-Transfer Enhancement in a Dimpled Diverging Microchannel with $\mathrm{Al}_{2} \mathrm{O}_{3}$-Water Nanofluid, J. Enhanced Heat Transf., vol. 25, pp. 347-365, 2018.

Nasir, F.M., Abdullah, M.Z., and Ismail, M.A., Experimental Investigation on the Heat Transfer Performance of Heat Pipes in Cooling HEV Lithium-Ion Batteries, Heat Transf. Res., vol. 49, no. 17, pp. 17451760, 2018.

Nayak, A.K., Singh, R.K., and Kulkarni, P.P., Measurement of Volumetric Thermal Expansion Coefficient of Various Nanofluids, Tech. Phys. Lett., vol. 36, pp. 696-698, 2010.

Nayak, S.K. and Mishra, P.C., Enhanced Heat Transfer from Hot Surface by Nanofluid based Ultra-Fast Cooling: An Experimental Investigation, J. Enhanced Heat Transf., vol. 26, pp. 415-428, 2019.

Nazari, M.A., Ghasempour, R., Ahmadi, M.H., Heydarian, G., and Shafii, M.B., Experimental Investigation of Graphene Oxide Nanofluid on Heat Transfer Enhancement of Pulsating Heat Pipe, Int. Commun. Heat Mass Transf., vol. 91, pp. 90-94, 2018.

Nguyen, C.T., Galanis, N., Roy, G., Divoux, S., and Gilbert, D., Pool Boiling Characteristics of WaterAlumina Nanofluids, Proc. of 13th Int. Heat Transfer Conf., Sydney, Australia, 2006.

Nguyen, C.T., Roy, G., Gauthier, C., and Galanis, N., Heat Transfer Enhancement Using $\mathrm{Al}_{2} \mathrm{O}_{3}-$ Water Nanofluid for an Electronic Liquid Cooling System, Appl. Therm. Eng., vol. 27, pp. 1501-1506, 2007.

Otanicar, T.P., Phelan, P.E., Prasher, R.S., Rosengarten, G., and Taylor, R.A., Nanofluid-Based Direct

Volume 27, Issue 1, 2020 
Absorption Solar Collector, J. Renew. Sustain. Energy, vol. 2, p. 033102, 2010.

Pak, B.C. and Cho, Y.I., Hydrodynamic and Heat Transfer Study of Dispersed Fluids with Submicron Metallic Oxide Particles, Exp. Heat Transf., vol. 11, no. 2, pp. 151-170, 1998.

Pal, S.K. and Bhattacharyya, S., Enhanced Heat Transfer of $\mathrm{Cu}$-Water Nanofluid in a Channel with Wall Mounted Blunt Ribs, J. Enhanced Heat Transf., vol. 25, pp. 61-78, 2018.

Pakdaman, M.F., Akhavan-Behabadi, M.A., and Razi, P., An Experimental Investigation on ThermoPhysical Properties and Overall Performance of MWCNT/Heat Transfer Oil Nanofluid Flow inside Vertical Helically Coiled Tubes, Exp. Therm. Fluid Sci., vol. 40, pp. 103-111, 2012.

Pang, C., Jung, J.Y., Lee, J.W., and Kang, Y.T., Thermal Conductivity Measurement of Methanol-Based Nanofluids with $\mathrm{Al}_{2} \mathrm{O}_{3}$ and $\mathrm{SiO}_{2}$ Nanoparticles, Int. J. Heat Mass Transf., vol. 55, nos. 21-22, pp. 5597$5602,2012$.

Park, K.-J. and Jung, D., Boiling Heat Transfer Enhancement with Carbon Nanotubes for Refrigerants Used in Building Air-Conditioning, Energy Build., vol. 39, pp. 1061-1064, 2007a.

Park, K.-J. and Jung, D., Enhancement of Nucleate Boiling Heat Transfer Using Carbon Nanotubes, Int. J. Heat Mass Transf., vol. 50, pp. 4499-4502, $2007 \mathrm{~b}$.

Parsian, A. and Akbari, M., New Experimental Correlation for the Thermal Conductivity of Ethylene Glycol Containing $\mathrm{Al}_{2} \mathrm{O}_{3}-\mathrm{Cu}$ Hybrid Nanoparticles, J. Therm. Anal. Calorim., vol. 131, no. 2, pp. 16051613, 2018.

Pastoriza-Gallego, M.J., Lugo, L., Legido, J.L., and Piñeiro, M.M., Thermal Conductivity and Viscosity Measurements of Ethylene Glycol-Based $\mathrm{Al}_{2} \mathrm{O}_{3}$ Nanofluids, Nanoscale Res. Lett., vol. 6, no. 1, p. 221, 2011.

Patel, H.E., Das, S.K., Sundararajan, T., Sreekumaran Nair, A., George, B., and Pradeep, T., Thermal Conductivities of Naked and Monolayer Protected Metal Nanoparticle based Nanofluids: Manifestation of Anomalous Enhancement and Chemical Effects, Appl. Phys. Lett., vol. 83, pp. 14, pp. 2931-2933, 2003.

Perez Huertas, S., Terpiłowski, K., Wisniewska, M., and Zarko, V., Influence of Polyvinylpyrrolidone Adsorption on Stability of Silica Aqueous Suspension-Effects of Polymer Concentration and Solid Content, Physicochem. Prob. Miner. Process, vol. 53, no. 1, pp. 121-135, 2017.

Pinto, R.V. and Fiorelli, F.A.S., Review of the Mechanisms Responsible for Heat Transfer Enhancement Using Nanofluids, Appl. Thermal Eng., vol. 108, pp. 720-739, 2016.

Popa, I., Gillies, G., Papastavrou, G., and Borkovec, M., Attractive and Repulsive Electrostatic Forces between Positively Charged Latex Particles in the Presence of Anionic Linear Polyelectrolytes, J. Phys. Chem. B, vol. 114, no. 9, pp. 3170-3177, 2010.

Prasher, R., Bhattacharya, P., and Phelan, P.E., Thermal Conductivity of Nanoscale Colloidal Solutions (Nanofluids), Phys. Rev. Lett., vol. 94, no. 2, p. 025901, 2005.

Prasher, R., Evans, W., Meakin, P., Fish, J., Phelan, P., and Keblinski, P., Effect of Aggregation on Thermal Conduction in Colloidal Nanofluids, Appl. Phys. Lett., vol. 89, pp. 1431-1438, 2006.

Pryazhnikov, M.I., Minakov, A.V., Rudyak, Y.V., and Guzei, D.V., Thermal Conductivity Measurements of Nanofluids, Int. J. Heat Mass Transf., vol. 104, pp. 1275-1282, 2017.

Putnam, S.A., Cahill, D.G., Braun, P.V., Ge, Z., and Shimmin, R.G., Thermal Conductivity of Nanoparticle Suspensions, J. Appl. Phys., vol. 99, p. 084308, 2006.

Putra, N., Roetzel, W., and Das, S.K., Natural Convection of Nano-Fluids, Heat Mass Transf., vol. 398, pp. 775-784, 2003.

Raeisian, L., Eggers, J.R., Lange, E.M., Mattke, T., Bode, A., and Kabelac, S., On the Controversy of Nanofluid Rheological Behavior, Int. J. Thermophys., vol. 40, p. 48, 2019.

Ragani, S. and Bahrami, A., Numerical Investigation of a Copper-Water Nanofluid Flowing in a Parallel Plate Channel, Heat Transf. Res., vol. 50, no. 7, pp. 617-632, 2019. 
Raja, M., Vijayan, R., Dineshkumar, P., and Venkatesan, M., Review on Nanofluids Characterization, Heat Transfer Characteristics and Applications, Renew. Sustain. Energy Rev., vol. 64, pp. 163-173, 2016.

Rashidi, S., Eskandarian, M., Mahian, O., and Poncet, S., Combination of Nanofluid and Inserts for Heat Transfer Enhancement, J. Therm. Anal. Calorim., vol. 135, pp. 437-460, 2019.

Ravikumar, S.V., Haldar, K., Jha, J.M., Chakraborty, S., Sarkar, I., Pal, S.K., and Chakraborty, S., Heat Transfer Enhancement Using Air-Atomized Spray Cooling with Water- $\mathrm{Al}_{2} \mathrm{O}_{3}$ Nanofluid, Int. J. Therm. Sci., vol. 96, pp. 85-93, 2015.

Robertis, E.De, Cosme, E.H.H., Neves, R.S., Kuznetsov, A.Yu., Campos, A.P.C., Landi, S.M., and Achete, C.A., Application of the Modulated Temperature Differential Scanning Calorimetry Technique for the Determination of the Specific Heat of Copper Nanofluids, Appl. Therm. Eng., vol. 41, pp. 10-17, 2012.

Routbort, J., Applications of Nanofluids: Current and Future, Argonne National Lab, Michellin North America, St. Gobain Corp., accessed from http://www.eere.energy.gov/industry/nanomanufacturing /pdfs/nanofluids_industrial_cooling.pdf, 2009.

Ruan, B. and Jacobi, A.M., Heat Transfer Characteristics of Multiwall Carbon Nanotube Suspensions (MWCNT Nanofluids) in Intertube Falling-Film Flow, Int. J. Heat Mass Transf., vol. 55, nos. 11-12, pp. 3186-3195, 2012.

Rueda-Garcia, D., Caban-Huertas, Z., Sanchez-Ribot, S., Marchante, C., Benages, R., Dubal, D.P., Ayyad, O., and Gómez-Romero, P., Battery and Supercapacitor Materials in Flow Cells. Electrochemical Energy Storage in a $\mathrm{LiFePO}_{4} /$ Reduced Graphene Oxide Aqueous Nanofluid, Electrochim. Acta, vol. 281, pp. 594-600, 2018.

Ruhani, B., Toghraie, D., Hekmatifar, M., and Hadian, M., Statistical Investigation for Developing a New Model for Rheological Behavior of ZnO-Ag (50\%-50\%)/Water Hybrid Newtonian Nanofluid Using Experimental Data, Phys. A., vol. 525, pp. 741-751, 2019.

Saadati, H., Hadad, K., and Rabiee, A., Safety Margin and Fuel Cycle Period Enhancements of VVER1000 Nuclear Reactor Using Water/Silver Nanofluid, Nucl. Eng. Technol., vol. 50, no. 5, pp. 639-647, 2018.

Saeedinia, M.A., Akhavan-Behabadi, M.A., and Razi, P., Thermal and Rheological Characteristics of CuOBase Oil Nanofluid Flow inside a Circular Tube, Int. Commun. Heat Mass Transf., vol. 39, pp. 152-159, 2012.

Sahu, M.K. and Prasad, R.K., A Review of the Thermal and Hydrodynamic Performance of Solar Air Heater with Roughened Absorber Plates, J. Enhanced Heat Transf., vol. 23, pp. 47-89, 2016.

Said, Z., Saidur, R., Sabiha, M.A., Hepbasli, A., and Rahim, N.A., Energy and Exergy Efficiency of a Flat Plate Solar Collector Using pH Treated $\mathrm{Al}_{2} \mathrm{O}_{3}$ Nanofluid, J. Clean. Prod., vol. 112, pp. 3915-3926, 2016a.

Said, Z., Saidur, R., and Rahim, N.A., Energy and Exergy Analysis of a Flat Plate Solar Collector Using Different Sizes of Aluminium Oxide based Nanofluid, J. Clean. Prod., vol. 133, pp. 518-530, 2016 b.

Saidur, R., Kazi, S.N., Hossain, M.S., Rahman, M.M., and Mohammed, H.A., A Review on the Performance of Nanoparticles Suspended with Refrigerants and Lubricating Oils in Refrigeration Systems, Renew. Sustain. Energy Rev., vol. 15, pp. 310-323, 2011a.

Saidur, R., Leong, K.Y., and Mohammed, H.A., A Review on Applications and Challenges of Nanofluids, Renew. Sustain. Energy Rev., vol. 15, pp. 1646-1668, 2011 b.

Sajadi, A.R. and Kazemi, M.H., Investigation of Turbulent Convective Heat Transfer and Pressure Drop of $\mathrm{TiO}_{2} /$ Water Nanofluid In Circular Tube, Int. Commun. Heat Mass Transf., vol. 38, no. 10, pp. 14741478, 2011.

Samokhvalov, Y., Kolesnikov, A., Krotov, A., Parkin, A., Navasardyan, E.S., and Arkharov, I.A., Heat Transfer in the Structure of a Spiral-Wound Heat Exchanger for Liquefied Natural Gas Production: Review of Numerical Models for the Heat-Transfer Coefficient of Condensation for a Hydrocarbon

Volume 27, Issue 1, 2020 
Mixture in a Horizontal Tube, J. Enhanced Heat Transf., vol. 25, pp. 109-120, 2018.

Sarafraz, M.M. and Hormozi, F., Experimental Investigation on the Pool Boiling Heat Transfer to Aqueous Multi-Walled Carbon Nanotube Nanofluids on the Micro-Finned Surfaces, Int. J. Therm. Sci., vol. 100, pp. 255-266, 2016.

Sarafraz, M.M. and Hormozi, F., Pool Boiling Heat Transfer to Dilute Copper Oxide Aqueous Nanofluids, Int. J. Therm. Sci., vol. 90, pp. 224-237, 2015.

Sekhar, Y.R. and Sharma, K.V., Study of Viscosity and Specific Heat Capacity Characteristics of WaterBased $\mathrm{Al}_{2} \mathrm{O}_{3}$ Nanofluids at Low Particle Concentrations, J. Exp. Nanosci., vol. 10, no. 2, pp. 86-102, 2015.

Selvakumar, P. and Suresh, S., Convective Performance of $\mathrm{CuO} /$ Water Nanofluid in an Electronic Heat Sink, Exp. Therm. Fluid Sci., vol. 40, pp. 57-63, 2012.

Selvam, C., Irshad, E.M., Lal, D.M., and Harish, S., Convective Heat Transfer Characteristics of WaterEthylene Glycol Mixture with Silver Nanoparticles, Exp. Therm. Fluid Sci., vol. 77, pp. 188-196, 2016.

Sertkaya, A.A., Determination of the Thermophysical Properties of a Zeolite Nanofluid, Heat Transf. Res., vol. 49, pp. 583-596, 2018.

Setia, H., Gupta, R., and Wanchoo, R.K., Stability of Nanofluids, Mater. Sci. Forum, vol. 757, pp. 139-149, 2013.

Sezer, N., Atieh, M.A., and Koc, M., A Comprehensive Review on Synthesis, Stability, Thermophysical Properties, and Characterization of Nanofluids, Powder Technol., vol. 344, pp. 404-431, 2019.

Shahrul, I.M., Mahbubul, I.M., Khaleduzzaman, S.S., Saidur, R., and Sabri, M.F.M., A Comparative Review on the Specific Heat of Nanofluids for Energy Perspective, Renew. Sustain. Energy Rev., vol. 38, pp. 88-98, 2014.

Sharifpur, M., Yousefi, S., and Meyer, J.P., A New Model for Density of Nanofluids Including Nanolayer, Int. J. Commun. Heat Mass Transf., vol. 78, pp. 168-174, 2016.

Sharma D. and Pandey, K.M., Review on Using Nanofluids for Heat Transfer Enhancement in Nuclear Power Plants, Kerntechnik, vol. 83, no. 5, pp. 426-438, 2018.

Sharma, K.V., Sarma, P.K., Azmi, W.H., Mamat, R., and Kadirgama, K., Correlations to Predict Friction and Forced Convection Heat Transfer Coefficients of Water based Nanofluids for Turbulent Flow in a Tub, Int. J. Micro. Nano. Therm. Fluid Trans., vol. 3, no. 4, p. 283, 2012.

Shatto, D.P. and Peterson, G.P., Flow Boiling Heat Transfer with Twisted Tape Inserts, J. Enhanced Heat Transf., vol. 24, pp. 21-45, 2017.

Sheikholeslami, M., CuO-Water Nanofluid Flow due to Magnetic Field inside a Porous Media Considering Brownian Motion, J. Mol. Liq., vol. 249, pp. 921-929, 2018.

Sheikholeslami, M., Gorji-Bandpy, M., and Ganji, D.D., Review of Heat Transfer Enhancement Methods: Focus on Passive Methods Using Swirl Flow Devices, Renew. Sustain. Energy Rev., vol. 49, pp. 444-469, 2015.

Shen, S., Narayanaswamy, A., and Chen, G., Surface Phonon Polaritons Mediated Energy Transfer between Nanoscale Gaps, Nano Lett., vol. 9, pp. 2909-2913, 2009.

Shin, D. and Banerjee, D., Enhanced Specific Heat Capacity of Nanomaterials Synthesized by Dispersing Silica Nanoparticles in Eutectic Mixtures, J. Heat Transf., vol. 135, no. 3, p. 032801, 2013.

Shome, B. and Jensen, M.K., Review on Laminar Flow and Heat Transfer in Internally Finned Tubes, $J$. Enhanced Heat Transf., vol. 24, pp. 339-356, 2017.

Sidik, N.A.C., Kean, T.H., Chow, H.K., Rajaandra, A., Rahman, S., and Kaur, J., Performance Enhancement of Cold Thermal Energy Storage System Using Nanofluid Phase Change Materials: A Review, Int. Commun. Heat Mass Transf., vol. 94, pp. 85-95, 2018.

Singh, A.K. and Raykar, V.S., Microwave Synthesis of Silver Nanofluids with Polyvinylpyrrolidone (PVP) 
and Their Transport Properties, Colloid Polymer Sci., vol. 286, pp. 1667-1673, 2008.

Singh, D., Toutbort, J., and Chen, G., Heavy Vehicle Systems Optimization Merit Review and Peer Evaluation, Argonne National Laboratory, Lemont, IL, Annual Report, 2006.

Sobhanifar, N., Ahmadloo, E., and Azizi, S., Prediction of Two-Phase Heat Transfer Coefficients in a Horizontal Pipe for Different Inclined Positions with Artificial Neural Networks, J. Heat Transf., vol. 137, p. $061009,2015$.

Sohel Murshed, S.M. and Estelle, P., A State of the Art Review on Viscosity of Nanofluids, Renew. Sustain. Energy Rev., vol. 76, pp. 1134-1152, 2017.

Song, B., Ganjeh, Y., Sadat, S., Thompson, D., Fiorino, A., Fernández-Hurtado, V., Feist, J., Garcia-Vidal, F.J., Cuevas, J.C., Reddy, P., and Meyhofer, E., Enhancement of Near-Field Radiative Heat Transfer Using Polar Dielectric Thin Films, Nature Nanotech., vol. 10, pp. 253-258, 2015.

Sözen, A., Çiftçi, E., Keçel, S., Gürü, M., Variyenli, H.I., and Karakaya, U., Usage of a DiatomiteContaining Nanofluid as the Working Fluid in a Wickless Loop Heat Pipe: Experimental and Numerical Study, Heat Transf. Res., vol. 49, no. 17, pp. 1721-1744, 2018.

Strandberg, R. and Das, D.K., Influence of Temperature and Properties Variation on Nanofluids in Building Heating, Energy Convers. Manage., vol. 51, pp. 1381-1390, 2010.

Subhedar, D.G., Ramani, B.M., and Gupta, A., Experimental Investigation of Heat Transfer Potential of $\mathrm{Al}_{2} \mathrm{O}_{3}$ /Water-Mono Ethylene Glycol Nanofluids as a Car Radiator Coolant, Case Stud. Therm. Eng., vol. 11, pp. 26-34, 2018.

Subramaniam, C.G., On the Effective Thermal Conductivity of Nanofluids with Fractal Aggregation, $J$. Heat Transf., vol. 141, no. 4, p. 044501, 2019.

Sultan, K.F., Experimental Analysis of Heat Transfer Enhancement and Flow with $\mathrm{Cu}, \mathrm{TiO}_{2}$ Ethylene Glycol Distilled Water Nanofluid in Spiral Coil Heat, Tikrit J. Eng. Sci., vol. 24, no. 3, pp. 63-77, 2017.

Sun, X.H., Yan, H., Massoudi, M., Chen, Z.H., Wu, W.T., and Sun, X.H., Numerical Simulation of Nanofluid Suspensions in a Geothermal Heat Exchanger, Energies, vol. 11, p. 919, 2018.

Sundar, L.S. and Sharma, K.V., Turbulent Heat Transfer and Friction Factor of $\mathrm{Al}_{2} \mathrm{O}_{3}$ Nanofluid in Circular Tube with Twisted Tape Inserts, Int. J. Heat Mass Transf., vol. 53, nos. 7-8, pp. 1409-1416, 2010 a.

Sundar, L.S. and Sharma, K.V., Heat Transfer Enhancements of Low Volume Concentration $\mathrm{Al}_{2} \mathrm{O}_{3}$ Nanofluid and with Longitudinal Strip Inserts in a Circular Tube, Int. J. Heat Mass Transf., vol. 53, nos. 19-20, pp. 4280-4286, 2010 b.

Sundar, L.S., Singh, M.K., and Sousa, A.C.M., Investigation of Thermal Conductivity and Viscosity of $\mathrm{Fe}_{3} \mathrm{O}_{4}$ Nanofluid for Heat Transfer Applications, Int. Commun. Heat Mass Transf., vol. 44, pp. 7-14, 2013.

Sundar, L.S., Otero-Irurueta, G., Singh, M.K., and Sousa, A.C., Heat Transfer and Friction Factor of MultiWalled Carbon Nanotubes- $\mathrm{Fe}_{3} \mathrm{O}_{4}$ Nanocomposite Nanofluids Flow in a Tube with/without Longitudinal Strip Inserts, Int. J. Heat Mass Transf., vol. 100, pp. 691-703, 2016.

Taghizadeh-Tabari, Z., Heris, S.Z., Moradi, M., and Kahani, M., The Study on Application of $\mathrm{TiO}_{2} /$ Water Nanofluid in Plate Heat Exchanger of Milk Pasteurization Industries, Renew. Sustain. Energy Rev., vol. 58, pp. 1318-1326, 2016.

Takabi, B. and Salehi, S., Augmentation of the Heat Transfer Performance of a Sinusoidal Corrugated Enclosure by Employing Hybrid Nanofluid, Adv. Mech. Eng., vol. 6, p. 147059, 2014.

Tang, E., Cheng, G., Ma, X., Pang, X., and Zhao, Q., Surface Modification of Zinc Oxide Nanoparticle by PMAA and Its Dispersion in Aqueous System, Appl. Surf. Sci., vol. 252, no. 14, pp. 5227-5232, 2006.

Tariq, H.A., Shoukat, A.A., Hassan, M., and Anwar, M., Thermal Management of Microelectronic Devices Using Micro-Hole Cellular Structure and Nanofluids, J. Therm. Anal. Calorim., vol. 136, p. 2171, 2019.

Taylor, R.P. and Hodge, B.K., A Review of Fully-Developed Nusselt Numbers and Friction Factors in Pipes

Volume 27, Issue 1, 2020 
with three-Dimensional Roughness, J. Enhanced Heat Transf., vol. 24, pp. 357-369, 2017.

Terekhov, V.I., Khafaji, H.Q., and Gorbachev, M.V., Heat and Mass Transfer Enhancement in Laminar Forced Convection Wet Channel Flows with Uniform Wall Heat Flux, J. Enhanced Heat Transf., vol. 25, pp. 565-577, 2018.

Thome, J.R., A Review on Falling Film Evaporation, J. Enhanced Heat Transf., vol. 24, pp. 483-497, $2017 b$.

Thome, J.R., A Review on Shell-and-Tube Heat Exchangers for the Chemical Processing Industry: Heat Transfer Augmentation, J. Enhanced Heat Transf., vol. 24, pp. 427-441, 2017a.

Tiara, M., Chakraborty, S., Sarkar, I., Ashok, A., Pal, S.K., and Chakraborty, S., Heat Transfer Enhancement Using Surfactant based Alumina Nanofluid Jet from a Hot Steel Plate, Exp. Thermal Fluid Sci., vol. 89, pp. 295-303, 2017.

Timofeeva, E.V., Routbort, J.L., and Singh, D., Particle Shape Effects on Thermophysical Properties of Alumina Nanofluids, J. Appl. Phys., vol. 106, no. 1, p. 014304, 2009.

Toghraie, D., Akbari, O.A., Koveiti, A., and Mashayekhi, R., Numerical Investigation of Turbulent Nanofluid Flow and Two-Dimensional Forced-Convection Heat Transfer in a Sinusoidal ConvergingDiverging Channel, Heat Transf. Res., vol. 50, pp. 671-695, 2019.

Tong, W., Bergles, A.E., and Jensen, M.K., Critical Review on Heat Flux and Pressure Drop of Subcooled Flow Boiling in Small-Diameter Tubes with Twisted-Tape Inserts, J. Enhanced Heat Transf., vol. 24, pp. 159-172, 2017.

Trisaksri, V. and Wongwises, S., Critical Review of Heat Transfer Characteristics of Nanofluids, Renew. Sustain. Energy Rev., vol. 11, pp. 512-523, 2007.

Trisaksri, V. and Wongwises, S., Nucleate Pool Boiling Heat Transfer of an Alternative Refrigerant with Nanoparticle Suspension, Int. J. Heat Mass Transf., vol. 52, pp. 1582-1588, 2009.

U.S. Department of Energy, About the Buildings Technologies, accessed from https://www.energy .gov/eere/buildings/aboutbuilding-technologies-office, 2019.

Vajjha, R.S. and Das, D.K., Specific Heat Measurement of Three Nanofluids and Development of New Correlations, J. Heat Transf., vol. 131, p. 071601, 2009

Vanaki, Sh.M., Ganesan, P., and Mohammed, H.A., Numerical Study of Convective Heat Transfer of Nanofluids: A Review, Renew. Sustain. Energy Rev., vol. 54, pp. 1212-1239, 2016.

Vlachokostas, A. and Madamopoulos, N., Daylight and Thermal Harvesting Performance Evaluation of a Liquid Filled Prismatic Façade Using the Radiance Five-Phase Method and EnergyPlus, Build. Environ., vol. 126, pp. 396-409, 2017.

Vlachokostas, A. and Madamopoulos, N., Liquid Filled Prismatic Louver Facçade for Enhanced Daylighting in High-Rise Commercial Buildings, Opt. Express, vol. 23, pp. A805-A818, 2015.

Waghole, D.R., Warkhedkar, R.M., Kulkarni, V.S., and Shrivastva, R.K., Experimental Investigations on Heat Transfer and Friction Factor of Silver Nanofliud in Absorber/Receiver of Parabolic Trough Collector with Twisted Tape Inserts, Energy Procedia, vol. 45, pp. 558-567, 2014.

Wang, B., Wang, X., Lou, W., and Hao, J., Thermal Conductivity and Rheological Properties of Graphite/Oil Nanofluids, Colloids Surf A, vol. 414, pp. 125-131, 2012.

Wang, B.X., Zhou, L.P., and Peng, X.F., A Fractal Model for Predicting the Effective Thermal Conductivity of Liquid with Suspension of Nanoparticles, Int. J. Heat Mass Transf., vol. 46, no. 14, pp. 2665-2672, 2003.

Wang, J.F., Xie, H.Q., Guo, Z., Cai, L., and Zhang, K., Using Organic Phase-Change Materials for Enhanced Energy Storage in Water Heaters: An Experimental Study, J. Enhanced Heat Transf., vol. 26, no. 2, pp. 167-178, 2019.

Wang, J.F., Xie, H.Q., Guo, Z., Guan, L.H., and Li, Y., Improved Thermal Properties of Paraffin Wax by the Addition of $\mathrm{TiO}_{2}$ Nanoparticles, Appl. Thermal Eng., vol. 73, pp. 1541-1547, 2014. 
Wang, X.Q. and Mujumdar, A.S., Heat Transfer Characteristics of Nanofluids: A Review, Int. J. Therm. Sci., vol. 46, pp. 1-19, 2007.

Wang, X.W., Xu, X.F., and Choi, S.U.S., Thermal Conductivity of Nanoparticle-Fluid Mixture, J. Thermophys. Heat Transf., vol. 13, no. 4, pp. 474-480, 1999.

Wasekar, V.M. and Manglik, R.M., Enhanced Heat Transfer in Nucleate Pool Boiling of Aqueous Surfactant and Polymeric Solutions, J. Enhanced Heat Transf., vol. 24, pp. 47-62, 2017.

Webb, R.L. and Kim, N.-H., Principles of Enhanced Heat Transfer, 2nd Edition, Boca Raton, FL: Taylor \& Francis, 2005.

Wen, D.S. and Ding, Y.L., Experimental Investigation into Convective Heat Transfer of Nanofluids at the Entrance Region under Laminar Flow Conditions, Int. J. Heat Mass Transf., vol. 47, pp. 5181-5188, 2004.

Wen, D.S. and Ding, Y.L., Experimental Investigation into the Pool Boiling Heat Transfer of Aqueous based $\Gamma$-Alumina Nanofluids, J. Nanopart. Res., vol. 7, pp. 265-274, 2005 b.

Wen, D.S. and Ding, Y.L., Formulation of Nanofluids for Natural Convective Heat Transfer Applications, Int. J. Heat Fluid Flow, vol. 26, pp. 855-864, 2005a.

Witharana, S., Palabiyik, I., Musina, Z., and Ding, Y.L., Stability of Glycol Nanofluids-The Theory and Experiment, Powder Technol., vol. 239, pp. 72-77, 2013.

Wong, K.V. and De Leon, O., Applications of Nanofluids: Current and Future, Adv. Mech. Eng., vol. 2, p. 519659, 2010.

Wright, L.M. and Han, J.-C., Heat Transfer Enhancement for Turbine Blade Internal Cooling, J. Enhanced Heat Transf., vol. 21, pp. 111-140, 2014.

Xing, M., Yu, J., and Wang, R., Performance of a Vertical Closed Pulsating Heat Pipe with Hydroxylated MWNTs Nanofluid, Int. J. Heat Mass Transf., vol. 112, pp. 81-88, 2017.

Xu, Y., Wang, X., Zhou, J., Song, B., Jiang, Z., Lee, E.M.Y., Huberman, S., Gleason, K.K., and Chen, G., Molecular Engineered Conjugate Polymer with High Thermal Conductivity, Sci. Adv., vol. 4, no. 3, p. eaar3031, 2018.

Xuan, Y. and Li, Q., Heat Transfer Enhancement of Nanofluids, Int. J. Heat Fluid Flow, vol. 21, pp. 58-64, 2000.

Xuan, Y. and Li, Q., Investigation on Convective Heat Transfer and Flow Features of Nanofluids, J. Heat Transf., vol. 125, no. 1, pp. 151-155, 2003.

Xuan, Y. and Roetzel, W., Conceptions for Heat Transfer Correlation of Nanofluids, Int. J. Heat Mass Transf., vol. 43, no. 19, pp. 3701-3707, 2000.

Xuan, Y., Li, Q., and Hu, W., Aggregation Structure and Thermal Conductivity of Nanofluids, AIChE J., vol. 49, no. 4, pp. 1038-1043, 2003.

Xue, Q.Z., Model for Thermal Conductivity of Carbon Nanotube-Based Composites, Physica B, vol. 368, nos. 1-4, pp. 302-307, 2005.

Yan, J.-F. and Liu, J., Nanocryosurgery and Its Mechanisms for Enhancing Freezing Efficiency of Tumor Tissues, Nanomedicine, vol. 4, no. 1, pp. 79-87, 2008.

Yang, C., Li, W., Sano, Y., Mochizuki, M., and Nakayama, A., On the Anomalous Convective Heat Transfer Enhancement in Nanofluids: A Theoretical Answer to the Nanofluids Controversy, J. Heat Transf., vol. 135, p. 054504, 2013.

Yang, L. and Xu, X., A Renovated Hamilton-Crosser Model for the Effective Thermal Conductivity of CNTs Nanofluids, Int. Commun. Heat Mass Transf., vol. 81, pp. 42-50, 2017.

Yang, X. and Liu, Z.H., A Kind of Nanofluid Consisting of Surface-Functionalized Nanoparticles, Nanoscale Res. Lett., vol. 5, no. 8, pp. 1324-1328, 2010.

Yilmazoglu, M.Z., Gokalp, O., and Biyikoglu, A., Heat Removal Improvement in an Enclosure with

Volume 27, Issue 1, 2020 
Electronic Components for Air Conditioning Devices, J. Enhanced Heat Transf., vol. 26, pp. 1-14, 2019.

You, S.M., Kim, J.H., and Kim, K.H., Effect of Nanoparticles on Critical Heat Flux of Water in Pool Boiling Heat Transfer, Appl. Phys. Lett., vol. 83, p. 3374, 2003.

Yousefi, T., Veysi, F., Shojaeizadeh, E., and Zinadini, S., An Experimental Investigation on the Effect of $\mathrm{Al}_{2} \mathrm{O}_{3}-\mathrm{H}_{2} \mathrm{O}$ Nanofluid on the Efficiency of Flat-Plate Solar Collectors, Renew. Energy, vol. 39, pp. 293298, 2012.

Yu, F., Chen, Y.Y., Liang, X., Xu, J., Lee, C., Liang, Q., Tao, P., and Deng, T., Dispersion Stability of Thermal Nanofluids, Prog. Nat. Sci. Mater., vol. 27, pp. 531-542, 2017.

Yu, W. and Choi, S.U.S., The Role of Interfacial Layers in the Enhanced Thermal Conductivity of Nanofluids: A Renovated Maxwell Model, J. Nanopart. Res., vol. 5, nos. 1-2, pp. 167-171, 2003.

Yu, W. and Xie, H., A Review on Nanofluids: Preparation, Stability Mechanisms, and Applications, $J$. Nanomaterials, vol. 2012, p. 435873, 2012.

Yu, W., Xie, H., Wang, X., and Wang, X.W., Significant Thermal Conductivity Enhancement for Nanofluids Containing Graphene Nanosheets, Phys. Lett. A, vol. 375, pp. 1323-1328, 2011.

Zamzamian, A., KeyanpourRad, M., KianiNeyestani, M., and Jamal-Abad, M.T., An Experimental Study on the Effect of $\mathrm{Cu}$-Synthesized/EG Nanofluid on the Efficiency of Flat-Plate Solar Collectors, Renew. Energy, vol. 71, pp. 658-664, 2014.

Zeiny, A., Jin, H., Bai, L., Jin, G., and Wen, D.S., A Comparative Study of Direct Absorption Nanofluids for Solar Thermal Applications, Sol. Energy, vol. 161, pp. 74-82, 2018.

Zeng, J. and Xuan, Y.M., Enhanced Solar Thermal Conversion and Thermal Conduction of MWCNT$\mathrm{SiO}_{2} /$ Ag Binary Nanofluids, Appl. Energy, vol. 212, pp. 809-819, 2018.

Zhai, Y.L., Xia, G.D., Liu, X.F., and Li, Y.F., Heat Transfer Enhancement of $\mathrm{Al}_{2} \mathrm{O}_{3}-\mathrm{H}_{2} \mathrm{O}$ Nanofluids Flowing through a Micro Heat Sink with Complex Structure, Int. Commun. Heat Mass Transf., vol. 66, pp. 158-166, 2015.

Zhang, H., Chen, H.-J., Du, X., and Wen, D., Photothermal Conversion Characteristics of Gold Nanoparticle Dispersions, Sol. Energy, vol. 100, pp. 141-147, 2014.

Zhang, W.-H., Lin, W.-K., Yeh, C.-T., Chaing, S.-B., and Jao, C.-S., A Novel Liquid-Packaging Technology for Highly Reliable UV-LED Encapsulation, Heat Transf. Res., vol. 50, pp. 349-360, 2019a.

Zhang, X.D., Gao, J.Y., Zhang, P.J., and Liu, J., Comparison on Enhanced Phase Change Heat Transfer of Low Melting Point Metal Melting Using Different Heating Methods, J. Enhanced Heat Transf., vol. 26, pp. 179-194, 2019b.

Zheng, Z.M. and Wang, B., A Prediction Model for the Effective Thermal Conductivity of Nanofluids Considering Agglomeration and the Radial Distribution Function of Nanoparticles, Acta Mech. Sinica, vol. 34, no. 3, pp. 507-514, 2018.

Zhou, D.W., Heat Transfer Enhancement of Copper Nanofluid with Acoustic Cavitation, Int. J. Heat Mass Transf., vol. 47, pp. 3109-3117, 2004.

Zhou, M.Z., Xia, G.D., Li, J., Chai, L., and Zhou, L.J., Analysis of Factors Influencing Thermal Conductivity and Viscosity in Different Kinds of Surfactant Solutions, Exp. Thermal Fluid Sci., vol. 36, pp. 22-29, 2012.

Zhu, H., Zhang, C., Tang, Y., Wang, J., Ren, B., and Yin, Y., Preparation and Thermal Conductivity of Suspensions of Graphite Nanoparticles, Carbon, vol. 45, no. 1, pp. 226-228, 2007.

Zhu, H.T., Han, D., Meng, Z., Wu, D., and Zhang, C.Y., Preparation and Thermal Conductivity of CuO Nanofluid via a Wet Chemical Method, Nano. Res. Lett., vol. 6, pp. 181-188, 2011.

Zimparov, V.D., Bonev, P.J., and Petkov, V.M., Benefits from the Use of Enhanced Heat Transfer Surfaces in Heat Exchanger Design: A Critical Review of Performance Evaluation, J. Enhanced Heat Transf., vol. 23, pp. 371-391, 2016. 